Why New Business Models Matter for Green Growth 


\section{OECD GREEN GROWTH PAPERS}

The OECD Green Growth Strategy, launched in May 2011, provides concrete recommendations and measurement tools to support countries' efforts to achieve economic growth and development, while at the same time ensure that natural assets continue to provide the ecosystems services on which our well-being relies. The strategy proposes a flexible policy framework that can be tailored to different country circumstances and stages of development.

OECD Green Growth Papers complement the OECD Green Growth Studies series, and aim to stimulate discussion and analysis on specific topics and obtain feedback from interested audiences.

The papers are generally available only in their original language, English, with a summary in the other if available.

OECD Green Growth Papers are published on www.oecd-ilibrary and are also available at www.oecd.org/greengrowth

Please cite this paper as

Andrea Beltramello, Linda Haie-Fayle and Dirk Pilat (2013), "Why New Business Models Matter for Green Growth", OECD Green Growth Papers, 2013-01, OECD Publishing, Paris.

doi: $10.1787 / 5 \mathrm{k} 97 \mathrm{gk} 40 \mathrm{v} 3 \mathrm{ln}$-en

(C) OECD 2013

Applications for permission to reproduce or translate all or part of this material should be made to: OECD Publishing, rights@oecd.org. 


\section{FOREWORD}

This report explores the potential contribution of new business models to green growth and examines how successful models can be scaled up and accelerated through appropriate policy action. It draws on 55 case studies from 14 OECD countries, combined with broader OECD research. The report was produced as a result of a project under the 2011-212 Programme of Work and Budget of the OECD Committee on Industry, Innovation and Entrepreneurship, under the activity "Delivering Green Growth". It benefited from close co-operation with the European Union and a preliminary report prepared by Technopolis Belgium SPRL.

The report was prepared by Dirk Pilat, Andrea Beltramello and Linda Haie-Fayle of the Structural Policy Division of the OECD Directorate for Science, Technology and Industry with input from Technopolis Belgium SPRL, Tomoo Machiba of the International Renewable Energy Agency, and Corinna Grabowski. It draws on responses to an OECD questionnaire, employed by experts to interview the companies, universities and authorities that participated in the project, and on discussions at an OECD/European Commission/Nordic Innovation joint workshop on "The Future of Eco-Innovation: The Role of Business Models in Green Transformation" held in Copenhagen in January 2012. The OECD Secretariat would particularly like to thank the country contacts, who have contributed with their expertise and help in compiling this report, and the companies, universities and authorities who were willing to share information and their experience.

\section{Country contacts}

Prof. Michele Rosano, Curtin University (Australia); Ms. Olivia de Ruyck, Mr. Dany Robberecht, Verhaert (Belgium); Ms. Mette Frimodt-Møller, Danish Business Authority, Mr. Markus Bjerre, Ministry of Business and Growth (Denmark); Ms. Teija Palko, Ministry of Employment and the Economy, Mr. Christopher Palmberg, Finnish Funding Agency for Technology and Innovation (Tekes) (Finland); Dr. Katrin Ostertag, Fraunhofer Institute for Systems and Innovation Research ISI (Germany); Dr. Panagiotis Panagiotakopoulos, Close the Loop (Greece); Mr. Howard Ross, Ministry of Trade and Labor (Israel); Dr. Mitsutaka Matsumoto, National Institute of Advanced Industrial Science and Technology (AIST) (Japan); Prof Hung-Suck Park, University of Ulsan, (Korea); Mr. Jonathan King, Ms. Claire Mortimer, Ms. Cerasela Stancu, Landcare Research (New Zealand); Mr. António Victor Carreira de Oliveira, Ministry of Economy and Employment (Portugal), Mr. Oscar Salas, GAIKER-IK4 (Spain); Ms. Samira Jabet, Mr. Tony Meurke, Swedish Agency for Economic and Regional Growth, Ms. Catrina Hedar, Swedish Agency for Marine and Water Management (Sweden), Dr. Richard Kashmanian, Environmental Protection Agency (EPA) (United States).

\section{Companies, universities and authorities}

Active House Alliance, Alcoa, Barton, BB Architects, Better Place, BIONADE, Brisa, Brite Hellas, Caroma, Corticeira Amorim, Cowell, CSIRO, Danfoss (Scanenergi), DigiEcoCity, Ecoera, Ecover, EDP Distribução, Endesa, Fifthplay, Frito Lay, Fulton Innovation, Grundfos, Intelen, INTEMAN, KankyoKeiei, Komatsu, Kwinana Industries Council, LanzaTech, LIFE Consortium, National Technical University of Athens, Orona, Panasonic, Preseco Oy, Qlean Scandinavia, HaloIPT (Qualcomm), Raidis Architecture, Refrigerants, Naturally!, Rentas, Revigrés, Roltext, Sekisui Chemical, Solray Energy, 
Stockholm authorities (Hammarby Sjöstad), TaKaDu, Tecmacal, Torresol Energy, Ulsan, University of New South Wales, Waste Solutions, Xanterra Parks\& Resorts, YikeBike and 3M. 


\section{TABLE OF CONTENTS}

ABSTRACT

1. WHY NEW BUSINESS MODELS MATTER FOR GREEN GROWTH …....................................15

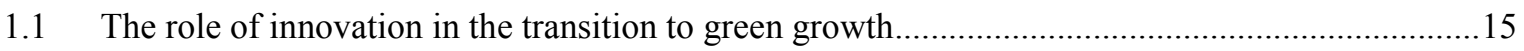

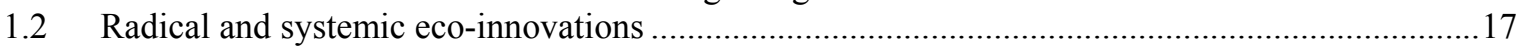

1.3 The role of business models in radical and systemic eco-innovations .........................................18

1.4 Business models and eco-innovation: Lessons from a literature review......................................19

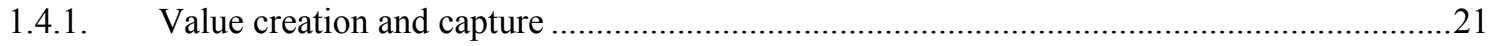

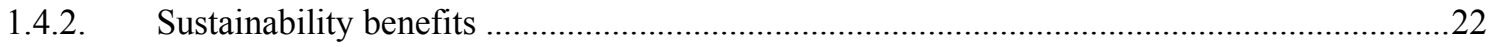

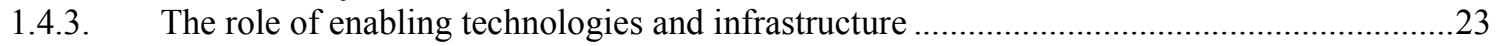

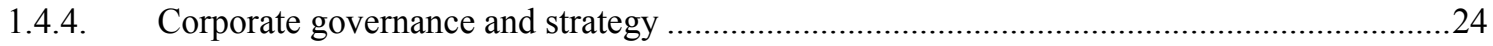

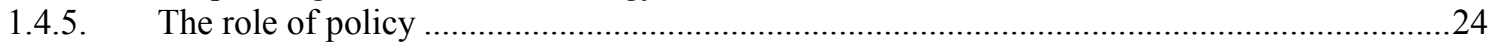

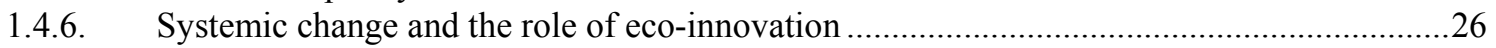

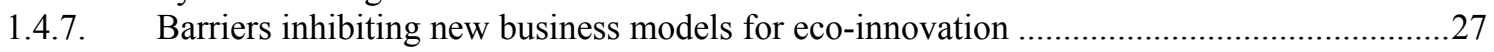

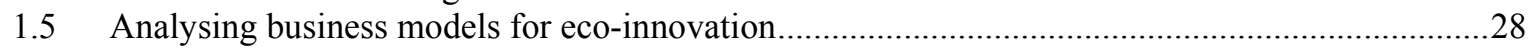

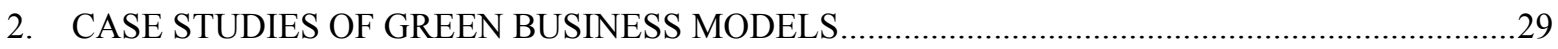

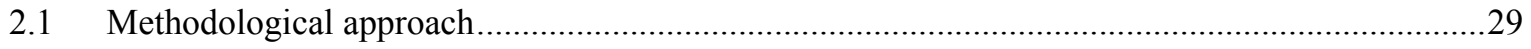

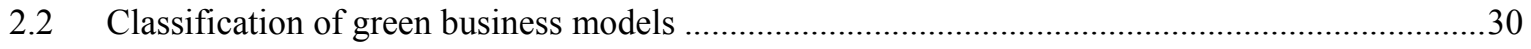

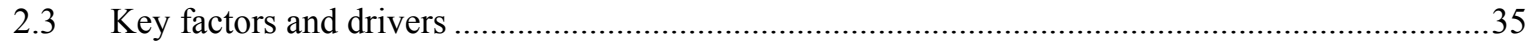

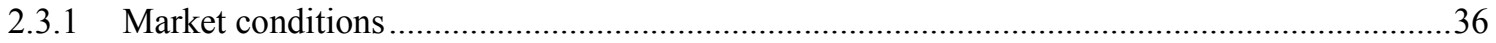

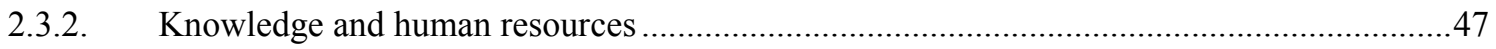

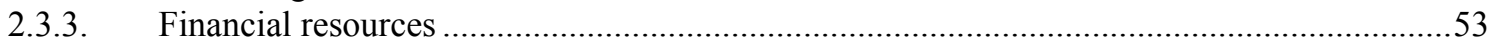

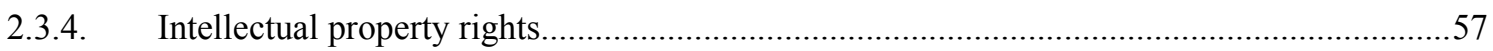

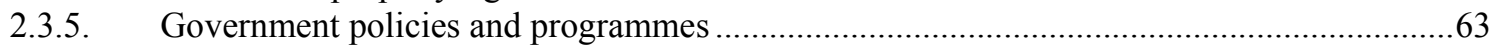

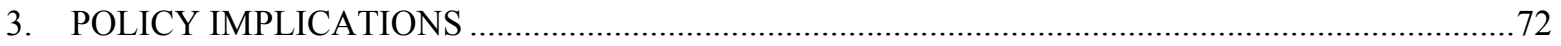

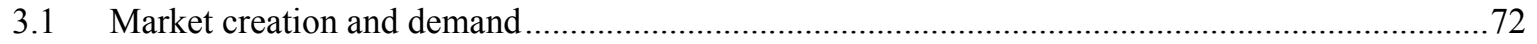

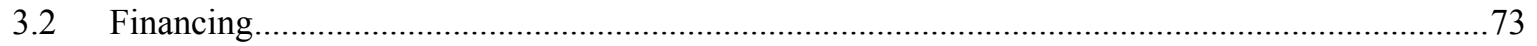

3.3 Entrepreneurship policies and barriers to entry, exit and firm growth..........................................74

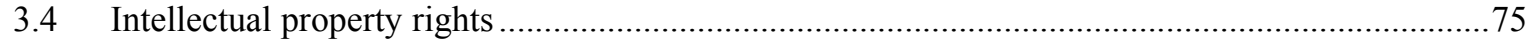

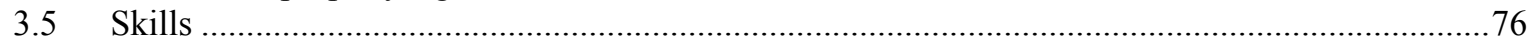

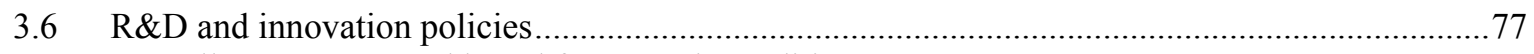

3.7 Overall governance and broad framework conditions ................................................................ 77

NOTES 


\begin{abstract}
New business models can make an important contribution to the transition to green growth. While some new business models involve large firms, others are small start-up firms that seek to exploit technological or commercial opportunities that have been neglected or not yet explored by more established firms. New firms tend to engage in more radical innovation than existing firms, and scaling up new business models can therefore help reduce environmental pollution, optimise the use of natural resources, increase productivity and energy efficiency, and provide a new source of economic growth. Although the market for green goods and services is growing, the development of new business models is affected by a range of barriers, many of which can be addressed by well-designed policies. Key areas for policy action include:
\end{abstract}

- Strengthening market demand for green products and services by providing long-term and stable incentives for firms to internalise the environment and natural resources in their decision making, including through a well-designed regulatory framework and supportive demand-side policies.

- Enhancing access to financing, including risk capital, by supporting market development for risk financing and the development of entrepreneurial skills.

- Removing perverse subsidies support for existing business models and incumbent firms, such as energy subsidies; reducing the barriers to entry, exit and growth of new firms and business models; and improving the regulatory environment for start-up firms and new business models.

- Reducing the costs of intellectual property rights, in particular for small and start-up firms.

- Supporting skills development, including for existing workers.

- Supporting R\&D and innovation, including testing, demonstration and verification.

- Improving governance, to ensure that national and regional policies for green growth are well aligned. 


\section{RÉSUMÉ}

Les nouveaux modèles économiques sont à même de favoriser dans une large mesure le passage à une croissance verte. Certains concernent les grandes entreprises, mais d'autres sont appliqués par de petites startups qui cherchent à utiliser les opportunités technologiques ou commerciales négligées ou pas encore exploités par les groupes plus établis. Les entreprises nouvelles se lancent plus volontiers que les autres dans l'innovation radicale et faire passer de nouveaux modèles économiques à l'échelle supérieure peut ainsi contribuer à réduire la pollution de l'environnement, optimiser l'utilisation des ressources naturelles, accroître la productivité et l'efficacité énergétique, et créer une nouvelle source de croissance économique. Le marché des biens et services verts est en expansion, mais le développement des nouveaux modèles économiques est ralenti par divers obstacles, dont beaucoup peuvent être supprimés au moyen de politiques correctement conçues. Les grands axes de l'action envisageable sont les suivants :

- Renforcer la demande de produits et services verts en créant des incitations durables et stables qui encouragent les entreprises à tenir compte de l'environnement et des ressources naturelles dans leurs décisions, moyennant en particulier un cadre réglementaire bien conçu et des politiques de nature à soutenir la demande.

- Améliorer l'accès aux financements, y compris au capital-risque, en appuyant une évolution du marché propice au financement du risque et le développement des compétences entrepreneuriales.

- Supprimer le soutien implicite aux modèles économiques existants et entreprises déjà implantées, par exemple les subventions à l'énergie; réduire les obstacles à l'entrée, à la sortie et à la croissance des entreprises et modèles économiques nouveaux; et adapter le cadre réglementaire aux startups et aux nouveaux modèles économiques.

- Réduire les coûts des droits de propriété intellectuelle, en particulier pour les petites entreprises et les startups.

- Apporter un appui au développement des compétences, y compris celles de la main-d'œuvre en activité.

- Soutenir la R-D et l'innovation, sans omettre les phases d'essai, de démonstration et de vérification.

- Améliorer la gouvernance pour faire en sorte que les politiques nationales et régionales aillent dans le même sens. 


\section{EXECUTIVE SUMMARY}

With the economic crisis continuing to affect growth, and environmental challenges mounting, governments around the world are increasingly seeking more innovative ways to promote economic activity and enhance sustainability. The OECD Green Growth Strategy recommended that green growth policies should encourage innovation, as this can enhance efficiency in the use of natural capital and foster new economic opportunities from the emergence of new green activities. However, incremental innovation alone will not achieve a decoupling of economic growth from environmental impacts. Increasing the development and uptake of more radical and systemic eco-innovations, including new business models, is therefore important for the long-term transformation towards a greener economy.

The objective of this report is to explore the potential of new business models for green growth and to examine how successful models can be scaled up and accelerated through appropriate policy action. To make the discussion as concrete as possible, the study examines the role of specific business models in supporting the commercialisation and uptake of green products, processes and technologies. Since business models are not yet well known to policy makers, a good number of real-life examples are presented and analysed. To build upon existing knowledge and understanding, the study also reviews the available literature and case studies in the field. The report aims to help governments develop and implement policies that enable the wider diffusion of new business models and eco-innovation practices and thus support the transformation of economies towards green growth.

In total, 55 case studies from 14 OECD countries are analysed in the report. The case studies demonstrate that a range of new business models and approaches are emerging that are relevant for green growth. Environmental concerns are typically still seen as an external challenge to existing business models, that affect the way business is done. However, sustainability can become an integral part of business model design if it is perceived as a potential generator of additional value to the company and its customers.

New business models, with a strong focus on sustainability, are currently emerging and include: green product/process based models; waste regeneration systems; alternative energy-based systems; efficiency optimisation by ICT; functional sales and management services; innovative financing schemes; sustainable mobility systems; industrial symbiosis; and green neighbourhoods and cities. Some of these, such as ecocities and industrial symbiosis, focus on the greening of an entire system and can therefore be considered as systemic innovations. Others, such as energy saving companies and models based on efficiency optimisation through ICT, are focused on more incremental changes. Yet others, such as cradle-to-cradle business models, take a life-cycle approach aiming for a society based on recycling and zero waste.

The case studies also point to a number of key barriers to the emergence and growth of new business models, most of which confirm previous OECD work. The most important of these is lack of market demand, which reduces the incentives for firms to develop innovations, and reduces their ability to scale an innovation. Other important barriers to new business models include lack of knowledge and human resources; limited access to the necessary financial resources; constraints related to intellectual property rights; as well as barriers resulting from government policies themselves, e.g. perverse incentives due to fossil fuel subsidies.

The following policy implications emerge from the analysis: 


\section{Market creation and demand}

- The analysis of new business models illustrates the important role of market demand for the development and deployment of eco-innovations. Market-based instruments, such as carbon taxes are an important component of the policy mix for "getting prices right", and help send the appropriate signals to firms, households and individuals to internalise environmental externalities. Such instruments are particularly important for business models focused on enhancing energy efficiency, such as energy saving companies. Moreover, perverse subsidies to incumbent firms, such as fossil fuel subsidies, reduce the ability of new firms to enter the market and compete with incumbents on a level playing field.

- Regulation of harmful substances and activities, performance standards, green labels and certificates, as well as technology-based standardisation, also play an important role in encouraging the development of new eco-innovative products, materials and processes. Such measures are often considered as the main drivers by firms. However, the use of regulatory measures should be carefully considered and regulations should be well designed to ensure that they are efficient and do not place any undue burden on businesses.

- The stability and certainty of the regulatory framework plays a key role in ensuring the long-term economic viability of many eco-innovations. To make long-term investments and commitments, firms require a stable regulatory environment and clear market signals, which includes a level playing field without competitive distortions.

- Well-designed innovative public procurement involving competitive tendering and outcomeoriented specifications can also strengthen markets for eco-innovation. Consumer subsidies also play a role for certain business models, although they are often a costly and inefficient tool to achieve public policy objectives.

- One finding from the case studies is that companies tend to value policy interventions that are tailored to the specific barriers they face, often targeting one particular aspect of the innovation process. This finding points to the need for an effective mix of policy instruments. Policy makers have generally recognised that supply-push and demand-pull policies do not work well in isolation, and a mix of the two types of instruments is often to be preferred, thus allowing policy to address failures and barriers throughout the entire innovation chain.

\section{Financing}

- Access to financing is a major constraint for many new business models, even if much of the financing comes from inside the firm, and some is provided by parent firms that may be at the origin of some new business models. However, financing is an important challenge for many young and innovative firms, and also for larger and riskier business models that engage in more systemic or radical innovations.

- Policy measures are therefore needed to enhance access to finance, in particular to help new business models grow and scale up. Financial constraints are particularly prevalent in markets for eco-innovation, where a number of specific market failures limit access to finance. Policy should take steps to ease access to finance for new and innovative firms, both with respect to debt (which the case studies confirm to be the prevalent source of external funding for enterprises) and equity finance. This could involve risk-sharing schemes with the private sector. For risky business models, where debt finance is often not an option, governments should take steps to foster seed capital and start-up financing, for example by acting as facilitators, or in providing networking and matchmaking services. 
- In addition to acting as facilitators and providing networking and matchmaking services, governments can also deploy public funds. But when they do so, policy makers should ensure that funds are channelled through existing market-based systems and private funds, and shaped with a clear market approach. Public policy should focus on using financial engineering approaches to develop the market for early-stage equity finance, rather than directly providing finance to private firms.

- Moreover, it is important to understand what is at the origin of the lack of finance. In some cases, the main bottleneck is a lack of high-quality projects and experienced entrepreneurs with the necessary business skills, rather than the funding as such. In this case, public policy may need to focus on the mentoring of entrepreneurs as well, e.g. through so-called accelerator programmes.

\section{Entrepreneurship and barriers to entry, exit and growth}

- While several green business models involve large firms, entrepreneurship emerges as a key driver of green business models and related eco-innovations. The majority of firms in the sample are small or micro firms, and many of them are start-ups who have come up with a new, bold vision and are looking to exploit technological or commercial opportunities that more established firms have neglected or not yet explored. This is especially evident in areas that require a systemic shift, as in mobility systems or green cities, but the disruptive effects of newcomers permeate all other types of business models.

- At the same time, the case studies show that some new business models face high barriers to entry. Perverse subsidies to incumbents or policy measures that delay the exit of failing firms may stifle competition and slow the process of reallocation of resources towards the firms that are more innovative and productive. For example, decreasing or removing energy subsidies can have a positive impact on demand for energy efficiency and thus enhance the scope for business models in this area, as it makes the true cost of energy more apparent to end users and increases the incentives for efficiency.

- Companies engaged in eco-innovation activities perceive burdensome regulations and complex administrative requirements as significant barriers to the growth of their business. Simplifying and reducing start-up regulations and administrative burdens can go a long way to lowering barriers to the entry of newcomers, and help support their growth. While not directly emerging from the case studies, barriers to exit such as bankruptcy regulations are important too; successful business models often require experimentation. Enabling talented entrepreneurs to fail and try again can be good for firm growth in the long run.

- New firms and business models may also face additional barriers to growth compared to existing firms, since they use innovative approaches that may not be fully aligned with prevailing regulations and policies. Governments can help such firms by providing tailored assistance, e.g. through a specialised portal focused on their needs, which can help enhance compatibility between government and entrepreneurs and also help place new developments and opportunities for eco-innovation on the policy agenda.

- Finally, government policies to support entrepreneurship, e.g. consultancy services, or support for internationalisation, also play a role. Policy makers should ensure that these measures reach the right target audience and provide an adequate quality level of services, as companies interviewed for the case studies (especially SMEs) often seem to be dissatisfied with public support to entrepreneurship. Enhancing the efficiency of such measures is also important in the context of growing budget pressures in many countries. 


\section{Intellectual property rights}

- Many firms attach a high degree of importance to IPR, which underscores the crucial role of well-functioning systems of intellectual property protection and enforcement. Patents are the most widely used form of IPR in the cases considered, but other forms, such as trade secrets, trademarks, copyright, confidentiality and non-disclosure agreements, are also used. Governments should ensure that IPR systems provide appropriate incentives for investment in innovation, while fostering the diffusion of knowledge and technologies.

- Patents and other categories of IPRs are particularly important for SMEs, especially start-ups that, unlike large and established firms, have few other means of protecting their innovations and use the patent as collateral. Recent OECD work shows that, in the cleantech sector, entrepreneurial companies that are patenting are more likely to receive financing by private investors. The costs of IPR, including the possible costs of legal protection, are an important barrier for many business models and in particular for SMEs. Governments should help ensure that young, innovative firms can easily and efficiently access the IPR system, and use it to create value from their intellectual assets.

- IPR is also important to facilitate co-operation and partnerships with other companies. Many case studies stress the need for firms to strike the balance between protecting their own IPR and sharing knowledge with other innovators and partners.

- The case studies also confirm that effective IPR protection promotes international technology transfer, as foreign technology providers may be confronted by the threat of imitation by local competitors.

Skills

- The case studies of new business models confirm the high value of education and training to fostering eco-innovation. Eco-innovations are often the product of multidisciplinary approaches, drawing on a wide range of technical expertise and scientific (as well as non-scientific) skills. The case studies also suggest that there are relatively few unique "green skills", and vocational skills that are required in "green jobs" typically overlap with those used in similar non-green occupations. Nonetheless, some green occupations do appear to require new educational or training pathways, e.g. research and engineering positions in the renewable energies sector or system analysts who develop ICT support for smart grids.

- The case studies also point to the existence of skills shortages in specific occupations and business models, such as efficiency optimisation by ICT and innovative financing schemes. Policy makers should ensure that the education and training system is well equipped to provide such new skills, or upgrade the skills of existing workers. A labour market information system that tracks and projects emerging skill needs and informs labour market actors could play a useful role in this respect. International mobility of human resources also plays an important role, e.g. in tapping into the necessary skills and in contributing to the creation and diffusion of knowledge. Government needs to facilitate such mobility.

- Companies are increasingly collaborating with other firms, but also partnering with universities and governments, to obtain the knowledge and skills they need to enhance their capabilities to innovate. Policy makers should facilitate these partnerships by fostering collaborative mechanisms, knowledge networks and research consortia.

- Some case studies of green business models suggest there may be a trade-off between the skills required for the management of day-to-day business processes and the creativity and ability required for further innovation. Although many decisions about how human resources are used 
and developed are the subject of firms' individual human resource management policies, governments should consider how it can induce higher levels of employee learning and training in the workplace.

\section{$R \& D$ and innovation policies}

- The case studies confirm that government support to R\&D is pivotal to overcome some of the market failures and systemic barriers that may result in a slow transition to low-carbon and energy-efficiency systems. While many companies interviewed for the case studies have benefitted from general support policies for $R \& D$, some of them lament the lack of R\&D policies targeted at specific clean technologies and forms of eco-innovation. Direct support for R\&D and innovation has the advantage that it can be focused on activities and actors that are the most important for meeting public policy goals.

- Policy makers should consider simplifying administrative procedures for obtaining funding and ensure that these meet business needs. Several firms, in particular SMEs, find the existing procedures too cumbersome, to the point that in some cases they were discouraged from applying for funding by the red tape and bureaucracy related to R\&D support programmes. Moreover, in some instances there seems to be a mismatch between government support (which focuses narrowly on the domestic market) and the needs of the companies whose business model is oriented towards exporting innovative goods, services and processes to the global market.

- Policies to support the testing, demonstration and verification of new technologies and products are considered critical by many firms, as these are important stages ahead of the commercialisation of technologies and products, in particular in areas such as alternative energybased business models and sustainable mobility systems.

\section{Governance and framework conditions}

- The role of the government appears to be particularly important in supporting new partnerships and creating favourable conditions for new business models. Government support is especially significant for larger scale projects, such as green cities. There are many examples of large-scale eco-innovative projects which would not have taken place without strong political support from national or regional governments, including clear and credible targets and high levels of regulatory stringency. National policies that focus on energy and resource efficiency can encourage firms to adjust their business strategies and contribute to the development of new business models.

- The design of public policies supporting green growth should explicitly consider the scope for new business models. This should take into account the possible wider impacts of business model changes on value creation, environmental impacts, and broader systemic changes. Although policy makers should not design policies to foster certain business models - as policy should remain neutral with respect to firms, technologies and sectors - certain policies may facilitate the emergence of new business models. For example, standards, labels and regulations on waste and recycling will facilitate the emergence of business models around life-cycle thinking.

- The impact of policies on the emergence of new business models should also be considered, for example on whether policies enable new business models to compete on fair terms with incumbent firms, including by fully accounting for environmental externalities.

- The need for policy support at the national level is often differentiated from policy support at the local level. The analysis of new business models points to the challenge of ensuring effective governance of support policies, as eco-innovation often has a strong local dimension, e.g. in the 
case of green cities, industrial symbiosis or sustainable transport systems. Implementation of many eco-innovative projects requires active support and involvement of regional or local government and municipalities. Aligning policies between local, regional and national levels is important to ensure that they are consistent, complementary and efficient.

Finally, policy makers will always need to question whether the emergence of new business models and the related innovation can simply be left to the market or whether policies are needed to support it and also what such policies should look like. This implies that it is important to carefully consider the rationale for policy intervention, and analyse the relevant market and systemic failures. Moreover, not all potential failures in innovation systems make government intervention necessary or desirable. Awareness of the possibility of government failure and rigorous ex ante evaluation of policies can help to limit the risk of costly but inefficient interventions. 


\section{INTRODUCTION}

By 2050, world GDP is projected to grow to USD 305 trillion, from USD 77 trillion in 2012. At the same time, 2.2 billion more people will be living on the planet compared to 2010, so that the world population will reach almost 9.2 billion people. This population will also become more urbanised: by 2050 , 2.8 billion more people are projected to be living in urban areas, which will contain almost $70 \%$ of the entire world population (OECD, 2012a). This growth will create billions of new consumers with needs for housing, food, water, clothing and transport. However, the shrinking availability of natural resources, deteriorating environmental conditions and changing climate will imply that the world can no longer pursue its current growth path.

The current economic crisis has further exposed the need for a reconsideration of traditional economic models and approaches. With the economic crisis continuing to affect growth, and environmental challenges mounting, governments around the world are increasingly seeking more innovative ways to promote economic activity and tackle global environmental challenges such as climate change and the scarcity of natural resources.

Many national and international strategies focused on sustainable development, green growth, sustainable production and consumption on the one hand, and innovation and knowledge-based development on the other hand, have emerged in recent years, and there is an increasing recognition of the role of eco-innovation as a tool to combine green and growth. The OECD Green Growth Strategy (OECD, 2011a) recommends that green growth policies should encourage innovation, which can produce economic gains, by eliminating sources of inefficiency in the use of natural capital. This can also foster new economic opportunities through the emergence of new green markets and related activities.

This study builds on this notion and explores the potential of new business models for eco-innovation, including how successful models can be further extended and scaled up. Since the role of new business models for eco-innovation is relatively new for many policy-makers, a number of case studies have been collected and analysed. These cases provide a better understanding of the business model concept and its role in enabling eco-innovation, including more radical and systemic innovation. The analysis also explores how governments can develop and implement policies to enable and drive green transformation, including through the development and wider diffusion of new business models.

The first chapter outlines the main challenges for attaining green growth and discusses the role of ecoinnovation in fostering green transformation. It reviews different types of eco-innovations and discusses the relationship between radical and systemic innovations and the enabling role that new business models can play. Chapter 2 reviews the literature on eco-innovations and focuses, in particular, on the role of business models. Chapter 3 proposes a conceptual framework to analyse the role of new business models for eco-innovation, considers their impact and examines a range of relevant public policies. It also applies this conceptual framework to the analysis of specific case studies. Finally, Chapter 4 highlights a number of key policy implications from the analysis. 


\title{
1. WHY NEW BUSINESS MODELS MATTER FOR GREEN GROWTH
}

\author{
Andrea Beltramello, Linda Haie-Fayle and Dirk Pilat
}

\subsection{The role of innovation in the transition to green growth}

"Green growth" (OECD 2011a, EC 2011) continues to be an important element in national and international debates on the economic crisis and recovery. The ongoing economic crisis continues to provide a unique opportunity to improve energy and materials efficiency and to implement structural reforms (OECD, 2010a). At the same time, there is a growing concern about the sustainability of economic growth, which underpins a demand for a "greener model of growth" (OECD, 2011a). Green growth involves a long-term transition of economic and industrial structures as well as a method of capturing short-term opportunities, notably in terms of reforming those government policies that could be considered inefficient or harmful to the environment.

The green growth agenda may differ somewhat in its assumptions, conceptualisation and assigned goals in OECD countries as compared to developing and emerging countries (Huberty et al., 2011; IIED, 2009; IGES, 2011). The common, overarching objective of green growth is to decouple economic growth from environmental degradation (OECD, 2011b). However, there are significant challenges in how the transition, i.e. a shift from the current resource-intensive economic system towards a future low-carbon, resource-efficient economy, is to be achieved, with different implications for OECD and non-OECD countries. While in OECD countries this transition mainly entails a structural change towards a resourceefficient, knowledge-based economy, in many developing countries, green growth requires strategies that contribute significantly to the objectives of development and poverty reduction.

Indeed, repeating the economic growth path of industrialised nations is not a sustainable path for developing countries and emerging economies. The challenge is to improve living standards without imposing an excessive burden on environmental carrying capacity (OECD, 2011b). Given the extent of accumulated knowledge and technologies, developing and emerging economies may be able to "leapfrog" to more sustainable economic structures. For example, the lessons of the current technological regimes suggest that there may be benefits in avoiding carbon-based energy systems, whilst progress on sustainable agriculture can help the poorest communities to escape from a vicious circle of poverty.

The transition to a greener economy is both a challenging and a long process, as there are many structural, political, technological and cultural obstacles that need to be overcome. So far, there has been rather limited evidence about how the two-fold objective of economic growth and decreased emissions and resource consumption can be achieved, and much larger, systemic changes may be required to transform the economy.

Recent OECD analysis shows that green innovation does not only have the potential to provide efficient and effective solutions to environmental challenges. It can also contribute to making companies more competitive, and hence work towards a stronger economy. First, eco-innovations can lead to increased productivity and energy efficiency, thus improving the cost competitiveness of businesses (Hallegatte et al., 2011). Second, the market for environmental goods and services is growing fast in both OECD and non-OECD countries. A comparative advantage in such markets can therefore be an important 
source of economic growth. Third, eco-innovation can contribute to the emergence of new business opportunities (OECD, 2010a).

Firms introduce innovations in response to factors such as regulations, the availability of public support or market demand (Figure 1). In most countries regulations appear to be an important motivation for firms. But market demand from customers is also an important determinant of eco-innovations, suggesting that companies are increasingly seizing the opportunities of increased sales and profit that "greening their business" can generate. Interestingly, (short-term) fiscal incentives are not considered an important motivation for firms, confirming the importance of long-term drivers for innovation.

Figure 1. Motivation of firms introducing environmental innovations, 2006-08

Firms citing factors as motivations, percentage of innovative firms

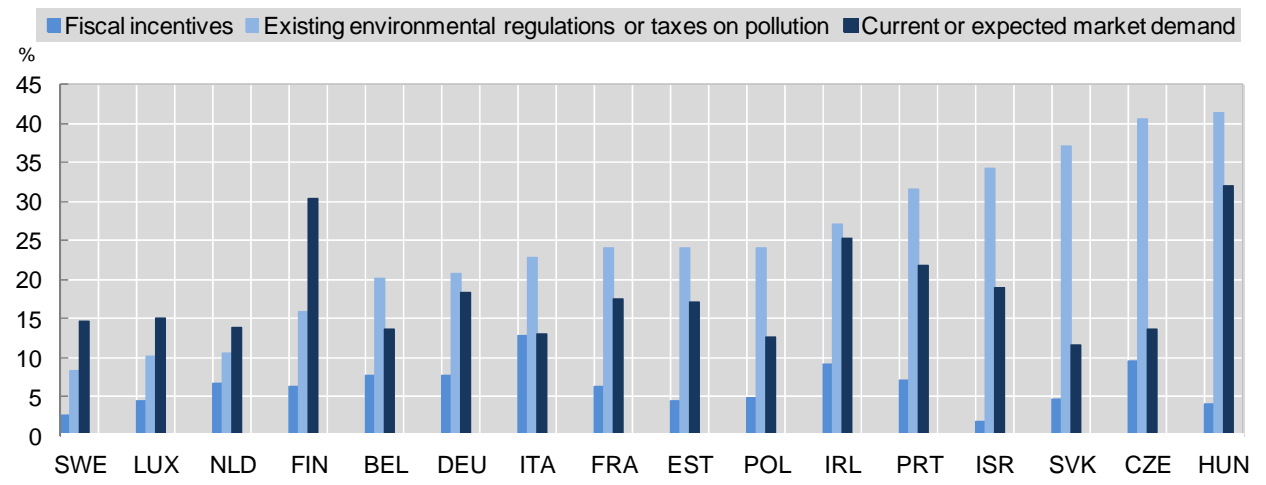

Note: The statistical data for Israel are supplied by and under the responsibility of the relevant Israeli authorities. The use of such data by the OECD is without prejudice to the status of the Golan Heights, East Jerusalem and Israeli settlements in the West Bank under the terms of international law.

Source: OECD (2011b), based on Eurostat (CIS-2008) and national data sources, June 2011.

Figure 2. Benefits of environmental innovations, 2006-08

As a percentage of innovative firms

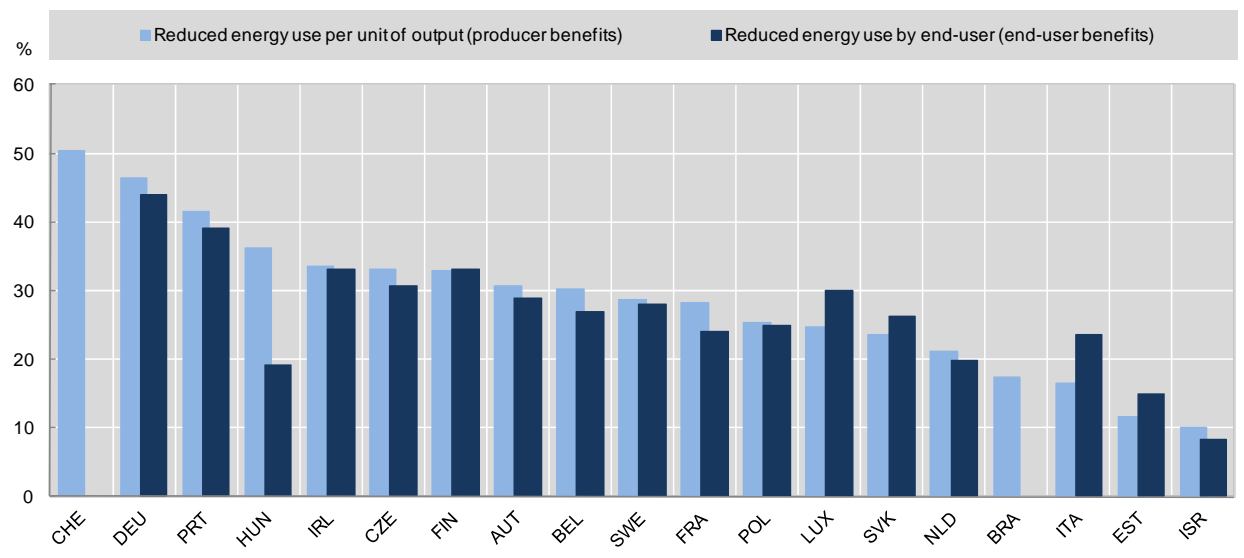

Note: For Brazil only the following activities are included in the services sector: ISIC Rev.4 Divisions 58, 61, 62 and 71.

The statistical data for Israel are supplied by and under the responsibility of the relevant Israeli authorities. The use of such data by the OECD is without prejudice to the status of the Golan Heights, East Jerusalem and Israeli settlements in the West Bank under the terms of international law

Source: OECD (2011b), based on Eurostat (CIS-2008) and national data sources, June 2011. 
The benefits of eco-innovation for firms may take many forms: reducing material or energy use per unit of output; reducing the enterprise's $\mathrm{CO}_{2}$ footprint; reducing water or pollution; or growing new markets, among others. For producers, but also for end users, reduced energy consumption appears to be an important effect of eco-innovation (Figure 2).

Eco-innovation can be distinguished from general innovation in three ways. First, it represents innovation which explicitly emphasises the reduction of environmental impacts, whether intended or not. Eco-innovation shares the characteristics of general innovation as defined in the Oslo Manual (OECD/Eurostat, 2005), and as such includes "the implementation of new, or significantly improved, products (goods and services), processes, marketing methods, organisational structures and institutional arrangements". However, eco-innovation differs from general innovation in that it lowers specific negative externalities (e.g., reducing the environmental costs of production) while generating positive spillovers from innovation that are well documented in the literature (Bernauer et al., 2006).

Second, eco-innovation often includes innovation in social and institutional structures (as with general innovation). A growing body of literature emphasise that changes to social norms, cultural values and institutional structures can be considered integral parts of eco-innovation (Rennings, 1998).

Third, achieving a successful transition to a greener economy (as for other global societal challenges) may require a larger degree of radical or disruptive innovation, relative to other areas where incremental innovation may be sufficient.

\subsection{Radical and systemic eco-innovations}

Solutions such as pollution control, cleaner production, eco-efficiency measures, and eco-design and green products are often applied by business. They are powerful tools to improve efficiency, as they can be introduced within existing production, process or business systems, without changing the underlying "technological regime". Such solutions are also relatively easy to manage, as they often involve few actors, and are often fast and relatively cheap to implement, because they involve only a product or a process and not a whole system. Therefore, they can generate results relatively quickly, having enabled substantial environmental improvements over recent decades, and thus contributing to a relative decoupling of economic growth from environmental pressure (OECD, 2011b).

However, the impacts of such solutions are often of a local and incremental nature and are insufficient to achieve an absolute decoupling of growth from environmental pressures. Furthermore, they may "lock in" traditional patterns of production and consumption and run the risk of reducing the future potential for green growth and sustainable development. Therefore, more radical solutions that imply changes to the existing technological regime are needed to enable the absolute decoupling of growth from environmental pressures.

To understand the basic mechanisms of different greening options from the innovation point of view, a distinction between three types of innovations can be made (Scrase et al, 2009):

- Incremental innovation, which aims at modifying and improving existing technologies or processes to raise the efficiency of resource and energy use, without fundamentally changing the underlying core technologies. Surveys of innovation in firms demonstrate that this is the dominant form of innovation and eco-innovation in industry.

- Disruptive innovation, which changes how things are done or specific technological functions are fulfilled, without necessarily changing the underlying technological regime itself. Examples include the move from manual to electric typewriters and to word processors, or the change from incandescent to fluorescent lighting. 
- Radical innovation, which involves a shift in the technological regime of an economy and can lead to changes in enabling technologies. This type of innovation is often complex and is more likely to involve non-technological changes and mobilise diverse actors. Radical innovations include not only the development of radical, breakthrough technologies but also a reconfiguration of product-service systems, for example, by closing the loop from resource input to waste output or "cradle to cradle" and the building of business models that re-shape the way consumers receive value on the one hand and reduce material use on the other.

A sophisticated combination of these different types of innovation, together with new organisational and managerial arrangements, could induce far-reaching changes in the techno-societal system and enable a long-term green transformation by affecting several branches of the economy, including consumers. One such example is the introduction of a new urban mass-transit system. This could involve a combination of changes to control systems, as facilitated by communications technologies, organisational practices (e.g. moves from hierarchical to networked collaboration), infrastructure management (e.g. those enabled by computing technologies), environmental monitoring, pushed by advances in remote sensing, manipulation techniques, as in genomics, or materials production, such as those made possible by modern industrial chemistry and nanotechnology (Steward, 2008; Scrase et al., 2009).

Such innovations are defined as systemic innovations, and are also referred to as transformative innovations (Scrase et al., 2009). They are more likely to take place beyond the boundaries of one company or organisation, as they often require the transformation, replacement or establishment of complementary infrastructures. From the perspective of the transition to a greener economy and the decoupling of growth and environmental impacts, more attention is being paid to systemic innovation as it could generate wider and continuing impacts in the medium to long-term (OECD, 2011b; Smith, 2008; Scrase et al. 2009). Systemic eco-innovation is increasingly considered to be a cornerstone of the green economy as it may help the society exit from the current hydrocarbon-based technology regime.

Radical and systemic innovations are highly complex as they often involve many actors and a range of technological and non-technological changes in organisational and institutional arrangements. One of the imperatives for these innovations is that both suppliers and consumers should embrace social and cultural changes and adopt new values and behaviour.

Systemic innovations are commonly characterised by fundamentally new engineering and scientific principles, major price-performance improvements, creating a major disruption in the market by making traditional practices obsolete, and being based on new ways of creating values (OECD, 2011a). Important systemic innovations include the transition to steam power; the development of the internal combustion engine and its impact on transport and industry; electrification; as well as the recent ICT revolution.

It is typically not possible to distinguish between different innovations ex-ante. In the end, the market determines what innovations are successful and achieve systemic impacts. At the same time, some innovations are more likely to achieve greater impact. For example, recent OECD work has examined the quality of patents, based on their citations, scope, renewals, etc. (OECD, 2011c), which provides some insights in the potential of such innovations. However, this only provides insights for some innovations.

\subsection{The role of business models in radical and systemic eco-innovations}

Business models are an important part of how eco-innovation is brought to the market and diffused. According to Osterwalder et al. (2010), "a business model describes the rationale of how an organisation creates, delivers, and captures economic, social, and other forms of values". The components of business models typically include: strategic decisions on customer segmentation; products and services and associated value to offer; business, development, trade and other partners; resources to create, and channels to deliver, value; and underlying cost structure and revenue streams to ensure the financial viability of the 
business. A business model can also be considered as a holistic approach towards explaining how firms conduct business (Zott et al., 2010).

A number of efforts have been made to understand and conceptualise business models that have a greener orientation, notably the business model concept that has recently been adopted in the discourse on sustainable services (Halme et al., 2007; EPA, 2009). It is commonly used in studies on product-service systems (PSS) based models, which are defined as business models that have "tangible products and intangible services designed and combined so that they are jointly capable of fulfilling specific customer needs" (Tukker, 2004).

In a study of eco-innovation experiences in the Nordic Region, FORA (2010) refers to "green business models". It defines them as "business models which support the development of products and services (systems) with environmental benefits, reduce resource use/waste and which are economically viable. These business models have a lower environmental impact than traditional business models". This study further distinguishes green business models from "classical green businesses" such as cleantech, by highlighting the fact that green business models aim to create economic and environmental win-win benefits for both the supplier and the customer. A recent study by Nordic Innovation (2012) distinguishes between two main types of green business models, namely incentive models, that create incentives for customers to use resources more efficiently, and life-cycle models, that focus on the greening of a companies' value chain.

The analysis of eco-innovation business models sheds light on whether, to what extent and how environmental values are reflected in their value propositions, customer segmentation, use of resources and collaboration patterns, as well as in managing cost and revenue streams. By replacing old business practices, innovative business models can enable firms to restructure their value chains and generate new types of producer-consumer relationships and to alter the consumption culture and patterns of use. Therefore, the business model perspective is also relevant to understand radical and systemic ecoinnovation, in enabling systemic changes and transformations. In addition, it is important to understand how policy can influence and facilitate the emergence of new business models that are effective in driving eco-innovation.

Governments around the world are increasingly recognising that business activities are an important part of the solution to major environmental and sustainability challenges, such as protecting ecosystems, tackling climate change, as well as enhancing livelihoods and reducing poverty and other social problems (IIED, 2009). Governments can help create the framework conditions that will assist companies to operate according to a business model through which they can meet their business objectives and make profits, whilst also contributing to meeting societal challenges, such as green growth.

\subsection{Business models and eco-innovation: Lessons from a literature review}

Although the majority of eco-innovation studies still focus on incremental innovations such as green products and eco-efficiency improvement, several theoretical and empirical studies have been increasingly exploring the concepts of radical and systemic change. In reviewing the empirical studies, a variety of product-service systems (PSS) - or incentives (see Nordic Innovation, 2012) - models were noted, namely: "functional sales", "energy service companies" (ESCO); "chemical management services" (CMS); "integrated pest management" (IPM) and "performance based pest management" (PPM) services; "Sharing" or "renting" based models; and "Design-build-finance-operate" (DBFO) models. A second group, such as cradle-to-cradle and industrial symbiosis, reflect business models built on life-cycle thinking. A third group is centred on the application of ICT, whereas a final group involves broad systemic innovation (e.g. eco-cities). Box 1 presents a systematic overview and definitions of each type of business model for eco-innovations that is discussed in the literature. 


\begin{tabular}{|c|}
\hline 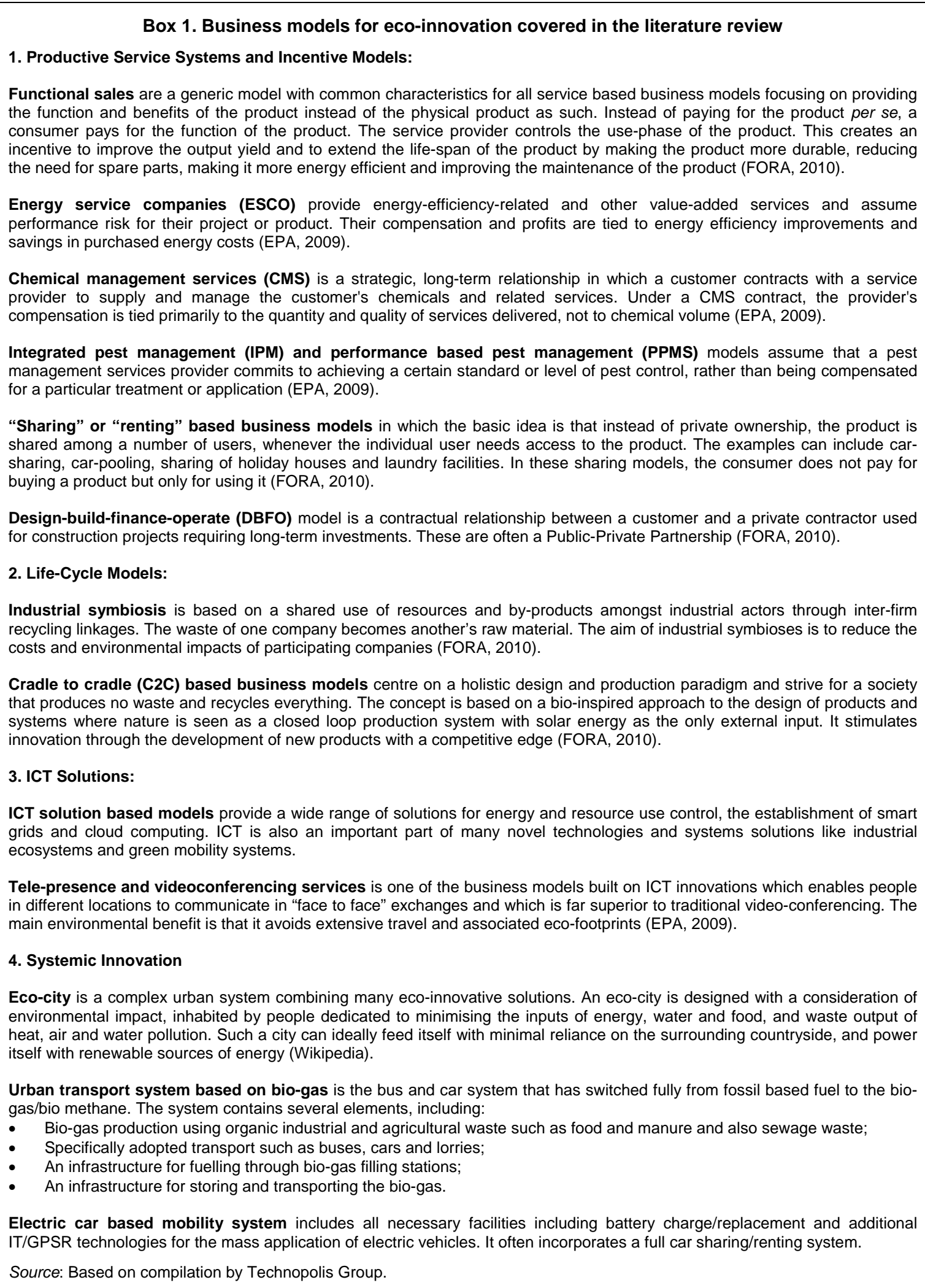 \\
\hline
\end{tabular}


A background literature review includes empirical studies that analyse and synthesise several cases studies, as well as others based on single cases of eco-innovations and business models. The literature review below focuses on: value creation and capture; sustainability benefits; the role of enabling technologies and infrastructure; corporate governance and strategy; the role of policy; barriers and drivers; and systemic changes.

\subsubsection{Value creation and capture}

Since the seminal work of Porter (1991) which highlighted the economic benefits that could be derived from the improved environmental performance of companies, researchers have found an increasing number of examples of companies that have exploited business opportunities linked to sustainability and eco-innovation. Many firms have shifted from viewing their environmental obligations as a burden to seizing new opportunities for value capture, while greening their business activities and producing ecoinnovative goods and services.

Value creation, both for the company and the customer, is at the heart of any business model. In business models for eco-innovation, economic value is of utmost importance, both for the company and its customers. Companies capture value by seizing new business opportunities, new markets and new revenue streams. These are natural aims of any business activity, including those involving eco-innovations. For example, product-service system studies carried out by Tukker (2004) and EPA (2009) analyse value creation in service oriented business models. In particular, they highlight the existence of tangible value (such as cost reductions and resource savings) as opposed to intangible value. The latter may include the improvement of the environmental image of the company, minimisation of potential financial risk for clients and the extra convenience and comfort associated with new services or products.

Osterwalder et al. (2010) highlight the following aspects of value creation: the newness of the ecoinnovative product or service; its improved performance, customisation and convenience in comparison to existing alternatives; improved design; better price; potential cost reduction and savings; higher accessibility; offering a result or function instead of a product; and many other things that make the product or service attractive to customers and create a preference for that product or service, as compared to the alternatives. Often value is increased by combining a product with services, or by the complete substitution of the product with a service.

The rapid growth in demand for clean technologies and green products and services offers potential new revenue streams both for old companies that are adjusting their production patterns and for start-ups that have been established to tap into green markets. For example, the studies by Tukker (2004), EC and COWI (2008), EPA (2009), FORA (2010) and Bowden et al. (2010) show a new generation of companies emerging that focus on providing new types of services, which promote material and energy efficiency, cut associated emissions and reduce the clients' overall ecological footprints. Studies of Meenakshisundaram and Shankar (2010) and OECD (2009) show that companies are tapping into the businesses fostered by sustainable mobility initiatives. Eco-city and industrial symbiosis practices are creating business opportunities for eco-design, eco-engineering and sustainable construction companies (Johnson and Suskewitcz, 2009; Martin, 2009, Van Berkel, et al., 2009).

Adopting more sustainable business models and eco-innovations provides a range of other benefits and values for companies that strengthen their competitiveness. These include increased savings of resources, cuts in associated cost and a reduction in waste management cost. For example, when companies co-operate in industrial symbiosis they obtain access to cheaper inputs and reduce their waste management costs, which in turn strengthens their competitiveness. In addition, they create a demand for technologies and systems that enables the exchange not only of materials and energy, but also of knowledge. Thus, a new market with global export potential is created (FORA, 2010). 
EC and COWI (2008), FORA (2010) and Bowden et al. (2010) suggest that branding and reputation are other important values that companies gain by implementing sustainable business models and promoting eco-innovations. With the increasing awareness of consumers and the inclusion imposition of environmental standards for procurement by public service clients, these values are becoming important competitive advantages for companies.

Other economic benefits mentioned in the literature are related to avoidance of costs, the minimisation of administrative expenses and reduced safety costs. In service-oriented models, such as ESCO, CMS and renting and sharing, the advantage to the customers is that they do not have to bear the investment costs and associated investment risks, as the operational costs are known in advance and are also transparent. Alongside investment advantages, there is a reduction in risk costs related to work safety, the production process, delivery and dead stock. In car sharing, members can achieve considerable cost savings annually by using the company's mobility services (FORA, 2010). Cost-saving benefits have also been demonstrated in eco-service models such as tele-presence/videoconferencing, equipment sharing ${ }^{1}$ and carrental (EPA, 2009, Berhrendt et al., 2003).

Offering functionality instead of a product is another way of framing a business model. There are a growing number of innovative business models that substitute the sales of, often unaffordable, products by offering their functionalities to customers. Such functionalities are normally framed as a result, experience, performance based service, which is often referred to as "Getting the job done". Examples of such functionalities are:

- Selling "drive-miles" instead of renting out cars in the car sharing business models.

- Lease-like "see through" insurance instead of window insurance.

- Selling "light services" instead of lighting equipment.

- Selling "comfortable walking" instead of floor carpets.

- Performance based pest management models in which the company sells certain standards, such as a "low level of pests" or a "high harvest", rather than being paid for particular pest control activities.

Additional comfort and flexibility is another value that customers acquire via many business models and the innovative designs incorporated into them. For example, the success of the bicycle-sharing system that is being increasingly introduced in many cities is largely due to the convenience and ease-of-use of this system. In addition, the system enables customers to access bikes at any time of the day or night and its proximity to, and linkage with, other modes of public transportation provides a high degree of flexibility (OECD, 2009).

\subsubsection{Sustainability benefits}

Environmental benefits are an important feature of business models for eco-innovation, and as such have been thoroughly assessed in studies of the impacts of business models, with mixed results. For example, Tukker (2004) found that most PSS-based business models result in modest, incremental environmental improvement in the short-term. Radical improvements can only be expected in the case of models based on "promising functional results". ${ }^{2}$ The exception is those types of PSS systems that make users less responsible for the careful use of a product, such as "product leasing".

Other studies of PSS-based business models give a more optimistic assessment of their environmental and sustainability impacts, including the following improvements: reduced resource and energy consumption and associated ecological footprints; reduced carbon and chemical emissions to air; reduced 
spills of water; reduced chemical waste and improved disposal; and a change of attitude towards more sustainable behaviour.

EPA (2009) and FORA (2010) estimated that functional sales models - where customers pay for the function provided (e.g. light) instead of the product - can reduce $50-60 \%$ or more of the resources needed for production and life-span operation of a product by improving its design. In addition to the energy saving and associated greenhouse gases reduction, ESCO projects were found to create improvements in indoor air quality, which also provided a healthy working environment.

As shown by Halme et al. (2007) and FORA (2010), new business models also tend to create incentives to maintain environmental improvements in the long run. For instance, DBFO models create incentives to reduce energy costs and to invest in environmental efficiency. CMS creates incentives for the reduced use of chemicals, the substitution of hazardous chemicals and also the potential for a "cradle to cradle" set-up. Leasing and sharing schemes provide incentives to design the product so that it can withstand impacts from multiple users and improve durability and quality. This, in turn, reduces the product volumes and the associated need for resources.

In many of the cases discussed, business models contribute to a faster introduction of environmental technologies, processes and products, such as the use of renewables, the replacement of oil and gas and the application of more sustainable (bio-) materials. Through mobility services, customers obtain access to electric cars that they might otherwise be reluctant to purchase because of the high initial investment costs and uncertainties of performance (Johnson and Suskewitcz, 2009; FORA, 2010).

At the same time, many studies (including FORA, 2010; Tukker and Tischner, 2006; and EPA, 2009) suggest that the environmental benefits associated with certain green business models depend largely on the way in which the products are used. Sharing of products may entail negative environmental impacts, if the access to a shared product increases the customers' use of the product. For example, car-sharing provides members with access to a car to which they otherwise would not have had access to. Moreover, the fuel consumption involved in picking up the shared item may exceed the environmental benefits gained from the product sharing.

\subsubsection{The role of enabling technologies and infrastructure}

The improved availability and the development of supporting infrastructure and technologies are very important if an innovation is to survive and succeed. Enabling technologies play an important role in creating systemic shifts. ${ }^{3}$ New technologies that fit best with pre-existing systems are likely to be adopted more easily and to be diffused more quickly. On the other hand, radical and transformative innovations are complex in nature and have linkages and dependencies with many components of the system; therefore, they cannot be easily adopted and diffused.

In particular, the literature has highlighted the role of ICT technologies that minimise inconveniences for customers and maximise the efficiency of the system. Novel greener solutions are increasingly becoming of interest to ICT companies, which see more and more business opportunities emerging in this area.

For example, the bike-sharing systems reviewed in OECD (2009) are supported by internet maps showing real-time data on the availability of bikes and parking spaces at certain stations at any time of the day. The software used in electric cars involved in the Better Place business model, which was designed and developed by the company, provides complete information for the drivers. It displays the energy level in the battery, locates the nearest battery recharging and swapping facility, and also enables drivers to handle their booking, parking and charging spots conveniently (Meenakshisundaram and Shankar, 2010). 
Similarly, many service-oriented business models, such as energy saving companies and tele-presence are dependent on ICT technologies that control and regulate the energy consumption in private homes, offices and industries or enable high-end videoconferencing (EPA, 2009).

The availability of supporting physical infrastructure is also often an important factor for ecoinnovative solutions. The success of the Linköping bio-gas based transport system was largely due to refuelling station systems specifically designed for that fuel, both for public buses and private cars (Martin, 2009). The Better Place electric car system developed an automated battery swapping facility which can replace depleted batteries with charged batteries within three minutes without any need for the driver to get out of the car.

\subsubsection{Corporate governance and strategy}

Eco-innovation projects and business models are often influenced by the internal governance of companies, the strategies that they adopt and the societal values that they promote. In particular, the literature has focused on three aspects of corporate governance and strategy:

- Alliances with stakeholders: Partnership networks with other companies and public authorities are important to the success of the eco-innovation projects. For instance, Better Place entered into alliances with electric car manufacturers, battery manufacturers and renewable energy producers. Such alliances were seen as win-win opportunities for all the parties involved (Meenakshisundaram and Shankar, 2010). Co-operation with local authorities is often a prerequisite for large-scale projects like industrial or urban symbiosis or establishing a city biogas transport system (Johnson and Suskewicz, 2009; Martin, 2009; Yang and Feng, 2008; and Van Berkel et al., 2009). Good communication among partners is critical to the success of some projects, and is often more important to their success than technology. An evident example is industrial symbiosis, which normally involves several companies and organisations. Christensen (2004) stresses that the communication in Kalundborg was facilitated by the small size of the community involved, the established acquaintances between the managers, the open, nonsecretive management style of the companies and the opportunities for co-operation in projects.

- The style of governance: This includes shifts in companies' attitude vis-à-vis corporate social responsibility (CSR), as highlighted in Louche et al. (2010) and Carillo-Hermosilla,et al; (2009) CSR is increasingly being perceived as a driver of innovation and many companies have started to engage in CSR as a core aspect of their innovation activities and business models.

- Company leadership: Many studies such as those of Confino (2011) and Louche et al., (2010) illustrate how the dedication of companies' leaders is an important driver for assimilating changes and introducing such concepts and systems as "cradle-to-cradle" or "closed loop". For example, thanks to the will of the company leadership and its dedication to sustainability goals, the Good Water Company invested in introducing an "up-cycling" system and more sustainable bio-plastic bottled water production (Bowden et al., 2010). Similar examples of dedicated leadership come from several other case studies (see Carillo-Hermosilla, et al ; 2009; Christensen, 2004).

\subsubsection{The role of policy}

Recent OECD work reviewed policies to unleash green innovation, ranging from pricing mechanisms to public investment in $\mathrm{R} \& \mathrm{D}$, from support to private investment in innovation, to policies to foster growth in new entrepreneurial firms. The report highlighted that in order to foster green innovation, policies should not only focus on the creation and supply of new technologies and innovations, but also on the diffusion and take-up of green innovations in the market place (OECD, 2011b). Policy initiatives both at 
the national and local level, along with general framework conditions, can play an important role in introducing and diffusing business models for eco-innovation:

- Policy initiatives at the national level: Some literature shows that several eco-innovations were developed partly as a consequence of strong political support from national governments, providing a clear vision and objectives and a high level of regulatory stability and stringency. For example, van Berkel et al. (2009) argue that the Eco-Town Programme (promoting urban and industrial symbiosis in Japan) was boosted when the government put in place a comprehensive legal framework towards a recycling-based society. The availability of investment subsidies, the entering into force of ambitious recycling legislation with quantified, product-specific targets, improved access to the significant technological resources of the private sector, and the widespread recognition of the urgent need to act on environmental issues, all contributed to the success of the Eco-Town Programme. Johnson and Suskewicz, (2009), Reiche (2010), Chertow et al. (2004), Carillo-Hermosilla et al., (2009) as well as several other authors have provided examples of large-scale eco-innovation projects that would not have taken place without strong political support from the national government, clear, stable and long-term visions and objectives, and high levels of regulatory stringency.

- Policy initiatives at the local level: Regional governments and municipalities have been found to play a fundamental role in the development and, especially, the diffusion of many ecoinnovations. This was the case with the introduction of a large-scale, bio-gas based transport system in the Swedish city of Linköping, including the entire network of buses, trains and private cars and the refuelling infrastructure (Martin, 2009). In particular, it was found that the success of the initiative resulted primarily from "political consensus and the municipalities' firm belief in the project". Local authorities can also help sustain eco-innovation projects by creating specific market conditions for companies. An extreme case of such market creation was the case of an advertising company that was given a monopoly advantage over a large section of billboard advertising in Paris, in return for operating the bicycle sharing system in that city (OECD, 2009).

- Market based instruments and framework conditions: These can contribute to ensuring the longterm economic viability of eco-innovations, especially by providing stability and certainty for businesses and consumers. For example, carbon pricing or other market instruments that put a price on environmental externalities will contribute to the credibility and viability of a policy regime. This is key to encouraging investors to take the necessary risks to bring about ecoinnovations (OECD, 2011b). In addition, a policy environment based on sound framework conditions (such as competition, openness to trade and investment, adequate and effective protection of intellectual property rights, efficient tax and financial systems) is fundamental to allow eco-innovation to thrive. Policies supporting entrepreneurship and new firms have a key role in unleashing eco-innovative business models (Box 2). 


\section{Box 2. Entrepreneurship and the role of new firms}

The analysis of business models also has potential implications for entrepreneurship policies. OECD analysis shows that a large share of radical innovations, that will be important in achieving green growth, emerge from new firms (OECD, 2011b; Figure below). New and young firms are prone to exploiting technological or commercial opportunities which have been neglected by more established companies, often because radical innovations challenge the business models of existing firms. Moreover, analysis for the United States shows that such new firms contribute substantially to the creation of new jobs (Haltiwanger et al., 2009; Bravo-Biosca, et al. , 2012). Policy needs to create the room for such new firms by enabling their entry, exit and growth, ensuring fair competition and improving access to finance, which remains a major constraint for the entry and growth of young firms.

\section{Patenting activity of young firms, 2007-09}

Share of young patenting firms and share of patents filed by young patenting firms, EPO and USPTO

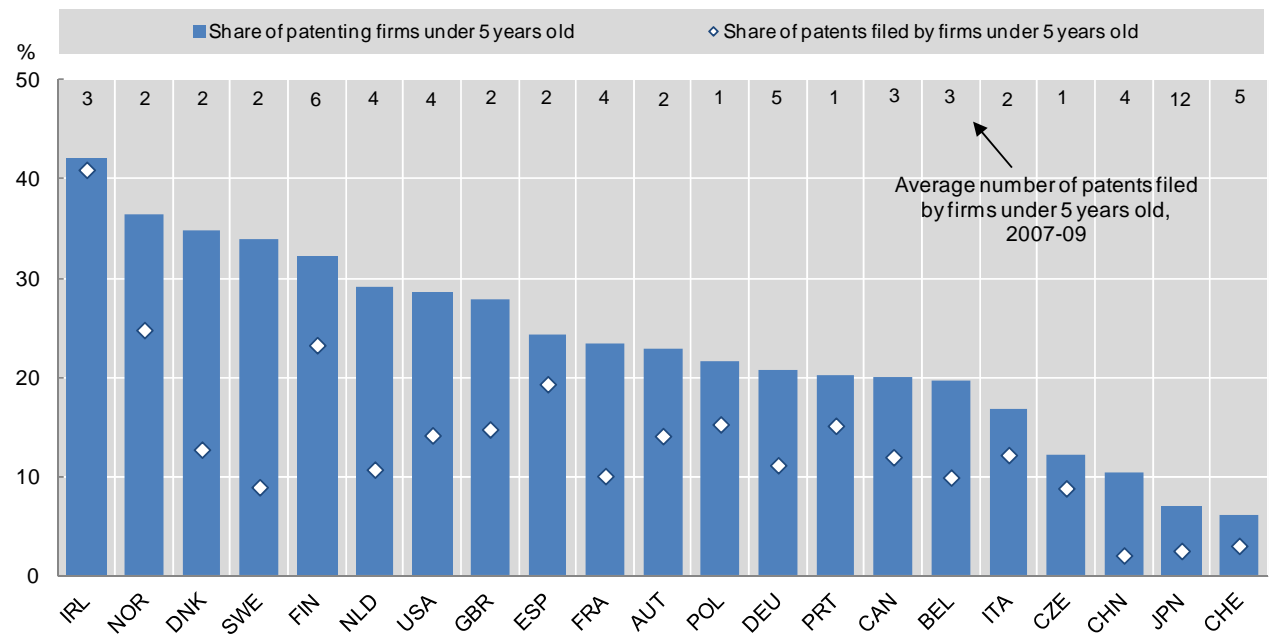

Notes: Patenting firms were linked to the ORBIS $\odot$ database, using combinations of string matching algorithm that maximise the precision of the match. The patent portfolio of firms refers to patents applied at the European Patent Office (EPO) and at the US Patent and Trademark Office (USPTO) between 2007 and 2009. Only countries with matching rates above 60\% of patent filings over the period considered are shown. Young patenting firms are firms featuring an incorporation date in ORBIS $\odot$ between 2004 and 2009.

Source: OECD calculations based on the Worldwide Patent Statistical Database, EPO, April 2011; and ORBIS॰ Database, Bureau van Dijk Electronic Publishing, December 2010; matched using algorithms in the Imalinker system developed for the OECD by IDENER, Seville, 2011.

\subsubsection{Systemic change and the role of eco-innovation}

Systemic change requires a full-scale shift in the technological regime of an economy, and can lead to fundamental shifts in the economy's enabling technologies. This type of innovation is often complex and is more likely to involve non-technological change and diverse actors. Johnson and Suskewicz (2009) argue that four interdependent and mutually reinforcing components are necessary for new systems to emerge and replace existing systems:

- An enabling technology (e.g. the creation of the microprocessor that launched the information age).

- An innovative business model (e.g. Google pairing its advanced search technology advertiser-paid search). 
- A careful market-adoption strategy (e.g. clean-tech offerings have to incubate in foothold markets, where the value proposition offered by early-stage technologies and business models is good enough for customers to overlook their shortcomings).

- A favourable government policy (supporting not just nascent technologies but also nascent business models, by amending regulations that inhibit their development).

Because of their complex and interdependent nature, there are not many examples of systemic innovations and those that do exist are easy to criticise (Johnson and Suskewicz, 2009).

The notion of systemic innovation suggests that technology is an important factor but that it cannot alone bring about radical change. The literature points to "soft factors" contributing to systemic change. These soft factors are about shifting to alternative practices, changing consumers' attitudes, moving to a different system of ownership and breaking with traditions. For example, studies of service based ecoinnovation business models focus on changing the traditional practices of doing business, as well as on changing customers' habits so that resources are used more efficiently, while functions or utilities are still delivered (FORA, 2010; Tukker and Tischner, 2004; and EPA, 2009).

Other studies show that systemic eco-innovations can only be made viable in the long term by introducing, upgrading or changing an adjacent technological system, including enabling technologies and supporting infrastructure. This, for example, is the case for eco-innovative mobility scheme business models (Martin, 2009; Johnson and Suskewicz, 2009; and OECD, 2009). Without the appropriate technical infrastructure, such as battery exchange and special parking stations, and software systems, like the Global Positioning System (GPS) and online monitoring, these schemes would not be able to succeed or to make a larger impact.

Finally, systemic change is at the heart of large-scale and complex eco-innovations, like industrial symbiosis and eco-cities. This change is about altering the prevailing practices of industrial and public actors and shifting from linear to circular systems of production and consumption. These business models, which involve breaking established traditions in industrial organisation and urban planning, require a rethinking and re-designing of the value chain, production and organisational and business strategies and a re-evaluation of the resources, products, by-products and waste. The change in these examples is also about building new tighter, inter-dependent and mutually beneficial collaborative networks and this requires sophisticated organisational capabilities.

\subsubsection{Barriers inhibiting new business models for eco-innovation}

The literature shows that green business models face a range of barriers on their way to implementation, which can be distinguished as being internal and external to a company:

\section{Internal barriers}

Internal barriers include: a traditional mindset among producers and providers and a lack of competencies and knowledge of sustainability issues; an insufficient number of reference cases; a lack of knowledge of possibilities on the part of higher management; a lack of integration between divisions in companies, for example, a division that develops a product and the people that develop the services or separation between organisational bodies for investment and the operation in organisations; increased development and production costs; insufficient R\&D capabilities (Carrillo-Hermosilla, et al., 2009; and FORA, 2010).

Many organisations do not have the necessary vision and resources to incur certain costs, such as implementation costs, in return for uncertain benefits, such as reduced risks and revenue growth. Even 
more progressive businesses remain locked into old-style economic models, which may inhibit more radical approaches (Confino, 2011). Organisational boundaries may also exist: for example, the procurement director is given incentives and rewards for cost reductions but not for risk reduction or contributions to revenue growth (FORA, 2010; Tukker and Tischner, 2004; Carrillo-Hermosilla et al., 2009).

\section{External Barriers}

External barriers include: a lack of market-pull due to the limitations of environmental tax legislation, the lack of green public procurement practices, as well as old fashioned routines and red-tape due to regulators and public procurement staff; lack of regulation and general government support for change; lack of capital for initial investment and for deployment of eco-innovations, which is often due to the fact that projects are perceived to be risky or there is a lack of knowledge amongst stakeholders about the economic benefits of green growth (FORA, 2010; Tukker and Tischner, 2004; and Carrillo-Hermosilla et al., 2009).

Access to finance appears to be particularly crucial. Confino (2011) notes the importance of the investment community to the promotion of company innovation. Investors effectively control developments in businesses and therefore their reluctance to support radical or sustainability-oriented changes is a serious barrier to the introduction of eco-innovations into ongoing business activities.

Finally, the adoption of eco-innovations is heavily dependent on consumers' attitudes (Martin, 2009; Meenakshisundaram and Shankar, 2010). For example, consumers who are accustomed to the luxury provided by large, petrol engine-powered automobiles and their various features and functions, may not be impressed by electric cars or less luxurious cars offered by car-sharing schemes.

\subsection{Analysing business models for eco-innovation}

Environmental sustainability is rarely at the core of value propositions of business models. The business community has been increasingly recognising the challenges posed by climate change, resource scarcity and environmental degradation, but these are not always incorporated into the main building blocks of companies' strategy and operations. "Green values" have been increasingly included in marketing strategies but they are not necessarily linked with a genuine integration of sustainability into the company's core operations. The main reason for this is that many businesses do not consider environmental sustainability as a key source of value creation. Companies often perceive sustainability as a challenge, or even an unnecessary cost. The mainstream thinking about business models is not concerned with issues of environmental sustainability, just as mainstream thinking about business is not primarily driven by environmental concerns.

Environmental concerns are primarily seen to be an external challenge to existing business models, leading to changes in the way business is done. Typically, the motivation behind such changes is pressure stemming from existing, or expected, regulation or an increase in the prices of energy and raw materials, which may put the company's cost structure and revenues at risk. In this context, sustainability can become an integral part of business model design if it is perceived as a potential generator of additional value to the company and its customers. 


\section{CASE STUDIES OF GREEN BUSINESS MODELS}

\subsection{Methodological approach}

An analysis of real-life examples can be helpful in understanding how green business models, especially those of the more radical type, contribute to introducing and diffusing eco-innovations. Case studies can provide deeper insights into how and why eco-innovations have succeeded or failed and the nature of factors and policies that have facilitated or hindered the innovation process.

The methodology for business case studies follows the approach adopted in earlier studies on open innovation and nanotechnology (OECD, 2008a; OECD, 2010b). The case studies involved face-to-face interviews with company representatives using a questionnaire as a detailed guide for discussion. OECD member countries nominated cases and country experts who conducted the questionnaire survey and interviews, and drafted the case studies. Eventually, 55 case studies were completed and are covered in the analysis in this report, which also considers material from previous studies on green business models (FORA, 2010; Nordic Innovation, 2012; UN Global Compact, 2012). Summary descriptions of the general features as well as potential impacts and benefits of all the eco-innovations and related business models can be found in Annex 1.

The reporting template for the case study is structured in five sections including an extended list of guiding questions:

- General features of eco-innovation covering information on types, functions, innovativeness/novelty, target users and business model.

- Impact and benefits including diffusion level, environmental, social and economic impacts now and in the future, as well as negative impacts.

- Innovation process covering stages of idea generation, $R \& D$, testing, business development and commercialisation.

- Factors that influence the innovation such as market conditions, organisation and networks, knowledge and skills, finance and resources, policies, IPR, value chains, enabling technologies and infrastructure.

- Overall lessons including determinants, future policy support and plans.

The analysis starts from an overview of the eco-innovation cases and focuses on the related business models. This exercise involves the following components:

i) Identifying a typology of green business models and grouping the case studies according to the identified categories;

ii) For each category, analysing the cases by focusing on the factors that influence the innovation: market conditions; knowledge, human and financial resources; IPR; government policies and programmes. For each of these factors, key drivers, success factors and barriers are identified and discussed; 
iii) Drawing policy implications from the analysis of the case studies, in particular: financing; entrepreneurship policies and barriers to entry, exit and growth; IPR issues; skills; market creation and demand-side policies; R\&D and other innovation policies.

An initial analysis of the role of various policy instruments was carried out for each type of ecoinnovation identified below. This was based on the information acquired from the case study template. The section in the case study addresses this issue by indicating the five most important policy instruments and assigning a priority using a 1-5 scale, where 1 is the least important and 5 is the most important.

\section{$2.2 \quad$ Classification of green business models}

In order to reflect the diversity of the cases included in the sample, the report applies a pragmatic approach to the classification of business model types. The cases were divided according to both their functionality (e.g. improved mobility and better use of resources) and key processes (e.g. product and process innovation; organisation and marketing innovation). The business model types thus identified can be described as follows:

- Greener products/processes based business models provide the buyer with economic and environmental benefits through their use. This group contains a very diverse set of innovative products and processes applied in companies that achieve better environmental performance by, for example, saving resources and minimising emissions and waste.

- Waste regeneration systems, which are based on the re-use or recycling of waste as new products. This business model is focused on valuing waste, or using it as an input for a new product to be sold on the market.

- Alternative energy-based systems include a wide range of applications, products and systems based on renewable energy deployment. Business models using these systems can be focused on sales or offer a technical service.

- Efficiency optimisation by ICT - ICT technologies provide a wide range of solutions for energy and resource use control, establishment of smart grids, cloud computing, as well as teleconferencing and online shopping. ICT solutions-based models generally can be of two types: ICT service-based models, which include companies ensuring the monitoring of the consumption or redistribution of resources; and ICT products-based models, which are centred on the ICT systems or software and hardware packages that are offered and sold to customers. Once the system is installed, customers learn to use it to monitor their resource use.

- Functional sales and management services models focus on providing the functions and benefits of the product instead of the physical product itself. The simplest models are based on delivering services using materials and techniques that are superior to alternatives from an environmental perspective. In the more developed models, instead of paying for the product itself the customer pays for the functional performance of the product. The service provider takes over the control of the use of the product. Therefore, the producer has an incentive to improve the output yield and to extend the life-span of the product by making it more durable, reducing the need for spare parts, making it more energy efficient and improving maintenance. These models can also encourage the remanufacturing and re-use of the product.

- Innovative financing schemes represent long- and medium-term investment arrangements often focused on the improvement of environmental performance, which is also linked to economic performance. The best known example is ESCO (Energy Saving Companies) providing energy efficiency and other services and taking on the risk of the performance of the project or product. Compensation and profits for the service providers are tied to energy efficiency improvements and savings in energy costs. The DBFO (Design Build Finance Operate) model is a similar 
contractual relationship between a customer and a private contractor. It is often used in construction projects that require long-term investments.

- New sustainable mobility systems are alternative transportation schemes with a reduced environmental impact. Examples include more efficient and cleaner public transport systems, car or bike-sharing/renting models and schemes for increasing the application of electric or bio-gas based vehicles.

- Industrial symbiosis involves sharing the use of resources and by-products amongst industrial actors on a commercial basis through inter-firm recycling linkages. In industrial symbiosis, traditionally separate industries engage in an exchange of materials and energy through shared facilities. The waste of one company becomes another's raw material.

- Green neighbourhoods and cities consist of complex and geographically wide systems combining many eco-innovative solutions and involving a large range of actors. Green neighbourhoods and cities are designed with the aim of minimising both inputs of energy, water and food, and waste outputs of heat, air, water and other pollution. Power comes mainly from renewable sources of energy. The main objective is to create the smallest possible ecological footprint and to produce the lowest amount of pollution possible, to efficiently use land, compost used materials, recycle them or convert waste into energy.

The cases thus reflect several of the models distinguished in Box 1, including incentive models, lifecycle models, models based on ICT, and systemic innovations.

The 55 case studies were collected from 14 countries: Australia, Belgium, Denmark, Finland, Germany, Greece, Israel, Japan, Korea, New Zealand, Portugal, Spain, Sweden, and the United States. All participating companies were classified under one of the above listed green business model types (Table 1). 
Table 1. List of business models case studies

\begin{tabular}{|c|c|c|c|}
\hline Type & Eco-innovation & $\begin{array}{l}\text { Companyl } \\
\text { Organisation }\end{array}$ & Country \\
\hline \multirow{15}{*}{$\begin{array}{l}\text { Greener Products and Processes } \\
\text { based models }\end{array}$} & Zero-waste Powder Coating & CSIRO & Australia \\
\hline & Dual-Flush Toilet & Caroma & Australia \\
\hline & Vanadium Redox Battery & University of New South Wales & Australia \\
\hline & Eco-Surfactant & Ecover & Belgium \\
\hline & Earth tray & Roltex & Belgium \\
\hline & Green cleaning products & INTEMAN & Spain \\
\hline & BIONADE & BIONADE & Germany \\
\hline & Reuse system house & Sekisui Chemical & Japan \\
\hline & Cork-based absorbents & Corticeira Amorim & Portugal \\
\hline & LIFE & LIFE Consortium & Portugal \\
\hline & Eco-featured tiles & Revigrés & Portugal \\
\hline & NetOLift & Orona & Spain \\
\hline & Pollution Prevention Pays (3P) & $3 \mathrm{M}$ & United States \\
\hline & Natural refrigerants & Refrigerants, Naturally! & United States \\
\hline & Sustainable Cuisine Program & Xanterra Parks \& Resorts & United States \\
\hline \multirow{6}{*}{ Waste regeneration systems } & $\begin{array}{l}\text { Enhancing the Value of Bauxite } \\
\text { Residue }\end{array}$ & Alcoa & Australia \\
\hline & BioBooster & Grundfos & Denmark \\
\hline & Sustainable olive oil production & Humolea & Greece \\
\hline & ECOVIA & Brisa & Portugal \\
\hline & Reuse of leather (CARRE) & Tecmacal & Portugal \\
\hline & Ecoera Biochar & Ecoera & Sweden \\
\hline \multirow{7}{*}{$\begin{array}{l}\text { Alternative energy-based } \\
\text { systems }\end{array}$} & Bio-carbon & Preseco Oy & Finland \\
\hline & PanePowerTM Solar Windows & Brite Hellas & Greece \\
\hline & Super Critical Water Reactor & Solray Energy & New Zealand \\
\hline & Cigar $®$ Biogas Reactor & Waste Solutions & New Zealand \\
\hline & Microbial gas fermentation process & Lanzatech & New Zealand \\
\hline & $\begin{array}{l}\text { Commercial Scale Concentrated Solar } \\
\text { Power (CSP) }\end{array}$ & Torresol Energy & Spain \\
\hline & Net-Zero Plant & Frito Lay & United States \\
\hline \multirow{8}{*}{ Efficiency optimisation by ICT } & Smart Energy Box and the Smart Grids & Fifthplay & Belgium \\
\hline & Social Energy Network, & Intelen & Greece \\
\hline & $\begin{array}{l}\text { Smart Wireless Network } \\
\text { Communication }\end{array}$ & Carta Sense & Israel \\
\hline & Water Infrastructure Monitoring & TaKaDu & Israel \\
\hline & $\begin{array}{l}\text { Remote monitoring of mining \& } \\
\text { construction equipment }\end{array}$ & Komatsu & Japan \\
\hline & $\begin{array}{l}\text { Inductive Power Transfer (IPT) wireless } \\
\text { charging, HaloIPT }\end{array}$ & Qualcomm & New Zealand \\
\hline & InovGrid & EDP Distribução & Portugal \\
\hline & eCoupled wireless power & Fulton Innovation & United States \\
\hline \multirow{2}{*}{$\begin{array}{l}\text { Functional sales and } \\
\text { management services models }\end{array}$} & LED lighting rental service & Cowell & Japan \\
\hline & Qlean Cleaning with Ultra-pure Water & Qlean Scandinavia & Sweden \\
\hline
\end{tabular}


Table 1 List of business models case studies (Cont)

\begin{tabular}{|c|c|c|c|}
\hline \multirow{2}{*}{ Innovative financing schemes } & $\begin{array}{l}\text { ESCO solutions, } \\
\text { Danfoss }\end{array}$ & Scanenergi & Denmark \\
\hline & Power Saving Consultancy Services & Kankyo-Keiei & Japan \\
\hline \multirow{4}{*}{ Sustainable mobility systems } & Zero Vehicle & $\begin{array}{l}\text { National Technical University of } \\
\text { Athens }\end{array}$ & Greece \\
\hline & Better Place & Better Place & Israel \\
\hline & Car rental at gas stations & Rentas & Japan \\
\hline & YikeBike & YikeBike & New Zealand \\
\hline \multirow{2}{*}{ Industrial symbiosis } & Kwinana Regional Synergies project & Kwinana Industries Council & Australia \\
\hline & Ulsan eco-industrial park & Ulsan & Korea \\
\hline \multirow{8}{*}{ Green neighbourhoods and cities } & Active Housing & Active House Alliance & Denmark \\
\hline & Housing in Torrelles de Llobregat & BB Architects & Spain \\
\hline & DigiEcoCity & DigiEcoCity & Finland \\
\hline & Eco system for apartments & Raidis Architecture & Greece \\
\hline & $\begin{array}{l}\text { LEED certified renovation historic } \\
\text { building }\end{array}$ & Barton & United States \\
\hline & Smart town in Fujisawa & Panasonic & Japan \\
\hline & Smartcity Málaga & Endesa & Spain \\
\hline & Hammarby Sjöstad & Stockholm authorities & Sweden \\
\hline
\end{tabular}

Note: One case study is not explicitly mentioned in the table for confidentiality reasons. The statistical data for Israel are supplied by and under the responsibility of the relevant Israeli authorities. The use of such data by the OECD is without prejudice to the status of the Golan Heights, East Jerusalem and Israeli settlements in the West Bank under the terms of international law

Source: OECD case studies.

Figure 3 illustrates the numerical breakdown of company case studies by type of business model. Greener products/processes account for the highest share of case studies, with 16 green business models. Large firms are overrepresented in the sample, with 18 firms having more than 250 employees, followed by small and micro enterprises, with 13 firms for each class size (Figure 4).

Data on the number of employees provides an indication of the distribution of companies by size across the different types of eco-innovations, and their weight within each category (Figure 5). Micro firms are represented in each business model category, while large and medium-size firms are especially present in business models based on greener products and processes. 
Figure 3. Number of case studies, by category of green business model

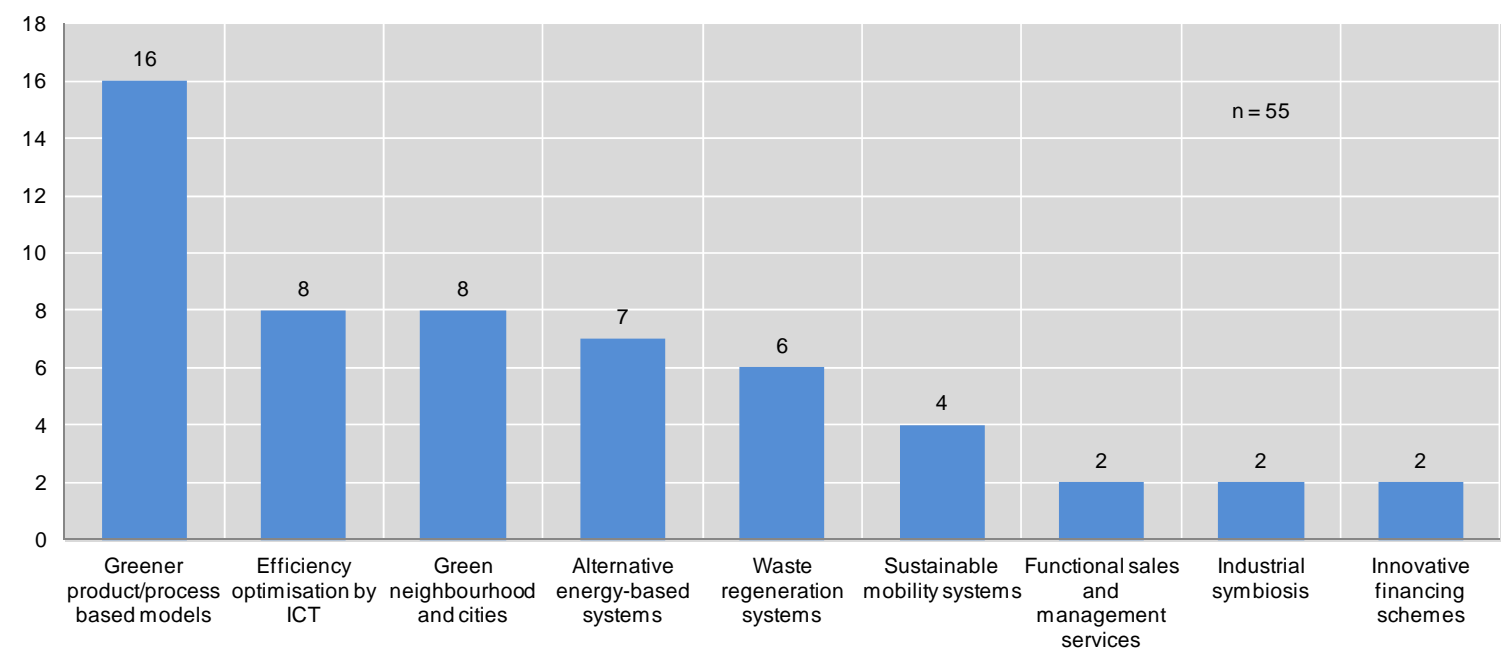

Source: OECD case studies.

Figure 4. Number of case studies, by firm size

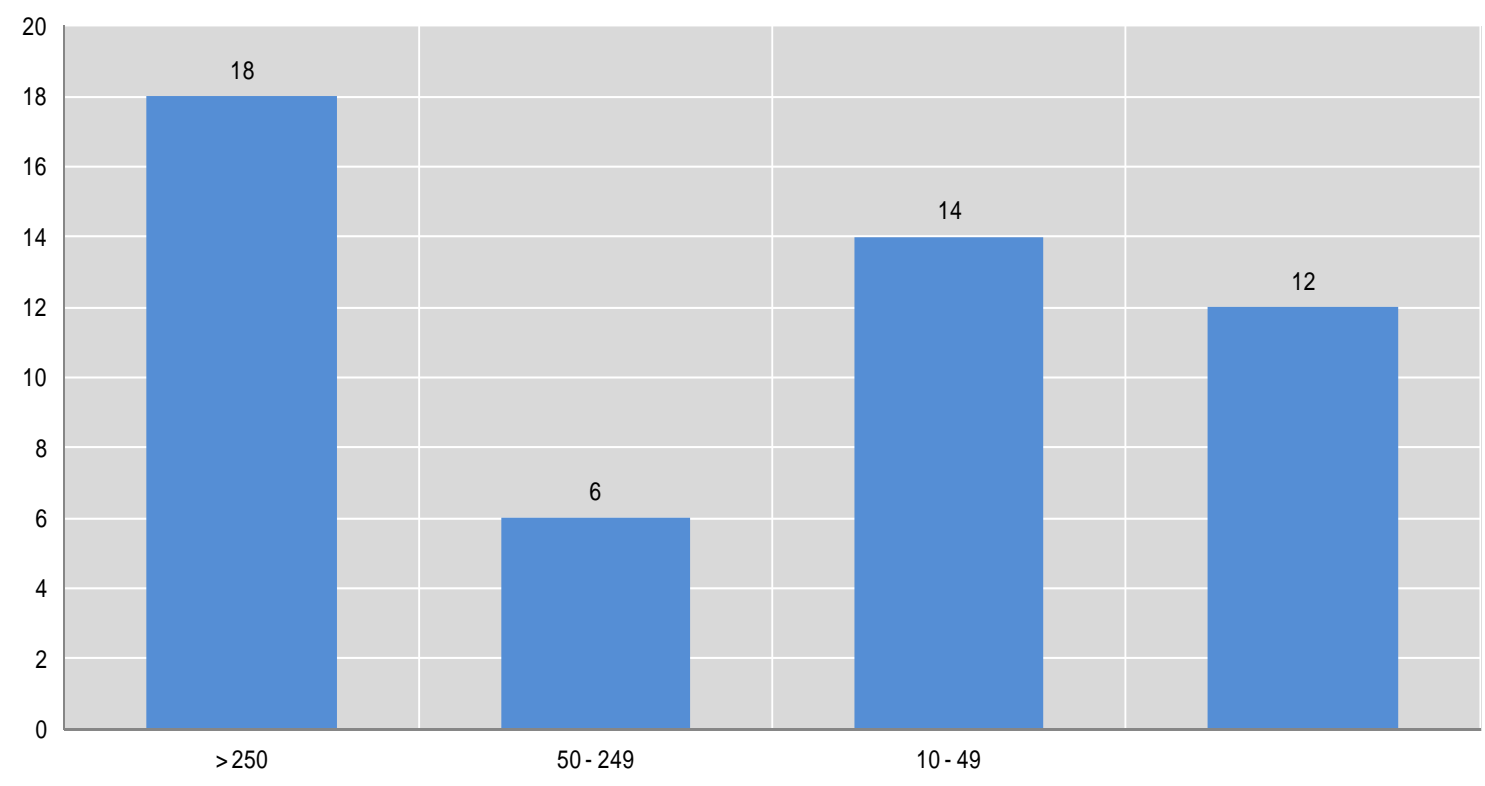

Note: 5 firms could not be classified given a lack of information on the number of employees.

Source: OECD case studies. 
Figure 5. Number of case studies, by firm size and category of green business model

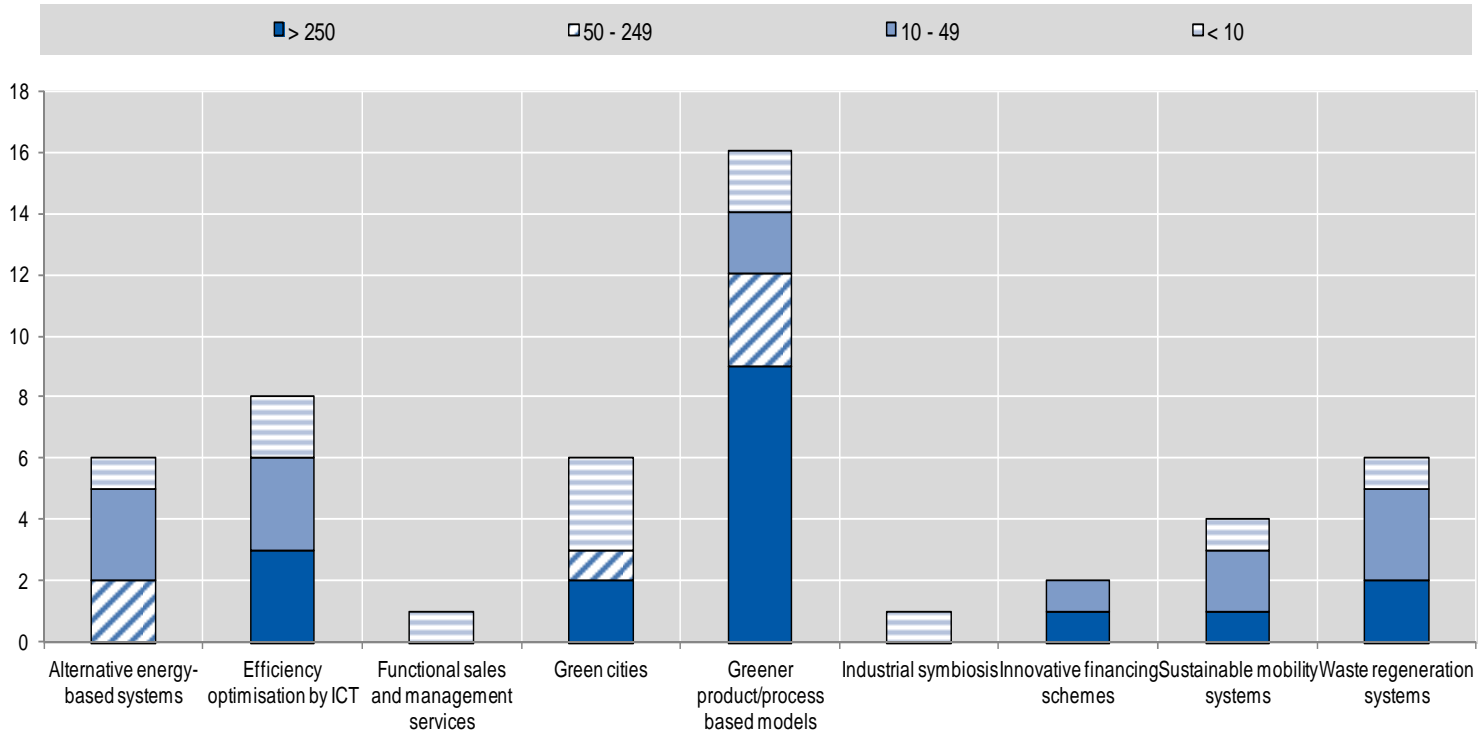

Note: 5 firms could not be classified given a lack of information on the number of employees.

Source: OECD case studies.

\subsection{Key factors and drivers}

This section analyses the case studies of green business models by focusing on the aspects that are particularly relevant to draw lessons for policy making, notably: market conditions; knowledge and human resources; financial resources; intellectual property rights; and companies' perceptions vis-à-vis the role of future policy support and the barriers posed by regulations, legislation or other government measures.

Box 3 summarises the main findings of an analysis of other aspects of business models that are not dealt with extensively in this report. These elements are based on the "business model canvas" proposed by Osterwalder et al., (2010), and include: main actors, customer relations and channels, resources, value creation, impact across the value chain, and contribution to radical/systemic change. 


\section{Box 3. Analysis of case studies from a systemic and value chain perspective: summary of main findings}

- Business models are relevant for advancing eco-innovations in the market. Eco-innovations are often linked to novel business models radically different from "business as usual". Instead of focusing on developing innovative technologies or products, companies create new ways of delivering value to customers, rethink their customer base, establish new alliances and reconfigure value chains, source new resources, etc.

- The analysed companies adapted their business models to a greater or smaller degree to be able to introduce eco-innovations. Some companies revisited their value propositions to customers; nearly all adapted their operations. Most changes in the analysed cases were related to company activities, notably to R\&D and product development. In the service oriented models such as functional sales and car sharing there was a more fundamental shift from product to service provision. Another often-observed change was to reconfigure the relationship with the old customers or revisit the customer segments.

- The value propositions of the majority of cases were based mainly on offering customers economic benefits, such as cost savings, new revenue streams and additional profits, and a better quality or service or product (e.g. flexible access, efficiency). Although environmental values have been rarely at the centre of business propositions, the expected environmental benefits, such as reducing the impact of waste or emission reduction, have been a relevant element supporting or inspiring new business models (e.g. waste regeneration, waste to energy, industrial symbiosis, and mobility). The environmental value proposed has been especially evident in the case of green neighbourhoods and cities where environmental aspects are among the key drivers of change.

- Potential environmental impacts are among the key expected outcomes of the analysed business models. A majority of the analysed models have a potential to generate indirect positive environmental impacts associated with resource and energy efficiency and with the use of new products or technologies with improved environmental performance helping to avoid air, soil, water contamination, and GHG emissions. These expected environmental impacts are often reframed to form part of the value proposition.

- The wider application of new eco-innovation business models may also have social impacts such as employment creation or improved quality of life. Business models based on new services and products (e.g. ESCO, new renewable energy units) appear to have a high potential to create new jobs. Incorporation of social elements in the business models increases the promise of systemic change. Green cities and mobility projects are exemplary in terms of sustainable lifestyle and new mobility paradigms.

- Many elements of the business models analysed appear to be transferable between companies and countries; clearly they have to be adapted to the local context, but lessons learned are widely applicable (e.g. industrial symbiosis and green city models have been adopted worldwide).

- Business models can only contribute to systemic innovation if they are widely diffused. Their diffusion and impact is, however, influenced by framework conditions, which determine the economic viability of any value proposition. However, new eco-innovation business models themselves may be one of the factors changing framework conditions and triggering the emergence of new production and consumption patterns (e.g. through raising awareness of various stakeholders, promoting new standards, and creating new markets).

Source: Analysis by Technopolis Group.

\subsubsection{Market conditions}

As discussed in section 1.1, customer demand is an important driver of eco-innovations. As highlighted by Schmookler (1966) and Griliches and Schmookler (1963), the larger an actual or potential market is, the more demand in this market will stimulate innovation, partly because the profitability of an invention rises with market size (other things being equal) and partly because when productive activity is directed to meeting demand in the market, it is more likely that an invention matches a need. Innovation depends on relative profitability, which in turn depends on demand. It follows that the potential to recoup investments will increase with growing market size. Hence, successful innovations are more likely in fastgrowing economies, particularly in markets where demand is strong and dynamic. ${ }^{4}$ 
Market conditions however can also be unfavourable to eco-innovations. For example, often environmental technologies are not taken up in the market because of inertia (Jaffe, et al., 2000). While a new environmental product or technology represents an improvement for many users, others may find it inferior to existing products and technologies. This may explain a reluctance to adopt such eco-innovations for some time after their commercialisation. In addition, in the early stage of diffusion, proper information on all the features of the innovation (e.g. costs and operating features) may not be fully available for all users, which may result in a low uptake of beneficial innovations.

Market conditions are mainly shaped by the role and behaviour of three categories of actors: end users/consumers; businesses, and the public sector. In particular, businesses do not only play an important role as innovators, they are also users of eco-innovations, including through their interactions with other firms in the supply chain. Industrial clients are important customers for environmental goods and technologies, especially in certain sectors. On account of its scale, demand from firms (as industrial users) may act as a significant driver of eco-innovation by other firms (as manufacturers and providers of goods and technologies) (del Río González, 2009). ${ }^{5}$

The important role of market conditions in "pulling" eco-innovation emerges clearly from the case studies on green business models:

\section{Greener products/processes based business models}

This group contains a very diverse set of innovative products, processes and technologies that have better environmental performances by saving material resources and energy and minimising emissions, waste and other hazardous impacts. The largest value for customers of companies that have adopted this business model appears to be associated with the potential economic savings due to avoidance of losses and more efficient use of resources, which are water, paint and energy in some of the cases included in the analysis. Both companies and users point to a green branding value in going for greener products. It creates a better image for the organisation, or even helps it to improve its environmental management standards.

Demand from customers (including both intermediate users and final users) is an important driver for eco-innovations in this type of business model. For example, the case studies show that industrial customers and retailers are increasingly recognising the importance of products and processes that enable them to save electricity and other forms of power for their industrial and commercial activities, due to rising energy costs. In the case of Roltex's earth tray, the greener product was developed to satisfy the demand of a major fast-food chain. This case study also shows the importance of communicating effectively the benefits of using a greener product. The look and feel of the earth tray was initially no different from conventional trays, and the fast-food chain saw no positive impact in terms of sales from introducing a greener product. This prompted the product provider to search for an innovative design aimed at giving the tray a greener look.

The importance of final demand emerges clearly in some of the business models in the food industry, as consumers are increasingly aware of and interested in purchasing healthy and organic food which has been produced locally. This growing awareness is reported to be one of the main drivers of innovation behind BIONADE's soft drink produced by fermentation, and the Sustainable Cuisine Program of Xanterra Parks \& Resorts.

The case studies also suggest that legislation has an important role in creating markets for greener products and processes. For example, $3 \mathrm{M}$ reports that soaring energy costs during the oil crises of the 1970s and resulting solvent raw material costs were among the main drivers behind the introduction of the 3P (Pollution Prevention Pays) programme to increase the company's efficiency and environmental sustainability. At the same time, $3 \mathrm{M}$ acknowledges that increasing government regulations to reduce 
volatile organic compounds (VOCs) in the United States also encouraged the emergence of this green business model. Along the same lines, the global partnership "Refrigerants, Naturally!" identified an emerging environmental challenge that would affect demand and the market for the products provided by the different companies participating in the initiative. Member companies and their suppliers recognise that increasingly more stringent legislation on fluorinated gases ("F-gases") ${ }^{6}$ in the European Union contributed to creating these market conditions.

This category of business models has considerable potential to attract new green and resourceconscious customers including individuals, companies and public organisations. At the same time, it can lead to systemic change by, for example, influencing or changing resource supply methods or shifting from a linear production mode towards closed-loop industrial schemes.

\section{Waste regeneration systems}

With the scarcity of natural resources, as well as the growing understanding of environmental concerns, waste is increasingly being seen as a resource. The business perspective is reflected in using waste as an input for producing products to be sold on the market. The case studies offer a number of examples of eco-innovations and business models based on enhancing the value of waste.

The models based on enhancing the value of waste normally target a narrow group of customers. The value captured by a company is associated with acquiring economic gains from the normally cheap input of waste, producing and selling new products and accessing new markets and customers. One additional value was that the business activities of the companies included in the case studies gave them a green reputation and this is increasingly becoming a competitive advantage. For example, Alcoa reports that along with the environmental benefits associated with its business model based on enhancing the value of bauxite residue, eco-innovation also offers branding value: the image of being an environmentally responsible company.

The market for waste management and recycling is already sizeable and growing. For example, Brisa (the largest motorway operator in Portugal) notes that the sector has an estimated turnover of over EUR 100 billion in the EU-25. It is a labour-intensive sector and provides between 1.2 and 1.5 million jobs. In addition, the recycling sector is providing increasing amounts of resources to manufacturing industries: at least $50 \%$ of the paper and steel, $43 \%$ of glass and $40 \%$ of the non-ferrous metal produced in the EU are currently derived from recycled materials.

At the same time, current market conditions can also represent a barrier to eco-innovation. For example, according to Swedish company Ecoera both the price of $\mathrm{CO}_{2}$ emissions and the price for destroying ecosystem services are too low to encourage the emergence of innovative business models in waste regeneration systems.

Business models based on waste regeneration systems can be of particular interest for developing countries, where it is common for municipalities to spend between $20 \%$ to $50 \%$ of their recurrent budget on solid waste management. At the same time, between $30 \%$ to $60 \%$ of all urban solid waste in developing countries may remain uncollected, and less than $50 \%$ of the population may be served. In some cases, up to $80 \%$ of the collection and transport equipment is out of service, in need of repair or maintenance. In most developing countries, open dumping with open burning is the norm (World Bank, n.d.a). Given these challenges, innovative companies have emerged whose main business operations involve providing news ideas, technologies and skills for managing waste more efficiently and effectively (Box 4). 


\section{Box 4. Waste regeneration business models in developing countries: Waste Concern in Bangladesh}

The Waste Concern Group is a Social Business Enterprise (SBE) comprising both "For Profit" and "Not-for Profit" enterprises, promoting waste management and recycling in Bangladesh. Dhaka suffers from intense solid waste generation, of which approximately $80 \%$ is organic waste. Waste Concern came up with a business model to convert organic waste to produce and sell good quality organic compost, for which there is high demand. Using a house to house collection service, the company collects organic waste and takes it to community-run composting plants to be converted into organic fertiliser. The organisation then arranges for fertiliser companies to purchase and nationally market the compost-based enriched bio-fertilizers. As a result, Waste Concern has created jobs for unskilled workers and reduced the total amount of solid waste to be handled by the municipality, while its compost has helped to improve soil quality.

The technology used for composting can treat 30 000-35 000 tons of waste per year and reduces emissions by 20000 tons of carbon dioxide. From 2001 to 2006, USD 1.24 million was saved by avoiding the import of chemical fertilizers. During the same time period, 124400 tons of waste was processed with 986 direct jobs being created annually. The total value of the compost sold in the local market was USD 1.10 million. Waste Concern is financially self-sustainable with $70 \%$ income from the sale of compost and $30 \%$ from door-to-door waste collection. The projects extend to over 20 cities and towns in rural areas of Bangladesh.

Source: Waste Concern (2012), India Governance Knowledge Centre (n.d.), Mair (2006).

\section{Alternative energy-based systems}

Renewable energy sources have received much attention in the last 25 years. Their large-scale introduction began with hydropower in the 1950s and 1960s and has taken off since 1990 because high oil prices and climate change policies have created more favourable market conditions. Most of the companies covered in the case studies have business models based either on producing renewable energy and selling it to compete with hydrocarbon based energy, or on selling products, and particularly equipment, to produce renewable energy.

The business model cases have different kinds of customers but all are professionals. They include builders and property developers for Brite Hellas, energy companies and regional governments for Torresol and waste water and organic waste owners for Solray, Waste Solutions and Preseco Oy. Firms, but also governments and other non-profit organisations, are prompted to adopt ever stricter goals for corporate energy efficiency. In order to achieve those objectives, they are increasingly putting pressure on their providers to supply energy generated from renewable sources, or acquire equipment that allows them to generate directly their own renewable energy.

Consumers do not play a direct role in these business models. At the same time, alternative energy systems have two kinds of customers. For the technology suppliers, the primary customers are the buyers of the technology systems that produce energy. Secondary customers are the consumers who buy the energy produced.

Companies highlight a number of specific trends that influence the market for alternative energy sources: energy price volatility; the increasing negative impact of greenhouse gas emissions caused by the current energy mix, which is dominated by fossil fuels; and risks related to the future availability of water worldwide, among others. These trends are confirmed by the OECD Environmental Outlook to 2050. According to the latest projections under a "business as usual" scenario, world energy demand in 2050 will be about $80 \%$ higher than today's level, with fossil fuels still accounting for $85 \%$ of the energy mix. GHG emissions are projected to increase by $50 \%$, primarily driven by a $70 \%$ growth in $\mathrm{CO}_{2}$ emissions from energy use. Water demand is also projected to rise by 55\%, with demand from the electricity sector accounting for a large part of the increase (OECD, 2012a). 
Another market trend that seems to have benefitted innovative business models based on alternative energy sources relates to doubts over the sustainability of first-generation (or conventional) biofuels. The extent to which biofuels are really carbon neutral is subject to considerable ongoing debate. Concerns have been raised about their neutrality over the entire life cycle of the product, the need to take into account land-use change resulting from conversion of land to biofuel production and whether or not "neutrality" requires additionality of carbon sequestration over and above that which would have taken place in any case. Another concern is the flow-on effect of increased biofuel crop cultivation on food prices (OECD, 2012c). The case studies suggest that a growing number of market players are questioning the economic viability of first-generation biofuels, net of government support. In this context, many renewable energy companies observe that markets and venture capital investors are showing an increasing interest for second-generation (or advanced) biofuels, which have the potential of providing greater economic returns at lower cost to the environment.

In some cases, government policy provided the decisive factor in creating a market for the ecoinnovation. For example for Preseco Oy, a Finnish company focussed on the efficient extraction of biogas from organic waste, the original idea for the eco-innovation came from basic research, and only later it developed into an industrial application with its related business model. According to the company, market conditions were not originally considered, but the potential for commercial applications of the invention became clearer when the EU introduced new regulation on the treatment of organic livestock.

At the same time, current market conditions can represent a hurdle to innovations in alternative energy sources. For example, some companies report that the conservative nature of industrial clients in some sectors have created high entry barriers to innovative business models, in particular because of vested interests, low absorptive capacity, concentrated markets and dominance of incumbent public utilities.

In addition, the market price of energy generated from renewable sources is often not competitive compared to cheaper alternatives, such as fossil fuels, which do not fully internalise the climate changerelated and negative environmental externalities that they bring about. Indeed, some firms acknowledge that, without specific government instruments targeting the generation and deployment of renewable energy sources, unfavourable market conditions would probably have prevented them from introducing their innovative business models. The potential of alternative energy-based systems to bring about systemic change is also evident in developing countries (Box 5). 


\section{Box 5. Alternative energy-based business models in developing countries: Solar Sister}

Solar Sister is a non-profit social enterprise that provides women with training and support to create solar micro-businesses, providing much needed household income for them and essential light for their communities across Sub-Saharan Africa. Over 1.4 billion people do not have access to electricity worldwide, almost all of whom live in developing countries. The majority of these are women who use inefficient and costly fuel-based lighting sources such as kerosene lamps, which greatly curtail their socio-economic activities once darkness sets. They spend up to $30 \%$ of their family income on energy that is insufficient, hazardous and unhealthy for people and the planet. Lack of access to electricity is both a cause and an effect of unremitting poverty.

Using an Avon-style distribution system, Solar Sister creates employment and income opportunities and provides vital access to clean energy technology by building and extending the supply chain through women's rural networks. Solar Sister provides the women with a "business in a bag" that includes seed capital, a start-up kit of inventory, training and marketing support. The women become their own bosses, creating sustainable businesses and use their natural networks of family, friends and neighbours to provide the most effective distribution channel to rural and hard-to-reach customers. As they sell solar lamps they earn a commission to increase their inventory and their sales capacity. Solar lamps afford more study time for children every day. They contribute to a $30 \%$ reduction in household expenses when used in place of expensive kerosene, also eliminating the toxic effects on women and children. Every dollar invested in a Solar Sister Entrepreneur generates over USD 46 in economic benefits in the first year alone, through earned income for the Solar Sister Entrepreneur, and the immediate cash savings of her customers as they avoid the cost of expensive kerosene. The project currently operates in three countries, with 171 entrepreneurs and has brought clean energy to over 30000 people. The goal is to build a Sub-Saharan network of 5000 entrepreneurs in five countries over the next five years.

Source: Solar Sister (n.d.); World Bank (n.d.b).

\section{Efficiency optimisation by ICT}

Models based on information and communication technology (ICT) solutions can generally be of two types: ICT service-based models, which include companies' monitoring of the consumption or redistribution of resources; and ICT product-based models, which consists of the ICT system itself or software and hardware packages that are offered and sold to customers. Once the system is installed, customers learn how to use it to monitor their resource use themselves.

All the case studies point to a fundamental role of market demand in stimulating eco-innovations business models based on efficiency optimisation by ICT. For the final user, the economic impact largely derives from efficiencies in energy- and water-use management and reduced ecological footprints associated with the supply of these resources.

For example in the area of energy management, when EDP Distribuicão (the electricity distribution operator in Portugal) deployed a network of smart grids through the InovGrid project, it conducted a survey to understand consumer expectations vis-à-vis the new technology. In general, clients showed great interest in the new services enabled by InovGrid-related infrastructures. More specifically, they were enticed by the possibility of a tariff plan that better suited their needs and of being alerted when their energy consumption varied by more than a certain percentage.

Significant market opportunities also exist in the water-management sector. Israeli company TaKaDu estimates that by 2030 more than half of the world's population will live in water-scarce areas; therefore it is a priority to preserve freshwater and increase the efficiency of water distribution. An estimated 250000 water utilities worldwide do not fully realise these efficiencies, and unaccounted-for water represents a significant share of all treated water. This, coupled with the challenges posed by aging infrastructure and the growing investment gap in the water sector, is stimulating demand from industry for better management of water networks. 
The timing of market conditions appears to be also very important. This is illustrated by the case of Fifthplay, a Belgian technology company that has developed an energy management control system (the Smart Energy Box) and introduced it to the market in partnership with the electricity utility Electrabel (Box 6).

\section{Box 6. Timing of market conditions: Fifthplay}

The case study on Fifthplay includes two eco-innovations developed by the company in the area of energy management: the Smart Energy Box (i.e. consumers can measure the consumption of their energy-using products as well as switch them on and off by using their computers, tablets and smartphones); and Smart Grids.

Similar services had been launched a few years earlier by two important technology multinationals. However, at the time, the market was not ready for this type of eco-innovation, as the benefits for end users were still not clear, and the services offered were not end-to-end solutions and focused only on one segment of the value chain.

Market conditions are very different today, and more conducive to this type of innovation: energy prices are generally rising, competition between providers has increased, and customers are more aware of their energy consumption (and of issues of sustainability and energy efficiency more generally). In addition, the company has been successful by adapting its business models to the new trends in the market, thus offering a whole end-toend solution.

Changing market conditions also enabled Fifthplay to persuade the electricity utility to become involved in a partnership: Electrabel became convinced of the business opportunity offered by consumer's willingness to monitor their energy consumption, and also seized the occasion to "green" its corporate image.

Adapting its business model to the timing of market trends is a fundamental part of Fifthplay's stategy in developing and deploying eco-innovations, as the willingness of the customers to change their behaviour when using appliances is a necessary condition for the successful introduction of an energy management product. Because the company believes that the market is not ready yet for disruptive energy management systems, its aim is to educate consumers gradually through an innovation at the product level (the launch of the Smart Energy Box) and thus prepare the market for more radical innovations at the system level (e.g. Smart grids and Smart cities).

Source : OECD case studies.

Because of the very nature of this type of business model, market trends in specific sectors can be especially important in stimulating innovations in efficiency optimisation driven by ICT. For example, applying ICTs to transportation (i.e. "intelligent transportation systems") can spur innovations leading to significant environmental benefits, such as limiting congestion and reducing emissions. One of the case studies concerns the HaloIPT (Qualcomm) (where IPT stands for "Inductive Power Transfer"), an innovative wireless charging system for electric vehicles developed by a company from New Zealand. Expectations of growth in the market for electric cars in the coming years prompted the company to undertake the development of this innovative product. The main target customers are early adopters of electric vehicles, such as businesses with large car fleets, local authorities, and delivery vans for large supermarket chains.

While recognising the importance of market conditions, it appears that consumer acceptance can also act as a barrier for some of the companies interviewed for the case studies. Consumers may be more conscious about rising energy prices and the possibility of choosing among different energy providers. However, this is rarely their prime concern, and often they are not willing to invest the time to acquire the basic knowledge that would allow them to make a more informed decision. 


\section{Functional sales and management services models}

The functional sales and management services model is a generic model with common characteristics for all service based business models. Generally, for all models there is a focus on providing the functions and benefits of the services linked to the product instead of the actual product itself. The simplest models are based on delivering services using more environmentally superior materials and techniques. In the more developed models, instead of paying for the product per se, a part of the transaction is a payment for the functions of the product and the service provider takes control of the use-phase of the product. By improving the control of the use-phase of the product, there is an incentive for the producer to improve the output yield and to extend the life-span of the product. This can be through making the product more durable, making it more energy efficient, reducing the need for spare parts or improving the maintenance of the product. These models can encourage the re-manufacturing and re-use of the product (FORA, 2010). The well-known examples identified in literature are chemical management models (CMS) and integrated pest management (IPM). Two additional business models that emerged from the collection of case studies are the provision of energy-saving lighting (Cowell of Japan) and non-chemical cleaning (Qlean of Sweden).

Market conditions appear to have been an important driver for eco-innovations in this category of business models, especially demand from industrial customers. For example, Cowell reported that the price of LED lighting decreased by one-third in the period from 2009 to April 2012, while performance increased thanks to technological advances. In addition, power shortages caused by the Great East Japan Earthquake and tsunami of March 2011 boosted public awareness of the importance of energy conservation, and thus increased the demand for more efficient lighting in Japan. But in spite of these favourable market conditions, Cowell discovered that the high initial capital investment required for LED lighting installation was too large a barrier for the deployment of this technology (especially among SMEs). Thus, they decided to adopt a new business model based on leasing, thus selling a function rather than the product itself.

However, inertia in the market may impede the formation of demand for environmental technologies, products and processes, thus making it very costly for companies (especially SMEs) to deploy their eco-innovations. According to Qlean, demand from public authorities through procurement could enlarge the market for greener services and thus influence consumption trends, especially for companies operating with a business model based on functional sales and management. However, procurement officials often lack the capacity to comply with increasingly complex rules, pursue value for money, while taking into account economic, social and environmental considerations.

\section{Innovative financing schemes}

The diffusion of eco-innovations, even when the innovation may be economically attractive, is often limited because of the up-front investment that is needed. This is often considered to be too high and, when combined with the uncertainties that the eco-innovation implies for the possible users, the product or service is not diffused. Thus, in order to promote diffusion, the risks associated with eco-innovation must be reduced.

The ESCO (Energy Service Company) model is one example that appeared in two case studies of an innovative method of financing eco-innovations: the ESCO solution by Danfoss (Scanenergi) of Denmark, and power-saving consulting services by the Kankyo-keiei Senryaku Soken (Kankyo-keiei) of Japan.

Rising energy prices, and the related willingness of companies to save on their energy consumption, have been important drivers behind the introduction of business models delivering innovative financing schemes. In addition, prospective customers recognise the value of branding themselves as "energy 
savers". However, these market trends are not strong enough to enable a demand for ESCO business models on a larger scale. A lack of awareness results in many companies not putting a high priority on energy savings, and not acknowledging that an investment on energy savings could have a very high return. This is also because in many cases the benefits provided by an ESCO are not tangible, and therefore less attractive for users. According to Danfoss (Scanenergi), standardisation could contribute to fostering a market for innovative financing schemes such as ESCO, by reducing information asymmetries and uncertainty.

\section{Sustainable mobility systems}

Sustainable mobility innovations are often underpinned by substantially re-visited business models. They represent a shift in the overall organisation of mobility services and introduce new infrastructure and vehicles. The sharing of cars or bicycles is one of the most widely diffused eco-innovation business models in the area of urban mobility. Product sharing or shared use is about creating systems, in which users do not own the goods, but have flexible access to them when and where needed. It is often considered a type of product-service system.

Several market trends underpin the emergence of innovative business models aimed at delivering sustainable mobility systems. Globally, the transport sector is a significant contributor to GHG emissions and local air pollution, as well as noise, especially in the most congested urban areas. For example, in 2009 $\mathrm{CO}_{2}$ emissions from the transport sector represented $23 \%$ of total world $\mathrm{CO}_{2}$ emissions. They are projected to double between 2010 and 2050, due in part to a strong increase in demand for cars in emerging and developing countries and also to a strong increase in aviation (OECD, 2012a).

In particular, urbanisation is putting mounting pressure on climate and the environment through increasing GHG emissions, outdoor air pollution, congestion and noise. The OECD Environmental Outlook to 2050 projects that, by 2050, 1.8 billion more people than today will live in urban areas, which will contain nearly $70 \%$ of the world's population (OECD, 2012a). Indeed, the idea for the YikeBike (a portable folding electric bike developed and marketed by a company from New Zealand) emerged after the inventor identified the need to move people efficiently around congested cities using a transport device that was portable and had a small environmental footprint.

Energy requirements in OECD countries with high levels of car ownership put significant pressures on the ability of governments to secure reliable oil supplies, and this makes them highly dependent on foreign sources of energy. At the world level, the transport sector depends almost entirely on oil products, with $93 \%$ of all the fuel used in the sector being oil-based in 2010 (International Energy Agency, 2011a). Demand for new transporation systems that would contribute to eliminating the dependency of the energy mix of OECD countries on fossil fuels was one of the main instigators for the vision of Better Place, an Israeli company whose business model focuses on facilitating mass consumer adoption of battery electric cars by making it more affordable and convenient to own and operate these vehicles.

Demand from end users was also an important factor behind the conception of an innovative business model by Rentas, a Japanese company. "NicoNico rent-a-car" consists of providing a car rental service with used cars at gasoline stations. Rentas identified the existence of a market for car rental services in urban areas, for daily use, and at low price, as opposed to the traditional market for car rental services used for holiday and leisure or medium- to long-distance business travel. Demand comes from a wide range of customers including young people who do not possess their own vehicle, and tend to think of the car as a service rather than as a product.

At the same time, some of the companies analysed through the case studies in this category of business models believe that market conditions remain generally unfavourable for eco-innovations geared 
towards sustainable mobility. For example, the inventors of the "Zero Vehicle" (an ultra-light vehicle for city use) at the National Technical University of Athens in Greece believe that psychological factors that have a bearing on consumers' car purchasing decisions (such as attitudes, lifestyles, personality and selfimage) are still biased in favour of conventional vehicles. When deciding which car to purchase, consumers focus on the overall vehicle price, fuel prices, fuel type, parking space availability, design and style, interior space and design, cargo volume, power and power-to-weight ratio, reliability, and brand image (International Energy Agency, 2012).

\section{Industrial symbiosis}

Industrial symbiosis (IS) is defined as engaging "traditionally separate industries in a collective approach to competitive advantage involving physical exchange of materials, energy, water, and byproducts. The keys to industrial symbiosis are collaboration and the synergistic possibilities offered by geographic proximity" (Chertow, et al., 2004). Mirata and Emtairah (2005) list the following benefits that have been produced by successful cases of industrial synthesis:

- Environmental benefits - improved resource use efficiencies, reduced use of non-renewable resources and reduced pollutant emissions.

- Economic benefits - reductions in the resource inputs costs in production, reductions in waste management costs and from the generation of additional income due to higher values of byproduct and waste streams.

- Business benefits - improved relationships with external parties, development of a green image, new products and new markets.

- Social benefits - new employment and raising the quality of existing jobs by creating a cleaner, safer and natural working environment.

The most well-known example of industrial symbiosis is Kalundborg, in Denmark, where the first exchanges took place in the 1970s. Industrial symbiosis is not only applied in industry, but can also have applications in the city system, such as in Jyvaskyla in Finland. This report includes two major industrial symbiosis projects: Kwinana Regional Synergies Project in Australia, and Ulsan in Korea.

In both cases, demand seems to have played an important role in kick-starting the process leading to these innovative business models. Demand came from the direct users of the industrial symbiosis process, i.e. companies wishing to save costs and generate new revenue streams. For example, the Ulsan industrial symbiosis park is considered to be an attractive location for business, both by existing companies and by new entrants. Demand for eco-innovations from local resident communities also proved to be a crucial factor. For example, in Kwinana the community was concerned with air and water emissions, waste management within the Kwinana Industrial Area, job security for those employed at the industrial park, and tenure of the industrial park itself. Social pressure resulted in the inclusion of wider social and environmental value from the outset of the project. Likewise in Ulsan, demand from the community for job creation and better quality of life contributed to the introduction of the industrial symbiosis project.

\section{Green neighbourhoods and cities}

Green neighbourhoods and cities are urban systems designed or redesigned to offer a high quality of life with minimum environmental impact. They involve the minimal use of energy, water and food, and waste output of heat, air, water and other pollution. Green city models combine many eco-innovative solutions ranging from novel designs and urban ecology to new technologies embedded in innovative buildings. The model engages a range of actors from both public and private sectors. Green cities should be self-reliant and thus should not over-exploit the surrounding region. Examples of green neighbourhoods 
and cities analysed include: DigiEcoCity in Finland; the Eco-system for block apartments in an urban context in Greece; the Fujisawa Sustainable Smart Town project in Japan; sustainable buildings in Torrelles de Llobregat, Spain; Smartcity in Spain; the Swedish city of Hammarby Sjöstad; and the LEEDcertified renovation of an historic building in the United States.

A common thread running through most of the case studies of sustainable neighbourhoods and cities is demand from the citizens, which is reported to be one of the main drivers and success factors for ecoinnovations in this area. In particular, citizens increasingly ask for monetary savings deriving from more efficient consumption of resources, such as water and energy. Non-monetary values, such as a better quality of life and the satisfaction coming from contributing to a better environment, are also very important for citizens who choose to settle in environmentally sustainable neighbourhoods, and pursue a more sustainable lifestyle. These findings are confirmed by the OECD Better Life Initiative: environmental quality is a key dimension of people's well-being, as quality of life is strongly affected by a healthy physical environment. Besides affecting people's health, the environment also matters intrinsically as many people attach importance to the beauty and healthiness of the place where they live, and because they care about the degradation of the planet and the depletion of natural resources.

While green neighbourhoods and cities can represent sustainable solutions for OECD countries in different geographic areas and diverse environmental conditions, they have a particular appeal for emerging and developing countries, as existing cities grow and new cities are built. Based on the projections of the OECD Environmental Outlook to 2050, the main growth of urban population will occur in the BRIICs and the rest of the world, not OECD countries (Figure 6). The urban population in the OECD is projected to grow by $26 \%$ between 2010 and 2050 (from 911 billion in 2010 to 1147 billion in 2050). In the BRIICS, urban population will increase by 74\% (from 1425 billion in 2010 to 2476 billion in 2050) and in the rest of the world by 131\% (from 1150 billion in 2010 to 2663 billion in 2050). Given these developments, it is clear that business models based on the designing and building of green neighbourhoods and cities hold a great potential in emerging and developing countries.

Figure 6. Urban population by region, 1970-2050

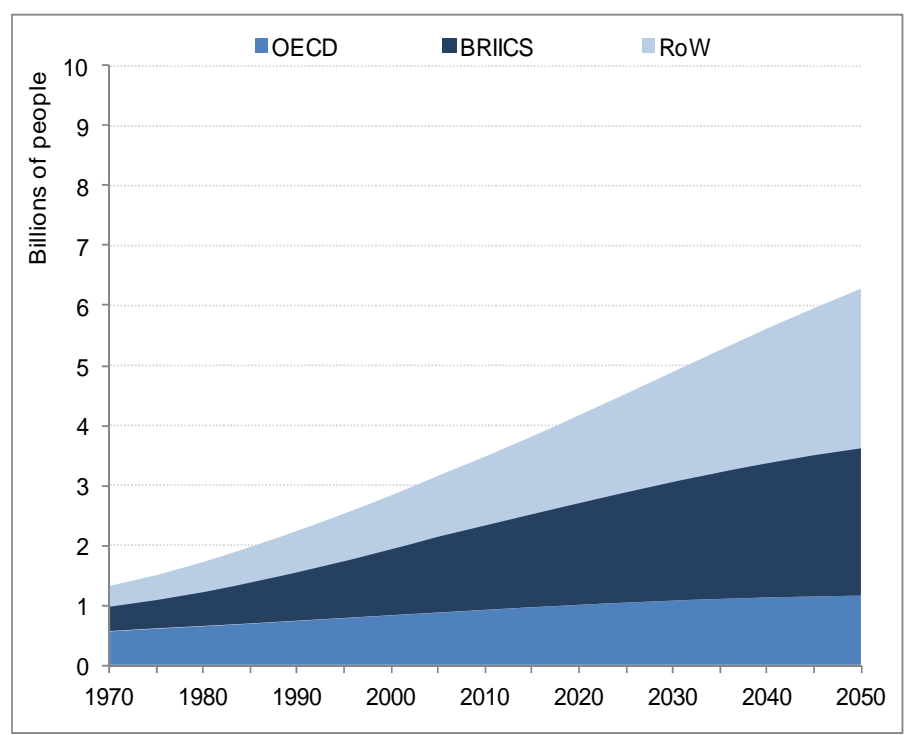

Source: OECD (2012a) based on UN (2010), World Urbanization Prospects: the 2009 revision, UN, New York. 
The importance of demand from emerging markets is evident from the case study of Finnish DigiEcoCity. The business model of the company consists of carrying out urban planning and selling the land use rights to real estate developers who engage in building the cities according to specifications based on ecological principles and digital innovations. China represents a very important market for this business model: one of the consequences of the country's rapid economic growth has been a massive movement of people from the countryside to cities, with significant negative environmental impacts deriving from the resulting urbanisation. This led DigiEcoCity to establish a joint venture with a local partner in China

In addition to partnering with companies from OECD countries, firms in emerging economies are developing their own business models and providing innovative solutions to solve environmental issues and threats to human health caused by urbanisation (Box 7).

\section{Box 7. Business models for green neighbourhoods and cities in emerging economies: Broad Group in China}

Broad Group is based in Changsha, China. It produces non-electric central air conditioning powered by natural gas and waste heat, other energy saving products and, more recently, sustainable buildings, the BSB (Broad Sustainable Building).

Buildings account for almost a third of final energy consumption globally and are an equally important source of $\mathrm{CO}_{2}$ emissions. Currently, both space heating and cooling as well as hot water are estimated to account for roughly half of global energy consumption in buildings. These end-uses represent significant opportunities to reduce energy consumption, improve energy security and reduce $\mathrm{CO}_{2}$ emissions due to the fact that space and water-heating provision is dominated by fossil fuels while cooling demand is growing rapidly in countries with very carbon-intensive electricity systems. The Broad Group manufactures the "Broad Sustainable Building" (factorymade). The prefabricated building derives its sustainability from eight aspects: earthquake resistance, energy conservation, air purification, durability, material saving, recyclable construction materials, construction materials free of formaldehyde, lead, radiation and asbestos and no construction sewage, dust or wastes. The energy efficient buildings help lower costs and can be constructed very quickly.

Among the sustainable buildings developed by the company, a 15-story tall hotel was constructed within six days, and a 30-story hotel in 15 days. The Broad Group is currently building the Sky City One in just seven months. This building is poised to become the world's tallest tower with a height of $838 \mathrm{~m}$, higher than the Burj Khalifa in Dubai.

Source: Broad Group (n.d); International Energy Agency (2011b).

\subsubsection{Knowledge and human resources}

Human capital spurs innovation through several channels: the generation of new knowledge; the adoption and adaptation of existing technologies and ideas; and the ability to adapt to changes and to learn new things. Formal education is of course a key factor in forming human capital. In addition, the use of material and human resources and the scope for further developing workers' skills and knowledge in the workplace can contribute significantly to a firm's innovation. International mobility of skilled human resources also plays an important role in innovation, as mobile talent contributes to the creation and diffusion of knowledge. Finally, collaboration with external partners (e.g. other companies and universities) often provides innovators with additional sources of skills and knowledge that can prove crucial for a successful outcome of innovations (OECD, 2010c).

The case studies confirm the importance of knowledge and human resources for companies engaged in eco-innovation activities, with some distinctions. On average, companies report that in-house resources and training are their main source of knowledge, skills and competencies for their eco-innovation activities. Collaboration with other companies is also reported to be important, as well as other forms of 
partnerships (although lower ranked): with universities, international actors, and government and nonprofit organisations (Figure 7). Thus, the case studies broadly confirm OECD indicators constructed on the basis of the Community Innovation Survey and national data sources (Figure 8) showing that internal sources of knowledge are often reported as the most important for innovation, but in some countries external market sources predominate. Institutional sources play a much smaller role: generally, less than $10 \%$ of innovating firms rank them as "highly important".

Figure 7. Sources of knowledge for innovation, by type, 2006-08

Percentage of innovative firms citing source as "highly important" for innovation

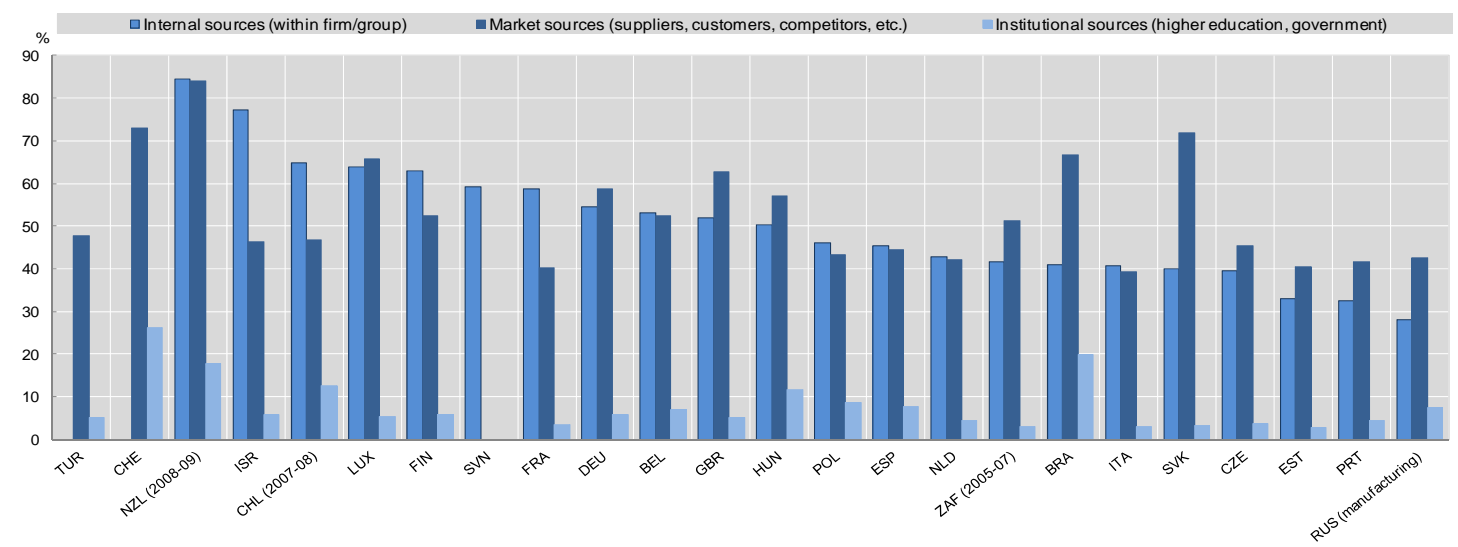

Notes: For Brazil only the following activities are included in the services sector: ISIC Rev.4 Divisions 58, 61,62 and 71. For Chile, data refer to 2007-08 and firms with ongoing or abandoned innovative activities are not identified. Data are based on ISIC Rev.2.1 and include a wider range of activities such as agriculture, forestry, fishing, construction, and some services. For New Zealand, data refer to 2008-09 and include firms with 6 or more employees. Innovative firms include technological and non-technological innovators. For the Russian Federation, data refer to manufacturing firms with 15 or more employees. For Turkey, data are based on NACE Rev.1.1 and exclude some activities within NACE Rev.2 Divisions J58 and J62. For South Africa, data refer to 2005-07 and include the retail trade sector.

The statistical data for Israel are supplied by and under the responsibility of the relevant Israeli authorities. The use of such data by the OECD is without prejudice to the status of the Golan Heights, East Jerusalem and Israeli settlements in the West Bank under the terms of international law.

Source: OECD, based on Eurostat (CIS-2008) and national data sources, June 2011.

The importance of partnerships is evident when looking at the top three average ranks by business model categories. Company partnerships are among the top three most important sources of knowledge and skills for all types of business models except functional sales and management services. University partnerships also feature strongly, having being chosen as one of the top three knowledge and skill sources on average by companies operating waste regeneration systems, functional sales and management services, and industrial symbiosis (Table 2). 
Figure 8. Knowledge and skill sources, average ranks, all business models

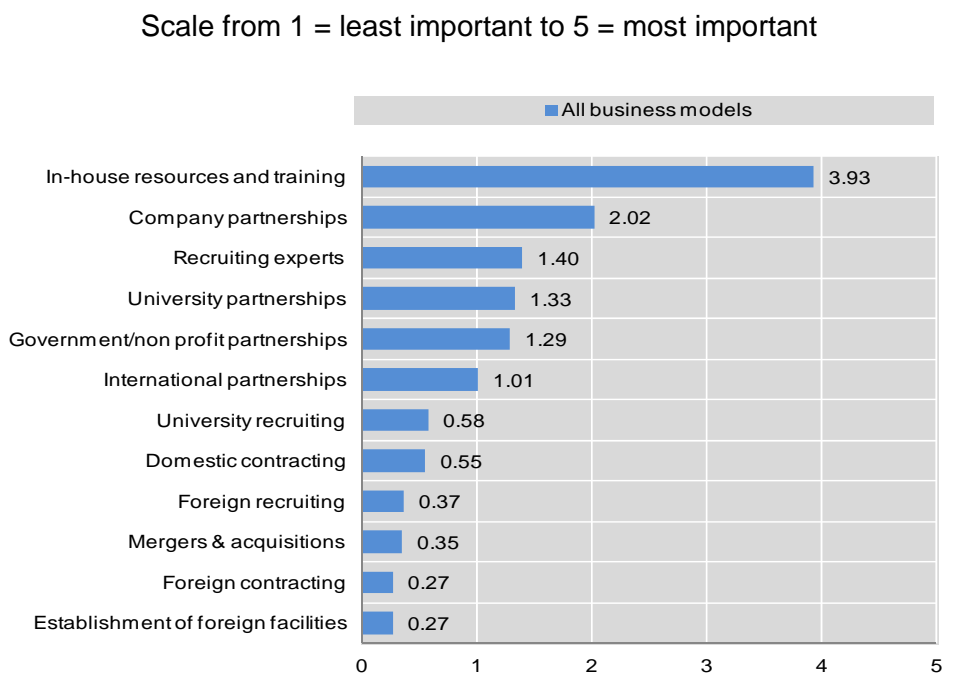

Notes: Companies were asked to rank the five most important sources of knowledge, skills and competencies for their organisations' eco-innovation activities, and their traditional business operations, where appropriate.

Source: OECD case studies.

Table 2. Top three knowledge and skill sources, by business model type

\begin{tabular}{|c|c|}
\hline Type of business model & Top three knowledge and skill sources \\
\hline \multirow{3}{*}{ Greener product/process based models } & 1. In-house resources and training \\
\hline & 2. Company partnerships \\
\hline & 3. Government/non-profit partnerships \\
\hline \multirow{3}{*}{ Waste regeneration systems } & 1. In-house resources and training \\
\hline & 2. Company partnerships \\
\hline & 3. University partnerships \\
\hline \multirow{3}{*}{ Alternative energy-based systems } & 1. In-house resources and training \\
\hline & 2. Recruiting experts \\
\hline & 3. Company partnerships \\
\hline \multirow{3}{*}{ Efficiency optimisation by ICT } & 1. In-house resources and training \\
\hline & 2. Recruiting experts \\
\hline & 3. Company partnerships \\
\hline \multirow{3}{*}{ Functional sales and management services } & 1. In-house resources and training \\
\hline & 2. University partnerships \\
\hline & 3. Domestic contracting \\
\hline \multirow{3}{*}{ Innovative financing schemes } & 1. Recruiting experts \\
\hline & 2. Company partnerships \\
\hline & 3. In-house resources and training \\
\hline \multirow{3}{*}{ Sustainable mobility systems } & 1. In-house resources and training \\
\hline & 2. International partnerships \\
\hline & 3. Recruiting experts \\
\hline \multirow{3}{*}{ Industrial symbiosis } & 1. University partnerships \\
\hline & 2. Company partnerships \\
\hline & 3. In-house resources and training \\
\hline \multirow{3}{*}{ Green neighbourhoods and cities } & 1. In-house resources and training \\
\hline & 2. Company partnerships \\
\hline & 3. International partnerships \\
\hline
\end{tabular}

Source: OECD case studies. 
Eco-innovations draw on a broad base of scientific knowledge. Matching scientific publications with green innovations (proxied by patents) shows that disciplines such as material science, chemistry and physics have a more consequential impact on technological eco-innovations than environmental sciences (Figure 9).

The importance of a multidisciplinary approach is confirmed by the case studies of green business models. Many companies mention that the development of eco-innovations requires technical expertise (e.g. in several fields of engineering) with a strong scientific base. In a number of cases, especially in the alternative energy sector, scientific expertise and engineering talent were mentioned as being among the top three drivers and success factors for the eco-innovation. For example, Torresol Energy developed a commercial-scale concentrated solar power plant in Spain thanks to the efforts of a team whose members had very different disciplinary backgrounds (e.g. civil engineering, architecture, and marine engineering, among others).

A multidisciplinary approach emerges as being crucial for several business models related to green neighbourhoods and cities, such as the Finnish DigiEcoCity. In the case of Greece's "Eco-System for block apartments in an urban context", it is reported that one of the most decisive factors for the success of the eco-innovation was the collaboration of four different scientific fields (architecture, mechanical engineering, environmental engineering and agricultural engineering).

Figure 9. The innovation-science link in "green" technologies, 2000-09

Share of scientific fields cited in total non-patent literature cited in patents for "clean" energy technologies

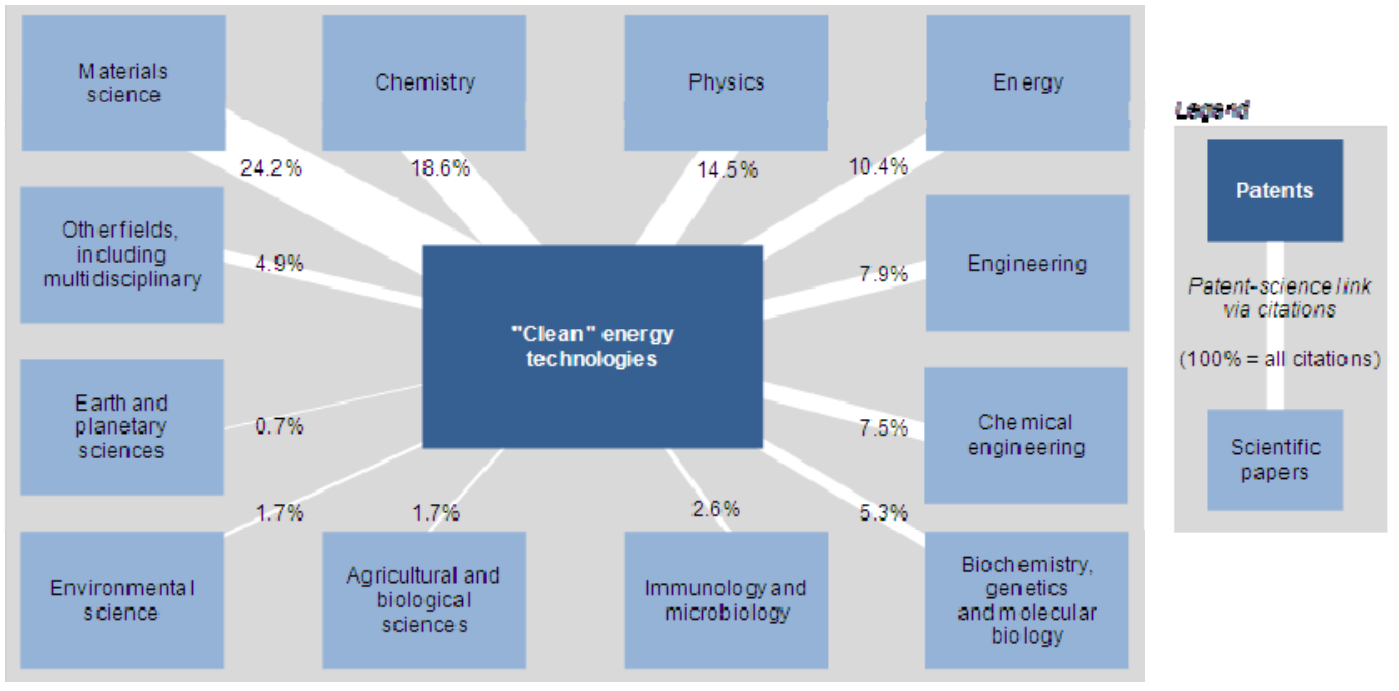

Source: OECD calculations, based on Scopus Custom Data, Elsevier, December 2010 and EPO, Worldwide Patent Statistical Database, April 2011.

Innovation covers a wide range of activities, and therefore requires a wide variety of skills. These include: basic skills and digital age literacy; academic skills; technical skills; generic skills (e.g. problem solving, critical and creative thinking, ability to learn, and ability to manage complexity); "soft" skills (e.g. communication, receptiveness to innovation) and leadership. Furthermore, managerial and entrepreneurship skills are often mentioned in terms of putting innovative ideas into practice and enabling organisations to adapt and respond in competitive environments (OECD, 2010c). 
The case studies attest to the importance of a broad range of skills for eco-innovation, beyond scientific and technical skills. Above all, business development and marketing skills seem to be highly valued by innovators in green business models (Box 8). At the same time, for some companies it is challenging to combine multiple knowledge bases and competencies. For example, Finland's Preseco Oy found that co-ordinating R\&D activities with business model development and marketing proved to be a significant barrier in undertaking its eco-innovation activities. In the case of Denmark's Danfoss (Scanenergi), the complex nature of ESCO projects implies that skills at a highly sophisticated level are required of the key accountants in the projects. They need to be able to co-ordinate between technical, economical and managerial divisions in the company. An ESCO project also requires a complex mix of staff including utility experts and project managers.

\section{Box 8. Combining different types of skills: LanzaTech}

LanzaTech developed a microbial gas fermentation process to produce ethanol fuels and chemical products that are used to make plastics and polymers. The knowledge and skills needed to advance the technology development shifted as the company's focus changed from bio-technology to chemical engineering. The R\&D staff now includes a wide range of disciplines from chemical and process engineers to microbiologists.

In addition to scientific and technical competencies, business development skills were required as the technology development progressed and the potential for its commercial application became clearer. Two key principles guide the company through knowledge and human resource development: targeting the best available skills and credentials; and ensuring that R\&D credibility is maintained by hiring business development people who have technical credentials as well. As stated by the company's co-founder and Chief Scientific Officer: "Because we are developing a technology and commercialising a technology, it's important that we have people with technical credibility."

A good balance between technology experts and business development professionals is also sought, and by encouraging teams to solve problems from a variety of approaches the company effectively brings together these skill sets. Hiring top talent and expertise, and encouraging ways of working in multidisciplinary teams, are mentioned as key drivers of the success of the eco-innovation.

Source: OECD case studies.

Although in-house resources and training are ranked as the top sources of knowledge and skills, the case studies show that collaboration with external entities also carries a lot of weight with companies and innovators. This is especially the case for partnerships with other companies and with universities, and also (though to a lesser extent) with government and other non-profit organisations. Such partnerships with external parties are an important source of external knowledge for companies, and reflect an increasing trend towards a more open approach to innovation. Through partnerships and collaborations, firms seek to stay abreast of developments, tap into ideas and technology and get new goods or services to market before their competitors $(\mathrm{OECD}, 2011 \mathrm{~b})$. At the same time, they can also involve some transaction costs, for example in relation to the sourcing and processing of new knowledge (OECD, 2010c).

Companies collaborate for a variety of purposes, such as developing quality management schemes (e.g. for reuse system houses, as reported by Japan's Sekisui), or facilitating technology transfers and exchanges of technical know-how among different industries and technologies (e.g. ceramic, photovoltaic and domotics in the case of Portugal's Revigrés). Collaboration between companies is at the core of the business model in a number of case studies involving partnerships. For example, in the case of the LIFE consortium in Portugal, the development of an eco-efficient and lightweight aircraft cabin with a low environmental footprint would not have been possible without the involvement and expertise of suppliers in the aviation and transport industries, design companies, research institutes and the close link with PEMAS (Portuguese Aerospace Industry Association). In addition, the project enabled participating companies to develop and consolidate new capabilities in the aeronautical interiors market, based on a cross-pollination approach using inputs from alternative transportation modes, home interiors and other 
seemingly unrelated areas. Industrial symbiosis provides another example where collaboration among companies is crucial for the success of the business model, as one company's waste becomes another company's raw material.

Partnerships with universities are also deemed to be very important, and can take several forms. Companies and academic institutions can enter into formal agreements such as research consortia, or other forms of long-term partnerships. For example, Ecover in Belgium collaborates with several universities (University of Ghent, University of Sheffield, London College of Art) for its long-term R\&D. Sweden's Ecoera reports that crucial knowledge, skills and competencies were obtained through a long-term partnership with academia in R\&D networks funded by EU programmes. Formal academia and industry partnerships are also key to the successful implementation of industrial symbiosis programmes, with universities providing companies with expertise in theory and applications of industrial ecology. This was the case for the Centre of Excellence in Cleaner Production at Curtin University, the Kwinana Regional Synergies Project in Australia, and the Centre for Clean Technology and Resource Recycling in Ulsan University for the Ulsan Industrial Symbiosis project in Korea.

But long-term formal partnerships are not the only form of collaboration between companies and universities. Often, companies source knowledge and skills from academia in order to carry out very specific, technical assignments. For example, New Zealand's HaloIPT (Qualcomm) sourced experts in the fields of engineering and power electronics design from the University of Auckland. In addition, several companies see universities as an important pool for recruiting individuals with the required skills and competencies.

Given the wide range of skills and expertise that are required for developing eco-innovations, and the potential sustainability impacts of green business models on the economy, the environment and society, collaboration with government and other non-profit organisations also feature strongly in the case studies. For example, the Active House Alliance functions as a platform including industrial actors from the full construction building value chain (architects, engineers, developers, component suppliers), research and academia (universities and institutes), but also non-governmental organisations with a stake in promoting green neighbourhoods and cities. Likewise, "Refrigerants, Naturally!" is a not-for-profit partnership of multinational companies and environmental organisations committed to fostering sustainability in the refrigeration sector, reducing greenhouse gas releases, and combating ozone layer depletion by substituting natural refrigerants for fluorinated gases.

Some companies perceive a gap between their demand for the skills required to develop ecoinnovations and introduce them into the market, and the skills supplied by universities or otherwise. This confirms evidence from a number of countries suggesting that skill shortages have already developed in certain sectors or occupations where green growth policies have created a need for new skills, or new combinations of familiar skills. Energy-efficient construction and retrofitting, renewable energy, energy and resource efficiency and environmental services appear to be among the most affected sectors (OECD, 2012c).

The case study of HaloIPT (Qualcomm) exemplifies this skills gap: the company carried out its R\&D in New Zealand, but as the country has a small labour market and historically the transport field is not a focus of the industry, there were constraints in accessing certain skills. In the case of the Yike Bike, while the company had no difficulty in finding technical expertise, and believes that New Zealand's education system provides the technical skills required, it is felt that the business sector lacks the skills to commercialise products and services effectively. Companies can also experience skills shortages that are specific to a business model type, such as innovative financing schemes and the ESCO in particular. For example, Danfoss (Scanenergi) reports that utility experts are very hard to recruit as they will often need 15 years of practical experience. They are very difficult to recruit in Denmark. 
Finally, the case studies illustrate the existence of a number of perceived trade-offs in the internal organisation and management of companies' innovation processes. In particular, there is a need to strike a balance between the skills required for the management of day-to-day established business processes and the creativity and ability to think out of the box that are required for further innovation. For example, New Zealand's Waste Solutions decided to adopt more freedom in its organisational structure and encourage innovative thinking to respond to changing market needs, while relying on the resources of its parent company to ensure the continuation of current business operations.

Another potential trade-off may exist between acquiring and retaining industry- and technologyspecific skills while allowing newcomers to bring fresh and radical ideas into established ways of doing things. For example, one of the factors that contributed to the YikeBike's success was a design team who were not traditional bike designers and were not working within a large bike company. Being 'outsiders,' they brought a range of alternative experiences and expertise to the design solution. This enabled them to look at the problem from a different angle and break from the conventions of traditional bike design.

\subsubsection{Financial resources}

Finance plays an essential role in enabling firms to invest in innovation. However, access to finance is a key constraint for business-led innovation, especially in the aftermath of the economic crisis. Access to finance is even more difficult for firms engaged in eco-innovation, due to the immaturity of the market, which increases the difficulties associated with accurately pricing the relative risk of investment in "green growth", making it more difficult for such firms to obtain financing at reasonable costs than for firms involved in more established markets (OECD, 2011b).

The case studies of green business models uphold the centrality of finance to the development and commercialisation of eco-innovation. At the same time, they also confirm that the financial and economic crisis has had a very strong and negative impact on the opportunities for firms to secure funds, especially for small and innovative start-ups.

On average, in-house resources are reported to be by far the most important source of funding for companies to develop their eco-innovations and introduce them to the market (Figure 10). Firms make use of in-house funds both for the early development, testing, and then demonstration stages of the innovation and for business development and commercialisation. Some of the larger companies included in the case studies were able to fund the entire innovation, from early development to commercialisation, through internal sources. However, most of the interviewed SMEs were obliged to complement funds generated internally with outside support. According to some organisations, internal funds would not have sufficed to carry out the R\&D required to develop and commercialise the innovation. One example is CSIRO in Australia. It partnered with a local manufacturer and marketer of paints and a state government body in developing innovative zero-waste powder coating. This ensured that the innovation was targeted at end user needs.

In most other cases, in-house revenues were sufficient to develop the innovation, but external support was necessary for the business development and commercialisation phase. In this respect, many companies experience the risk of falling into a "valley of death" between the early stages of R\&D/testing/demonstration and subsequent commercialisation. For example, in the case of the vanadium redox battery developed by the University of New South Wales in Australia, government funding allowed the technology to reach the business development and commercialisation stage. Without this grant, the innovation would have stayed at the research stage only. At the same time, the University also acknowledges that government policy in supporting early renewable energy research together with associated funding was a major contributor to the success of this innovation. 
Figure 10. Funding sources, average ranks, all business models

Scale from $1=$ least important to $5=$ most important

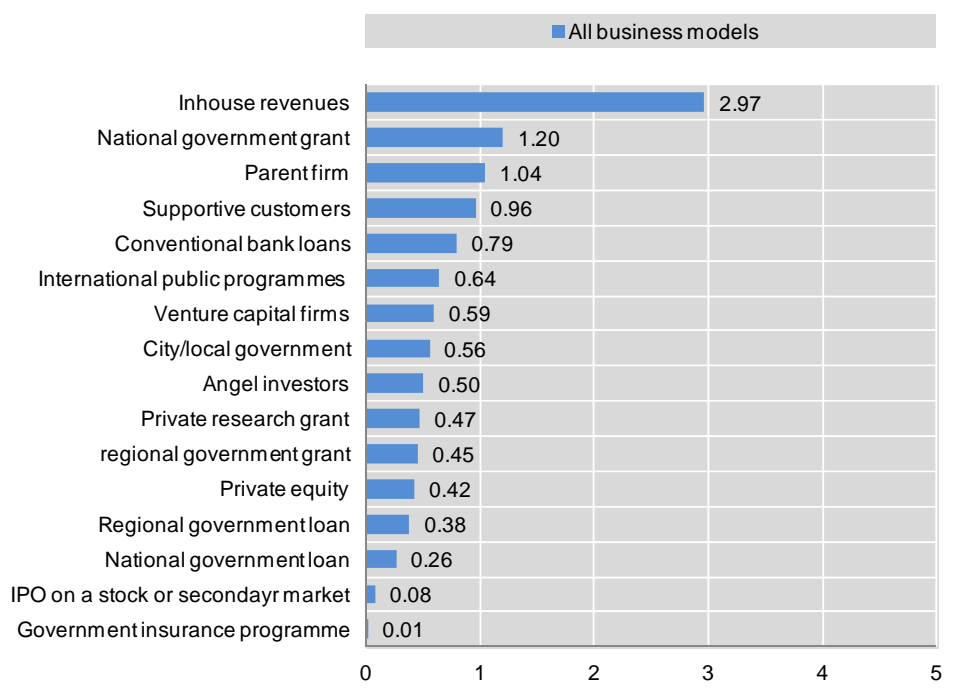

Notes: Companies were asked to rank the five most important sources of funding for their organisations' eco-innovation activities, and their traditional business operations, where appropriate.

Source: OECD case studies.

Besides the central role played by in-house revenues, a breakdown of the most important funding sources by business model category highlights that external finance - both equity and debt finance, under several forms - can also be significant for specific eco-innovations (Table 3):

\section{Equity financing}

Venture capital was ranked on average the first most important source of funding for alternative energy-based business models and sustainable mobility systems, and the second most important source of funding for innovative financing schemes. This confirms previous OECD research underlying the importance of venture capital in the cleantech sector (Criscuolo and Menon, 2012). For example, venture capital was among the main sources of initial funding for innovative companies in Finland (Preseco Oy); Israel (Better Place; TaKaDu) and Japan (Kankyo-keie). Venture capital investors have also supported several start-up firms in New Zealand (HaloIPT, LanzaTech, YikeBike). However, the latter were unanimous in stating that New Zealand has a small pool of venture capital investors, therefore businesses can struggle to find a funder whose portfolio, interest and experience are relevant to their specific area. The limited size of venture capital funds is also considered to be an obstacle by companies in Europe.

Broader private equity also plays an important role, having been ranked on average the second most important source of funding for sustainable mobility systems and industrial symbiosis.

Finally, angel investors were also deemed very important by companies operating with alternative energy-based systems. For example, angels funded LanzaTech, YikeBike and Solray Energy in New Zealand. However, angel investors in a small economy like New Zealand tend to invest limited sums and to be risk-averse in their selection. 


\section{Parent firms}

Access to funds from corporate parents is very important for companies operating innovative financing schemes and for companies with business models based on efficiency optimisation by ICT.

It emerges from the case studies that, for some companies, the ability to innovate may be closely linked to the financial health of the parent company, and even more to the appetite for risk of the parent group. For example, Waste Solutions struggled to obtain financing from its parent company due to the global financial crisis, as available budgets for innovative research or development projects were tightened. At the same time, one of the benefits of relying on a larger company is that when an innovation is successful, and meets the parent company's business development criteria, innovators can tap into much larger funds relative to what SMEs may have access to.

\section{Supportive customers}

Funds made available by supportive customers (e.g. through advance payments) are important for companies in greener products and processes based models, efficiency optimisation by ICT models, and waste regeneration systems (in this latter case, supportive customers were ranked on average as the top source of funding).

\section{Bank loans}

Although banks across OECD countries have considerably shrunk their lending portfolios in the aftermath of the financial and economic crisis, conventional bank loans still represent one of the main sources of finance for companies providing functional sales and management services and for companies operating in the green neighbourhood and cities business model category.

Some companies report great difficulties in obtaining finance from banks. This is because uncertainty over the success of some innovative ventures based on green business models is too high for risk-averse financial institutions, and in some cases the projected return on investment (ROI) is too far in the future or below the level deemed safe by the bank. It clearly emerges from the case studies that difficulties in obtaining conventional bank loans concern mostly SMEs, or large-scale systemic projects such as industrial symbiosis.

\section{Government support for innovation}

Given the specific barriers to accessing finance for firms investing in eco-innovation, as well as the important learning and demonstration effects which will not be realised in the absence of initial support, government might need to play a role in fostering environmental technologies and green business innovation (OECD, 2011b). Amongst the various forms of support, national government grants emerge as the most prominent, since they feature in the top three most important sources of finance on average for several green business models (i.e. greener products and processes, waste regeneration systems, alternative energy-based systems, industrial symbiosis). Public support is reported as being particularly important for financing business models based on green neighbourhoods and cities, at the city/local level as well as regional and national levels (through loans).

A number of EU funds (e.g. Structural Funds, Eco-innovation Programme, Intelligent Energy Europe, LIFE Programme) contributed to financing innovation activities in a large majority of European countries. New Zealand's HaloIPT (Qualcomm) was set up as a company in the United Kingdom partly because of the availability of national and EU funds for product development. 
Notwithstanding the central role of financial support from the government, some companies consider that public funds are not sufficient to sustain their innovation activities effectively, especially those aimed at bringing products and services to the market.

Table 3. Top three funding sources, by business model type

\begin{tabular}{|c|c|}
\hline Type of business model & Top three policy instruments \\
\hline \multirow{3}{*}{ Greener product/process based models } & 1. In-house revenues \\
\hline & 2. National government grant \\
\hline & 3. Supportive customers \\
\hline \multirow{3}{*}{ Waste regeneration systems } & 1. Supportive customers \\
\hline & 2. In-house revenues \\
\hline & 3. National government grant \\
\hline \multirow{3}{*}{ Alternative energy-based systems } & 1. Venture capital firms \\
\hline & 2. Angel investors \\
\hline & 3. National government grant \\
\hline \multirow{3}{*}{ Efficiency optimisation by ICT } & 1. In-house revenues \\
\hline & 2. Parent firm \\
\hline & 3. Supportive customers \\
\hline \multirow{3}{*}{ Functional sales and management services } & 1. In-house revenues \\
\hline & 2. Conventional bank loans \\
\hline & 3. Regional government loan \\
\hline \multirow{3}{*}{ Innovative financing schemes } & 1. Parent firm \\
\hline & 2. Venture capital firms \\
\hline & 3. In-house revenues \\
\hline \multirow{3}{*}{ Sustainable mobility systems } & 1. In-house revenues \\
\hline & 2. Private equity \\
\hline & 3. Parent firm \\
\hline \multirow{3}{*}{ Industrial symbiosis } & 1. National government grant \\
\hline & 2. Private equity \\
\hline & 3. In-house revenues \\
\hline \multirow{3}{*}{ Green neighbourhoods and cities } & 1. In-house revenues \\
\hline & 2. Conventional bank loan \\
\hline & $\begin{array}{l}\text { 3. City/local government; National government loan; Regional government } \\
\text { loan }\end{array}$ \\
\hline
\end{tabular}

Source: OECD case studies.

Undoubtedly, access to finance represents the single most important stated barrier to developing and (especially) commercialising eco-innovations. Yet, the case studies of green business models show that firms and research organisations have striven to obtain funds from several sources, and thus overcome the 
financial hurdles they encounter. The case of New Zealand's Solray Energy is a good illustration of these strategies, involving, for example, co-development partnerships (Box 9).

\section{Box 9. Strategies to overcome barriers in accessing finance: Solray Energy}

The biggest barrier experienced by Solray Energy to date has been the financing required to prove the concept and demonstrate the ability of the technology to produce outputs at suitable levels of yield. The main barrier the company faces in the future for the development and commercialisation of its super critical water reactor is accessing directly or indirectly (e.g. through co-development) the financing required to develop full-scale commercial models.

Funding for Solray Energy's innovation process included the following sources:

- $\quad$ Private investment (representing the most significant source)

- $\quad$ Government funding in the form of grants

- $\quad$ Local government funding.

As it planned the business development and commercialisation strategy for its super critical water reactor, Solray Energy anticipated that the financial requirements necessary for scaling up the technology would be significant. Hence, it was decided to focus on a co-development business model as an interim phase, before making any decision on seeking additional finance. Co-development partnerships "embody mutual working relationships between two or more parties aimed at creating and delivering a new product, technology or service" (Chesbrough and Schwartz, 2007). While traditional innovation-oriented business models are based on the idea of developing a product from internal R\&D and then producing, marketing and selling the product, the use of partners in R\&D can significantly reduce R\&D expenses (Chesbrough and Schwartz, 2007). Co-development partnerships are an expression of a broader trend towards open innovation: confronted with rising R\&D costs, companies collaborate with external partners, whether suppliers, customers or universities (OECD, 2008a).

The most decisive factor in the success of the innovation was securing sufficient, long-term finance to actually get beyond the proof of concept and to demonstrate the innovation. Solray Energy's current strategy for attracting future financial resources is to utilise its IPR portfolio to enter into co-development arrangements through licensing.

Solray Energy perceives that there is a gap in available government and private funding for commercialising technologies, while funding for blue sky research and for proof of concept is more easily available in New Zealand. Although eco-innovations remain trapped in the "valley of death" in many other countries, the company feels that this may be an issue for New Zealand in particular, given the scarce domestic availability of angel and venture capital investment and a lack of inward foreign venture capital.

Source: OECD case studies.

\subsubsection{Intellectual property rights}

Recent econometric work carried out at the OECD on the determinants of the high growth financing sector shows that, in the cleantech sector, entrepreneurial companies that are patenting are more likely to receive financing by private investors. This highlights the importance of improving IPR policies to make patenting more efficient and less costly, which will enable entrepreneurial companies to signal their innovative capacity and thus facilitating financing at all stages of a product's development (Criscuolo and Menon, 2012).

Patent counts can provide a measure of innovation in environmental technologies, and give an indication of the extent to which firms are being successful in their eco-innovation efforts. ${ }^{7}$ From a relatively small base, innovations in technologies related to climate change mitigation and solar energy are an increasing share of patent portfolios. In 2007-09, the share of Patent Cooperation Treaty (PCT) patents in solar energy was three times their share in 1997-99. However, patent applications in energy storage or 
material recycling technologies are increasing at a slower pace than total patents (Figure 11). Inventive activity in energy generation from renewable and non-fossil sources remains centred in European countries: in the late 2000s, the EU27 represented 37\% of all PCT filings in this field (Figure 12).

Figure 11. Patents in selected environmental technologies, 1997-99 and 2007-09

\section{As a percentage of total PCT applications}

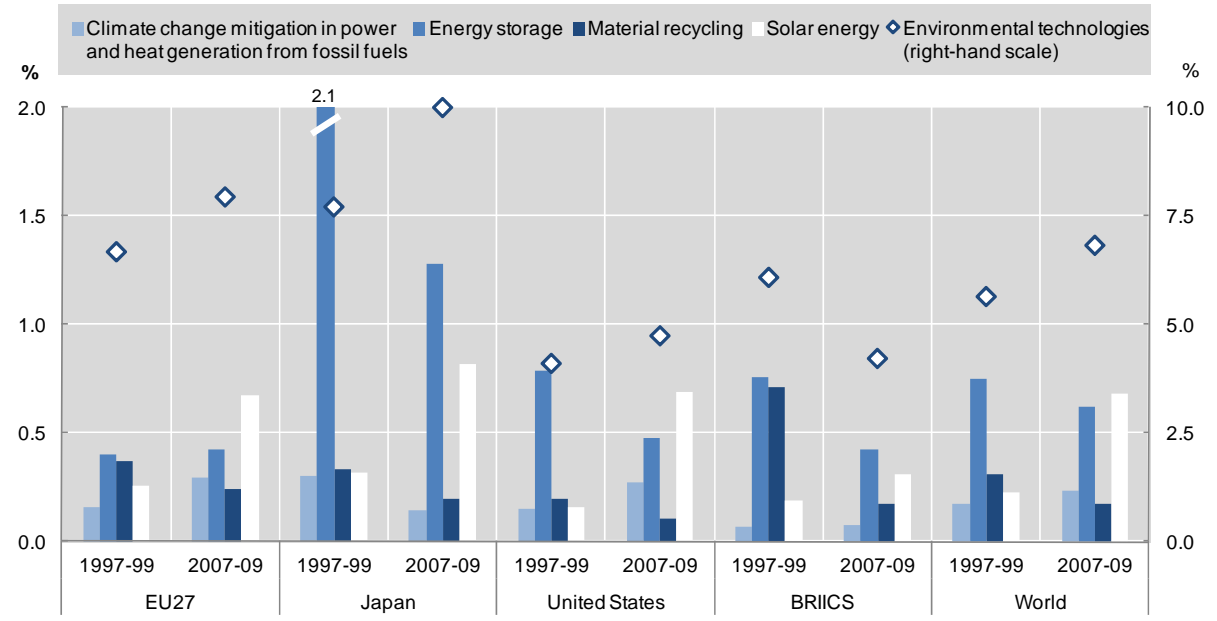

Notes: Data relate to patent applications filed under the Patent Co-operation Treaty (PCT), at international phase, published by the WIPO. Patent counts are based on the priority date, the inventor's country of residence and fractional counts. Patents in technologies related to climate change mitigation in power and heat generation from fossil fuels, energy storage and solar energy are identified using subclasses of the European Classification (ECLA) code Y01. Patents in technologies related to material recycling are based on codes of the International Patent Classification (IPC). BRIICS refers to Brazil, the Russian Federation, India, Indonesia, China and South Africa.

Source: OECD, Patent Database, May 2011. 
Figure 12. Countries' share of patents for energy generation from renewable and non-fossil sources, 2007-09

Patent applications filed under the PCT

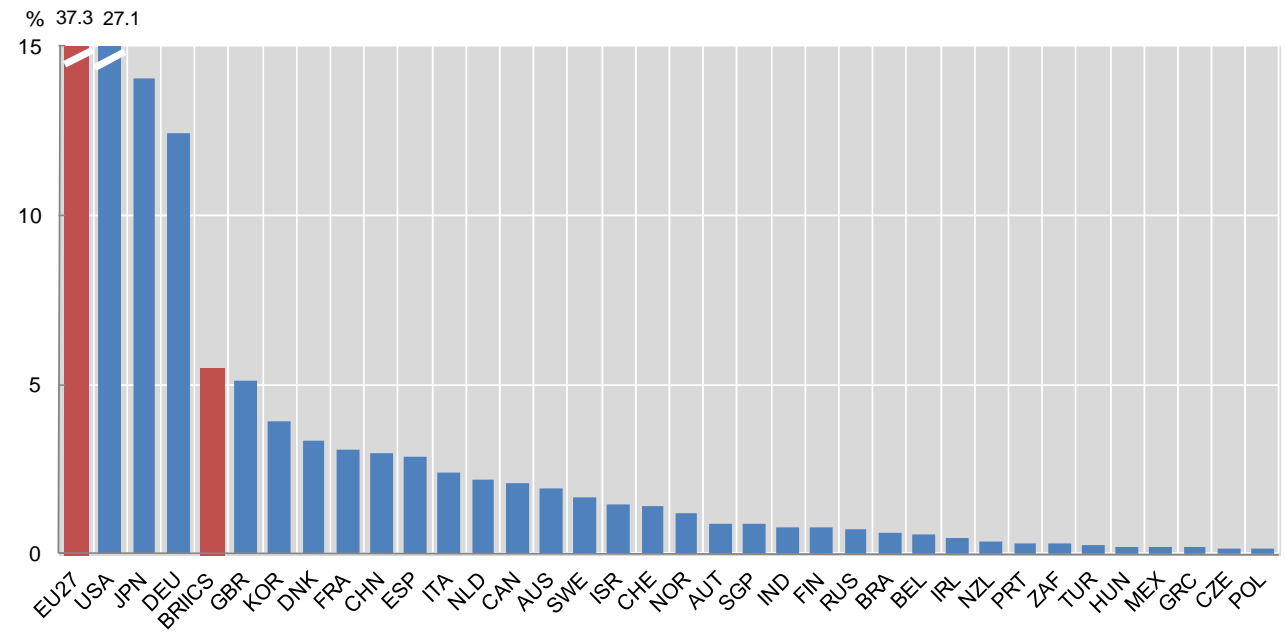

Notes: Data relate to patent applications filed under the Patent Co-operation Treaty (PCT), at international phase, published by the WIPO. Patent counts are based on the priority date, the inventor's country of residence and fractional counts. Patents in technologies related to climate change mitigation in power and heat generation from fossil fuels, energy storage and solar energy are identified using subclasses of the European Classification (ECLA) code Y01. Patents in technologies related to material recycling are based on codes of the International Patent Classification (IPC). BRIICS refers to Brazil, the Russian Federation, India, Indonesia, China and South Africa.

The statistical data for Israel are supplied by and under the responsibility of the relevant Israeli authorities. The use of such data by the OECD is without prejudice to the status of the Golan Heights, East Jerusalem and Israeli settlements in the West Bank under the terms of international law.

Source: OECD, Patent Database, May 2011.

The case studies on green business models confirm the importance of IPR for the development and deployment of eco-innovations. Business models in 36 case studies involve the application or granting of some form of IPR (patents, trademarks and/or copyrights) related to their eco-innovations (Figure 13). In 17 case studies, companies did not seek protection from their intellectual property. This is due to several reasons, and it also seems to depend on the nature of the business models. For example, out of the seven cases in the green neighbourhood and cities category, only in two of these did the companies involved seek IPR protection. One of those two companies (Finland's DigiEcoCity) stated that its eco-innovation consists of a "model city", which should be replicable, where IPR protection was sought for the specific solutions and technology used to implement the green city concept in practice.

Even for companies that did apply for patents or other rights, the degree of importance of IPR protection varies quite significantly. For example Danfoss (Scanenergi), a company providing an innovative financing scheme, states that IPR protection only plays a small role in supporting ESCO projects. 
Figure 13. Use of IPR in green business models

Number of business models in which any patents, trademarks of copyrights relating to the eco-innovation were applied or granted

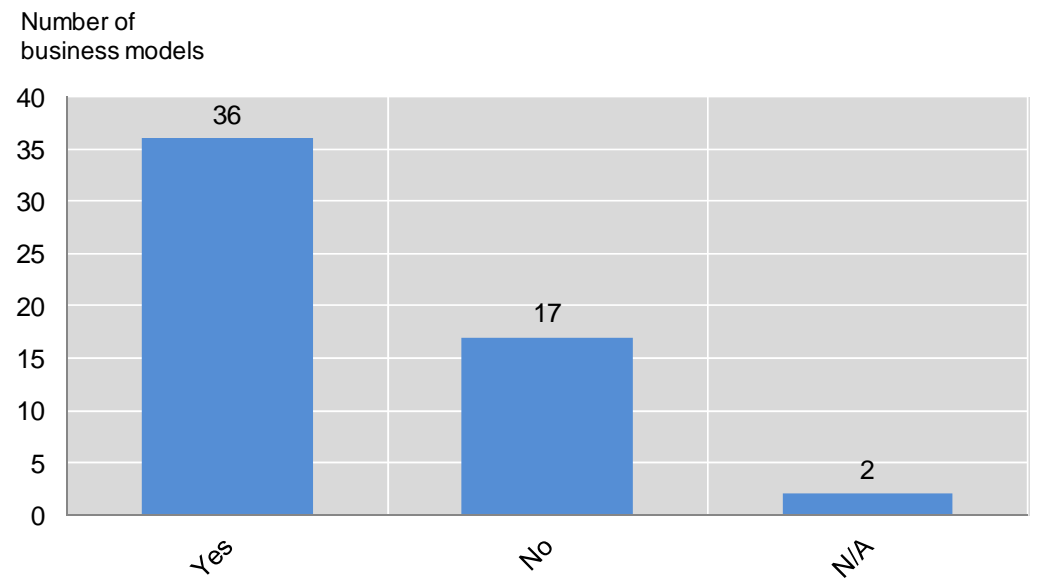

Note: N/A refers to case studies for which information was not available or provided.

Source: OECD case studies.

Nonetheless, many companies consider that IPR protection has been fundamental to their ecoinnovations. For example, Belgian company Ecover stated that an investment in a 7-year long R\&D project can only be profitable if the innovator has the exclusivity of its result. Brite Hellas and Intelen (both from Greece) held that IPR was one of the main drivers and success factors for the eco-innovation. New Zealand's Solray Energy believed that the creation of an IPR portfolio was crucial for creating an asset that is commercially saleable.

Among the benefits provided by IPR, two emerge as being particularly beneficial for green business models:

- An IPR portfolio can ease access to finance. For example, for Intelen (Greece) one of the most important benefits of IPR is that it facilitates fundraising for the company's innovation activities. The case studies thus confirm the results of previous OECD work (Criscuolo and Menon, 2012), which found that patenting firms in cleantech tend to receive more finance from private investors than non-patenting firms.

- IPR can also facilitate co-operation and partnerships with other companies. For example, Solray Energy's current business model is centred on international co-development arrangements based on retaining foreground IPR (i.e. the rights created by the parties within the framework of a codevelopment agreement), which removes the need for the company to secure further major national or international investment for its own development of the technology. According to the LIFE consortium in Portugal, IPR mechanisms facilitate knowledge sharing: formal nondisclosure agreements were signed among partners, thus safeguarding individual contributions to the common project and establishing the framework for joint exploitation of the project's final results. For Torresol (Spain), an important driver behind the innovation in concentration solar power installations was collaboration with third entities enabled by special agreements.

Patenting is the most widespread means to protect IPR generated from eco-innovations among the 37 business models that have applied for or have been granted some form of IPRs. However, other types of 
IPR are also used, such as trade secrets, confidentiality and non-disclosure agreements with partners, copyrights, and trademarks (Figure 14). Some companies use a mix of different instruments: for example, Bionade (Germany) has a patent on the production process of the fermented soft drink, but the formula of the drink is a trade secret. Also YikeBike (New Zealand) believes in creating a mix of IPR protection, from the quick and relatively inexpensive approaches for early protection of the innovation to the more expensive and cumbersome process of patenting.

\section{Figure 14. IPRs used to protect eco-innovations, excluding patents}

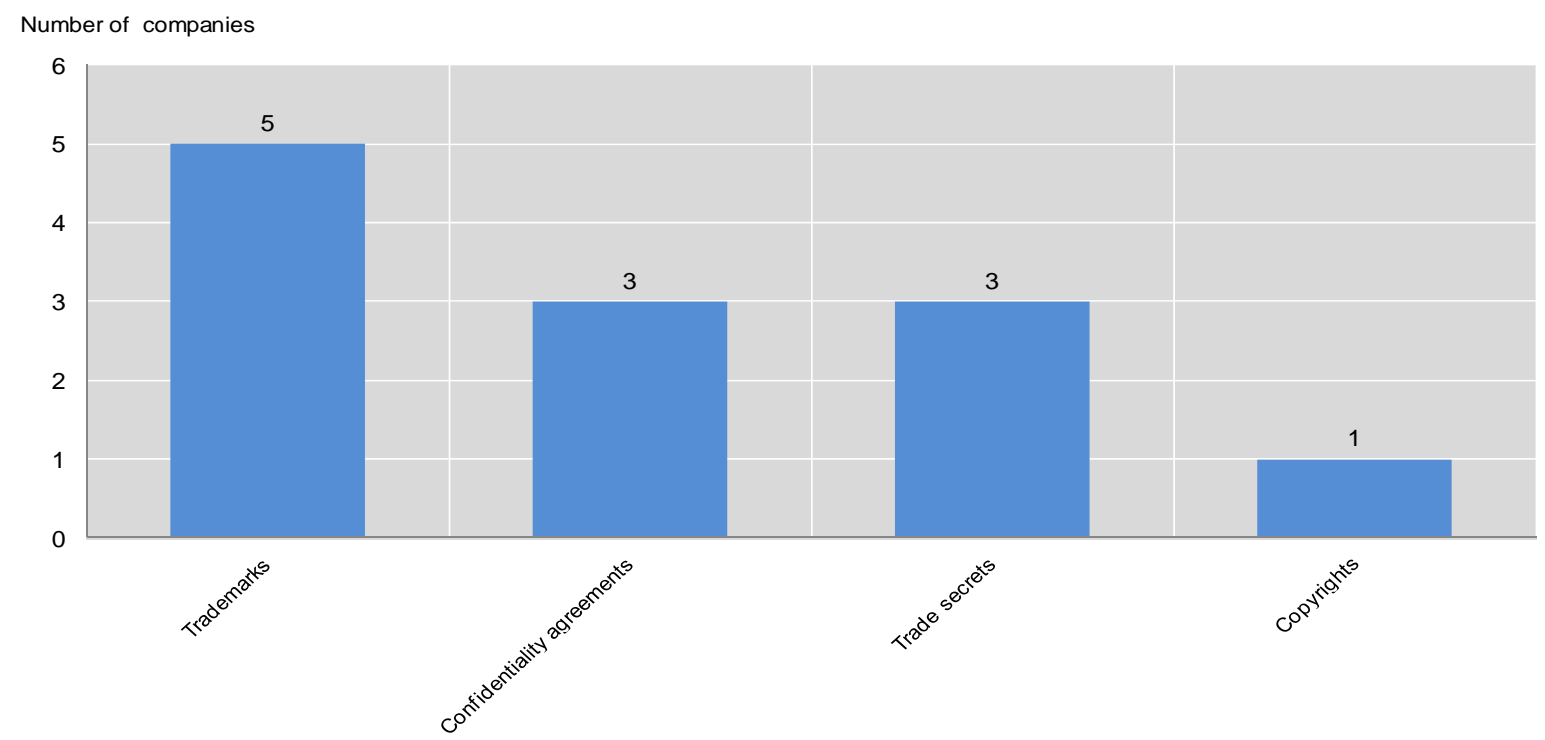

Source: OECD case studies.

Regarding trade secrets, not all companies believe that they are a reliable enough instrument to protect their IPR. For example, Solray Energy's preferred strategy for the protection of intellectual property is to use registrable rights. The company believes that the strict protocols necessary for trade secrets to be legally and economically valid without costly due diligence are often misunderstood, thus it prefers not to rely on them.

The internal management of IPR can also be challenging for companies, although it is recognised as a key success factor for development and commercialisation of eco-innovations. LanzaTech (New Zealand) has a decision-making process in place to determine when it is suitable to apply for patents and when for trade secrets, depending on the issue and the jurisdiction concerned. Deciding on the right timing for seeking IPR protection can also be crucial. For example, Waste Solutions for New Zealand only started to protect the IPR related to their Waste to Energy project once it had already been commissioned to partners, therefore it was too late to stop a partner in the project utilising the trademarked name "Cigar". As a result, while Waste Solution owns the trademark in 12 jurisdictions around the world, it does not own it in the Philippines and Thailand, two of the locations with its initial and most numerous installations to date.

Working with international partners seems to be a valuable feature of the eco-innovation process, but can also pose some risks in relation to IPR, especially in regard to technology transfers. For example, LanzaTech's approach to commercialising the technology does not involve technology transfer agreements. At the same time, LanzaTech's joint-venture partners play a part in protecting the company's IPR. Another company from New Zealand, Waste Solutions, expressed doubts over transferring certain elements of know-how to local partners, after former project partners in Thailand became competitors and 
some of the company's staff were lost to them. On the other hand, Solray Energy's current business strategy is to utilise its IPR portfolio to enter negotiations initially with a small number of licensees in strategically placed territories, and to fund the continued development of its technology through a codevelopment mechanism, while retaining the IPR to the core technology and any new developments in it.

Many companies involved in eco-innovation activities appear to be looking at ways to strike the right balance between the need to protect their IPR while, at the same time, sharing knowledge with other potential innovators. For example, although HaloIPT (Qualcomm) sought protection for its IPR, it also supported and invested in the open innovation system at Auckland University whereby different companies from different sectors provide a set sum that enables them access to certain IPR coming out of the University. The company supports this approach as it enables small companies to access new research. Bringing companies together can facilitate fertilisation of innovation and collaboration across different sectors. Eco-innovation is of such global importance that there may be more rationale for global bodies and national governments to support selective or open innovation. Solray Energy notes that some movements are being made towards acquiring and exploiting intellectual property on a national or a collective basis. YikeBike sees the adoption of their bike design by other companies as a means to gain greater market acceptance for the upright and electric YikeBike design. Finally, some companies are using IPR to protect only parts of their eco-innovations. For example, in the case of CartaSense (Israel), the software is open and enables all partners to use and integrate the system, while the smart wireless network is protected.

Companies' strategies also differ in terms of the geographical coverage of their IPR. Some of them file applications for IPR only in their countries, others in several countries that are key markets for the ecoinnovations (notably with the United States Patent and Trademark Office, but also in Australia, Japan, Brazil, China, India, Russia, and Singapore). Some companies also file applications for IPR with the European Patent Office, and for patents under the Patent Co-operation Treaty.

The cost of patenting or of securing other forms of IPR protection emerges as the most significant challenge for companies engaged in eco-innovation activities. For example, Roltex in Belgium considered filing an application for a European patent but the cost was considered to be too high. The company opted instead for a national patent, which was less difficult to get both from an administrative and financial point of view. In this respect, lack of financing is often one of the main obstacles for companies to obtain IPR protection. For example, on the basis of the experience of its "Zero Vehicle" project, the National Technical University of Athens reports that independent researchers cannot support the cost of the legal protection of a patent without institutional support for applied research or the involvement of industrial partners.

Financial impediments can be particularly severe for SMEs. The international IPR system requires firms who wish to engage with it to have access to significant financial resources or internal capability. A significant amount of money is required at very early stages in the process in order to protect IPR, and for SMEs this is often outside the ability of the company to fund. In addition, the defence of any IPR protection is very difficult and expensive and to some SMEs there appears to be little point in protecting the initial IP if they do not have the financial resources to defend the ownership. Another challenge that confronts SMEs in particular is the lack of capacity to understand international IPR processes. These hurdles are illustrated by the case of Waste Solutions from New Zealand (Box 10). 


\section{Box 10. Challenges for SMEs to protect IPR: Waste Solutions}

As an SME struggling to access funding for the innovation itself, Waste Solutions did not have the financial resources available to defend its IPR. Based on its experience, the company believes that IPR protection does not provide sufficient return on investment to justify the expenditure.

In addition, Waste Solutions believes that lack of adequate legal counsel can represent a significant barrier for SMEs to reap the benefits of the international IPR system. The company feels that its small commercial size at the time it sought legal advice meant that it did not receive the serious attention or the results its investment in legal fees deserved. It had to follow up and drive the process to an unnecessary degree, and failure to register the trademark in one location by its lawyers led to the loss of intellectual property protection in that jurisdiction.

Waste Solutions believes that a system of results-based legal representation (i.e. a system where payment for legal fees is tied to the outcome of the case) would potentially result in a domestic IPR system which is more easily accessible for SMEs. The company also considers that it would be beneficial if the government could minimise the barriers to initial protection of IPR, and moreover, that there was some form of assistance for SMEs in the defence/enforcement of international IPR protection.

Source: OECD case studies.

Finally, IPR policies can hold substantial sway over companies' decisions and strategies related to their engagement in eco-innovation activities. For example, one of the stated reasons behind HaloIPT's (Qualcomm) decision to set up operations in the United Kingdom was the country's company-friendly IPR legislation.

\subsubsection{Government policies and programmes}

Overall, it emerges from most case studies that policies and government intervention played a positive role in implementing eco-innovative projects. A number of eco-innovations (e.g. projects on alternative energy, mobility, waste recycling) have benefitted from national and EU innovation measures. Large-scale projects like green cities have been promoted by local governments and have enjoyed the financial support from local investment programmes. Furthermore, stricter environmental standards and regulatory pressures have triggered business interest in introducing eco-innovations or have created markets for new services enabling business to comply efficiently with the requirements.

At the same time, some case studies illustrate the negative impacts of policies on eco-innovation activities. In particular, difficulties arise due to excessive 'red-tape' in government support measures, inflexible environmental regulations, distorting government subsidies for certain sectors (e.g. subsidies for fossil fuels, mining) and resource pricing that does not take account of environmental cost. The absence of long-term national development strategies and programmes and increased uncertainty related to public support is an increasing concern for eco-innovators.

Policy measures were ranked in order of their importance for advancing eco-innovation activities in the future. Figure 15 summarises these observations for all the case studies. The results suggest that supply side policy measures play a significant role in promoting most types of eco-innovations, notably in their early stages. 
Figure 15. Policy instruments, average ranks, all business models

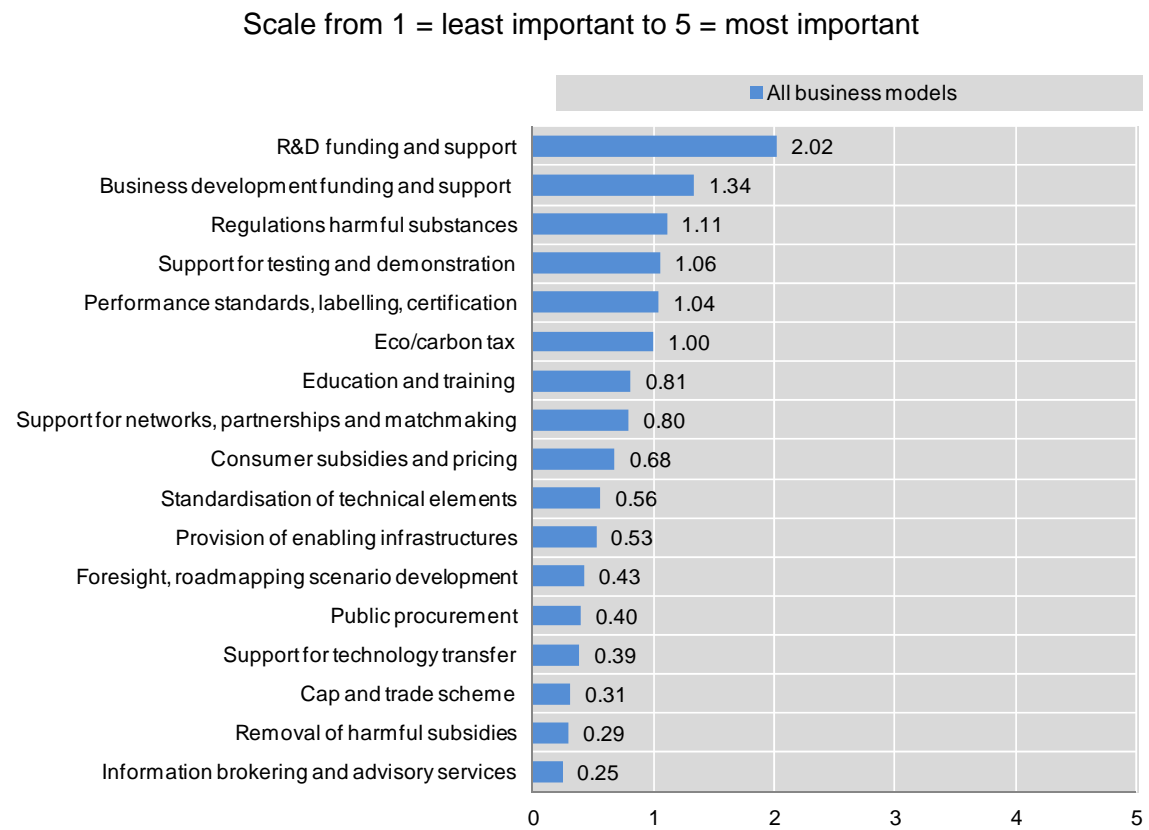

Notes: Companies were asked to rank the five most important policy instruments for advancing their organisations' eco-innovation activities.

Source: OECD case studies.

Supply side instruments are particularly important for companies' activities, the choice of partners as well as revenue streams. A number of areas were considered particularly important.

\section{Funding and support measures for $R \& D$}

The great majority of organisations and companies across business model categories and countries acknowledged the crucial role of public policy in supporting companies' R\&D efforts. Government support was given in several forms, such as research grants (e.g. in Belgium, Finland, New Zealand, Portugal, Spain, Sweden, United States, and at the European Union level) and matching grants (e.g. the Co-operative Research Centre funding model for the Kwinana industrial symbiosis project in Australia). A number of funding programmes and other measures target eco-innovations specifically, but some of the companies and organisations analysed in the case studies also benefitted from general support to R\&D. Some of the actors involved in green business models believe that more $R \& D$ support programmes aimed at green innovation would be helpful.

At the same time, several companies (especially SMEs) feel that administrative procedures for obtaining funding are too cumbersome, to the point that in some cases they were discouraged from applying by red tape and bureaucracy related to R\&D support programmes.

\section{Early stage business development}

In some countries, companies believe that public policies and programmes are well geared to support eco-innovations through the development and testing stage, but that greater consideration should be given to supporting the business development and commercialisation of such innovations. This is especially the 
case when green technologies and business models require significant investment in order to be brought to the market and scaled up. Venture capital investment is usually required at this stage, but because of the uncertainty surrounding eco-innovations and related risks, and the potentially high social returns, public policy may need to step in, at least at the initial stage.

In some cases, companies feel that the capacity of the public sector in managing programmes in support of eco-innovation can be improved. Often funding decisions are made by civil servants with a scientific background, but they may lack the skills required to appraise the commercial potential of the ecoinnovations. This can lead to a mismatch between the criteria required for R\&D funding from the government's perspective and the innovator's business model. For example, one company questioned the sequencing of grant disbursements in his country, where funding was given to business plans before the innovation had been conceptually proven or demonstrated.

Some companies also stress the crucial role of foreign markets for the scaling-up and business expansion of their eco-innovations. For example, in the case of LanzaTech, the government representation network of New Zealand abroad (through New Zealand Trade and Enterprise, as well as the Ministry of Foreign Affairs and Trade) was instrumental in enabling access to business contacts in overseas market during the commercialisation phase. However, in some instances there seems to be a mismatch between government support (which focuses narrowly on the domestic market) and the needs of the companies whose business model is oriented towards exporting innovative goods, services and processes to the global market.

Instruments supporting testing, demonstration, verification

Innovations do not come to the market straight from $R \& D$ : there are many stages of innovation from the conception of an idea to successful commercialisation as marketable products and services. The testing, demonstration and verification phases come just before commercialisation and are increasingly seen as critical. Demonstration involves tests of first-time or early-stage technologies and may be pilot or fullscale. Verification includes testing of ready-to-market technologies and reporting on their performance to guarantee their quality to users (OECD, 2010a).

The importance of these aspects of the innovation process is well understood and underlined by the organisations and firms covered by the case studies of green business models. There is a perception that testing and demonstration do not receive public support at the adequate level warranted given their prominence. This is especially the case for eco-innovations developed in the context of alternative energybased business models and sustainable mobility systems.

\section{Provision of enabling infrastructure}

Certain types of infrastructure are of crucial support for innovation activities. In particular, transport and ICT infrastructure is increasingly viewed as essential for economic success and raising productivity.

Provision of enabling infrastructure was ranked among the top three policy instruments for innovative financing schemes and green neighbourhoods and cities. For example, an enabling infrastructure and enabling technologies are important determinants of the success of green city projects. They can include ICT and satellite technologies that control the efficiency of processes, as well as infrastructures for water, energy, waste management and transport. In addition, the provision of enabling technology and infrastructure is shown to be a priority for ICT based solutions. There is a major role for Internet and wireless technologies, as many new ICT systems use Internet based platforms such as social networks in the case of Intelen, and online monitoring systems in TaKadDu. Key drivers for sustainable mobility models include co-ordination and planning capacity, supported by ICT and logistic systems that support 
the management and servicing of the fleet of vehicles or of batteries. An infrastructure is also necessary to support the vehicles, as are the technical teams that are responsible for servicing and maintaining the products and the network.

While confirming the importance of supply-side policies, an analysis of average ranks of policy instruments by business model category shows that demand-side measures and market-based instruments also play an important role (Table 4).

Table 4. Top three policy instruments, by business model type

\begin{tabular}{|c|c|}
\hline Type of business model & Top three policy instruments \\
\hline \multirow{3}{*}{ Greener product/process based models } & 1. R\&D funding and support \\
\hline & 2. Performance standards, labelling, certification \\
\hline & 3. Regulations on harmful substances and activities \\
\hline \multirow{3}{*}{ Waste regeneration systems } & 1. R\&D funding and support \\
\hline & 2. Eco/carbon tax \\
\hline & $\begin{array}{l}\text { 3. Support for testing and demonstration; regulations on } \\
\text { harmful substances and activities }\end{array}$ \\
\hline \multirow{3}{*}{ Alternative energy-based systems } & 1. Support for testing and demonstration \\
\hline & 2. Business development funding and support \\
\hline & 3. R\&D funding and support; eco/carbon tax \\
\hline \multirow{3}{*}{ Efficiency optimisation by ICT } & 1. R\&D funding and support \\
\hline & 2. Business development funding and support \\
\hline & 3. Standardisation of technical elements \\
\hline \multirow{3}{*}{ Functional sales and management services } & 1. Business development funding and support \\
\hline & 2. Consumer subsidies and pricing \\
\hline & 3. Regulations on harmful substances and activities \\
\hline \multirow{3}{*}{ Innovative financing schemes } & 1. Eco/carbon tax \\
\hline & 2. Provision of enabling infrastructures \\
\hline & $\begin{array}{l}\text { 3. Support for testing and demonstration; R\&D funding and } \\
\text { support }\end{array}$ \\
\hline \multirow{3}{*}{ Sustainable mobility systems } & 1. Foresight, roadmapping, scenario development \\
\hline & 2. R\&D funding and support \\
\hline & 3. Business development funding and support \\
\hline \multirow{3}{*}{ Industrial symbiosis } & 1. Foresight, roadmapping, scenario development \\
\hline & 2. Business development funding and support \\
\hline & 3. R\&D funding and support \\
\hline \multirow{3}{*}{ Neighbourhoods and green cities } & 1. R\&D funding and support; education and training \\
\hline & 2. Eco/carbon tax \\
\hline & 3. Provision of enabling infrastructure \\
\hline
\end{tabular}

Source: OECD case studies. 
Among demand-side measures, the following emerge as being particularly helpful:

\section{Regulations on harmful substances and activities}

Since its original formulation by Porter (1991) and Porter and van der Linde (1995), the notion that relatively stringent but well-designed environmental regulation (including regulation of harmful substances and activities) can spur innovation and improve competitiveness (the so-called "Porter Hypothesis") has received some theoretical and empirical support. ${ }^{8}$ Anecdotal evidence emerging from the case studies appears to confirm the hypothesis. Regulations on harmful substances and activities feature among the top three policy instruments for greener products and processes, waste regeneration systems, and functional sales and management services.

By affecting the consequences (e.g. health, safety, and environment) of products or services, these regulations can have a direct impact on demand for eco-innovations. For example, the experience of Waste Solutions with regulatory requirements for industrial, agricultural, food-processing and municipal waste water both in its domestic market (New Zealand) and internationally shows that clients will not move to adopting eco-innovations unless they are forced to, even when financial incentives are present.

Regulatory measures controlling the use of harmful substances were also very important in assisting the emergence of a very specific innovative technology in the functional sales and management services category of business models, i.e. Qlean's cleaning process based on the use of ultra-pure water. The fact that this technology has a negligible impact on the environment is the biggest advantage that Qlean has over most of the traditional chemical cleaning technologies.

In the case of the Kwinana industrial symbiosis project in Australia, regulatory pressure from the Department of Environment and Conservation (DEC) and the Water and Rivers Commission of the state government of Western Australia was considered a key factor. The air emission quality and water discharge quality standards helped to encourage the adoption of the innovation. In addition, improved water security, reduced energy costs, lower waste generation and improved waste storage all added to the benefits of the innovation. However, regulations were also considered barriers that prevented or delayed the implementation of synergies, e.g. existing water and energy utility regulations and environmental regulations requiring intensive approval procedures for by-product reuse (van Beers, 2008).

The case study of $3 \mathrm{M}$ illustrates how companies sometimes introduce innovative green business models not only in response to, but also in anticipation of stricter environmental regulations (see Box 11).

At the same time, some companies (even those who acknowledge the positive impact of regulation on innovation) hold that strict regulatory requirements can act as a barrier to their business models, for example as regards legislation on waste.

\section{Box 11. The impact of environmental regulation on green business models and eco-innovation: $3 \mathrm{M}$}

In the mid-1970s, most companies in the United States focussed on treating pollution through end-of-pipe technologies and processes to comply with the Clean Air Act and the Clean Water Act. But in 1975, 3M introduced its Pollution Prevention Pays (3P) Programme with the aim of preventing pollution at its source, rather than treating it. This approach was based on the premise that preventing pollution is typically more effective, more technically sound, and more economical than conventional pollution control to meet regulatory requirements, for example as regards reduction of volatile organic compounds (VOCs). At the time of the introduction of this programme, environmental legislation was inspired by criteria of treatment of pollution, rather than prevention. Therefore, $3 \mathrm{M}$ anticipated regulatory requirements later introduced by the United States Environmental Protection Agency.

Source: OECD case studies. 


\section{Performance regulations and standards, green labelling, and certification}

Performance-based approaches can encourage eco-innovations by providing firms with flexibility in how they achieve the desired outcomes and stimulate and try out new ideas, technologies and business practices. Information-based measures such as labelling and certification are also important for ecoinnovation, as they provide consumers with access to high quality, reliable information on green products and services and thus contribute to overcoming information asymmetries.

These measures were ranked on average as the second most important category of policy instruments in developing new green products and processes. The growing popularity of green labels and of introducing environmental management standards into companies has created new opportunities for the development of products with improved environmental performance. For example, the Federal Government's Water Efficiency Labelling Scheme in Australia was deemed to be a major driver in the duel flush toilet innovation. In Europe, the eco-label encourages companies to innovate to come up with ever greener products and services, by making it clear to consumers whether their purchases are environmentally sustainable. Another piece of EU legislation that was reported to have an impact not only on the innovative company but also on its suppliers is the Regulation on Organic Production and Labelling of Organic Products, as foods may only be marked as "organic" if at least $95 \%$ of their ingredients are organic.

Though they do not appear among the top three policy instruments, these measures also play an important role in stimulating eco-innovations in other business model categories:

- The products of waste regeneration can receive additional support from green labels and certificates, as in cases of the organic soil conditioner produced from olive waste (Humolea). Green or bio-labelling can pave the way to new markets for such products.

- Standards and green labelling appear to create incentives for some renewable energy based systems.

- Performance standards, labelling and certification all seem to be important factors that help to persuade potential customers to use ESCO services.

- In the case of sustainable mobility systems, stricter fuel economy or $\mathrm{CO}_{2}$ emission standards around the world have been among the main drivers of innovation for alternative-fuel vehicles, including electric cars.

- For green neighbourhoods and cities, strict emission standards and energy labelling for buildings have had a positive impact on firms that have adopted "greener" business models.

Finally, renewable portfolio standards or quotas (RPS) require that a minimum percentage of generation sold or capacity installed be provided by renewable energy. Obligated utilities are required to ensure that the target is met, either through their generation, power purchase from other producers, or direct sales from third parties to the utility's customers (Criscuolo and Menon, 2012). These measures aim to create a market for renewable energy and can contribute to fostering green business models in alternative energy-based systems. For example, Frito Lay reports that the State Renewable Portfolio Standards in Arizona supported its efforts to implement innovative renewable energy generation processes.

\section{Standardisation of technical elements}

Technology-based standards affect eco-innovation by setting technical specifications for ensuring interoperability, securing minimum safety and quality, achieving variety reduction (and thus economies of scale) and providing common information and measurement. The standardisation of technical 
specifications for environmental technologies is key to accelerating their successful deployment, as ecoinnovations are characterised by a high level of information asymmetry and uncertainty. Standardisation helps create critical mass in the formative stages of a given market. Standards can focus demand for ecoinnovations that might otherwise be spread over multiple technical solutions. They are especially important in network industries, in that they can facilitate a critical mass of users. In this connection, standards ease the emergence of technological platforms - independently supplied yet inter-operable components with shared technical standards.

Unsurprisingly, public support for the standardisation of technical elements is among the top three most important government instruments for business models focusing on efficiency optimisation by ICT. For example, standardisation is seen as a key driver of the deployment of smart grids by EDP Distribuição in Portugal, smart metering by Fifthplay in Belgium, and wireless technologies by Fulton Innovation in the United States. But technical standardisation is also pivotal for ESCO business models and functional sales and management services, as it tackles information asymmetries and removes customers' uncertainty. For example, in Cowell's view the setting of standards for LED lighting equipment under the Product Safety of Electrical Appliances and Materials Law in Japan favoured the company's business model by enhancing consumer confidence.

Some case studies pinpoint the importance of the international dimension of standardisation. International co-operation can play a crucial role in diffusing eco-innovative products and technologies. For example, international standardisation is essential for companies to deliver smart metering or wireless services on a wide scale, as different standards in different regions and countries would result in excessive market fragmentation. One company advocated the introduction of a single global standard for wireless power implementation through the collaboration of developers, manufacturers and distributors. This would go a long way towards solving several issues around wireless devices, such as: supply chain management, production costs, costs of implementation, device and infrastructure integration, efficiency, safety, power needs across a wide range of products and brand, and environmental impacts.

Blending or use mandates aim at a minimum share or quantity of biofuels in the transport fuel market. It emerges from the case studies that these measures stimulated R\&D and business development in advanced biofuels, although they were sometimes withdrawn (as was the case in New Zealand). At the same time, while blending requirements can be neutral for public budgets (unless they are accompanied by financial support for biofuels), the higher production costs of biofuels can result in increased fuel prices for the final consumer (OECD, 2008b).

\section{Consumer subsidies and pricing}

By providing market opportunities and price competitiveness to eco-innovative products and services, price-based instruments are considered by firms to help increase the market certainty and the confidence of innovators and investors, ultimately encouraging them to proceed with further investment in R\&D, product development and mass production. They can do so by raising the price of most pollutant and energyinefficient products and technologies, through fiscal and financial disincentives (e.g. environmental taxes and charges), or by lowering the price of cleaner products and technologies, through fiscal and financial incentives (e.g. direct subsidies and tax incentives).

Consumer subsidies and pricing measures are ranked on average among the top three policy instruments only in the functional sales and management services category of business models. Yet, the potentially useful role of pricing measures was mentioned by several other companies across business models, and in particular in the following areas: greener products and processes (e.g. subsidies for purchasers of reuse system houses, fiscal and financial incentives for energy-efficient products); alternative energy based systems (e.g. feed-in tariffs, other fiscal incentives for solar energy and renewable energy 
from biomass); efficiency optimisation by ICT (e.g. consumer subsidies on monthly fees for energy monitoring and saving devices); sustainable mobility systems (e.g. fiscal and financial incentives for alternative-fuel vehicles, eco-point system for car-sharing users); and green neighbourhoods and cities (e.g. eco-point system for housing).

\section{Public procurement}

Demand from public authorities through procurement can help create or enlarge markets for green products and services and influence production and consumption trends. In addition to its direct impact on the market, pro-innovation public procurement may also create indirect effects such as positive externalities and innovation spillovers.

However, government procurement does not seem to play a fundamental support role for the green business models in the case studies, with a few exceptions in the greener products and processes category and in alternative energy based systems. For example, among the government initiatives that would be most helpful to advance the use of natural refrigerants as cooling agents in refrigeration and airconditioning equipment, Refrigerants, Naturally! lists the specification of HFC-free refrigeration in public procurement contracts. According to Preseco Oy, innovative public procurement could be helpful in increasing demand for system-level solutions while reducing investment risks.

As for market-based instruments, they appear to create strong incentives for many of the eco-innovation types covered in the analysis:

\section{Environmental and carbon taxes}

Environmental and carbon taxes are an important component of the policy mix for "getting prices right", and thus sending the appropriate signals to firms (to invest in eco-innovation and improve efficiency) and to households and individuals (to internalise the environmental externalities generated by their purchasing patterns, and thus reorient consumption towards greener products and services).

The importance of carbon taxes is confirmed by the case studies of green business models, as they appear among the top three most important instruments for waste regeneration systems, innovative financing schemes, and green cities. In particular, carbon taxes are the main incentive for innovative financing schemes such as ESCO business models. This can be explained by ESCO's focus on controlling energy consumption and the associated carbon emissions. Some companies voice concerns over the current price of carbon emissions, which is considered to be too low and thus does not represent a strong enough signal for firms to "green" their business models.

Among market-based instruments, emission trading schemes were not considered to be very important by the companies included in the case studies, with some exceptions. For example, processing organic waste can result in dramatic reductions in, or a complete absence of, methane and carbon emissions. Therefore, a cap-and-trade scheme can serve as an additional incentive instrument to capture value by reducing greenhouse gas emissions and generating emission credits, which can be sold on the carbon market. A carbon trade scheme can also play a role in implementing bio-gas projects.

\section{Cross-cutting measures and the international dimension}

As for more cross-cutting measures, support for networks, partnerships and matchmaking emerge as moderately important from some of the case studies. Foresight, roadmaps and scenario development are among the top three policy instruments for sustainable mobility systems and industrial symbiosis. This is probably because both types of business models have large transformative potential that can help to reverse current unsustainable mobility and production patterns. Therefore promoting such projects requires the 
building of shared visions of the future systems and the design of roadmaps towards the realisation of these visions. The role of the public sector as a partner in championing such processes is crucial.

Finally, public support to technology transfers was also conducive to eco-innovation in one of the case studies of alternative energy-based systems. In this specific case, Waste Solutions reports that the Clean Development Mechanism (CDM) played an important role in facilitating the transfer of climate change mitigation technologies. 


\section{POLICY IMPLICATIONS}

Governmental policy has long been central in moving forward next-generation technologies and in promoting radical innovation and systemic changes (Scrase et al., 2009; OECD, 2011b). The role of governmental policy is also repeatedly stressed in the reviewed case studies. In particular, key messages from the case studies emerge in the following policy areas: financing; barriers to entry, exit and growth; IPR issues; skills; market creation and demand; entrepreneurship policies; and R\&D and innovation policies. Finally, the analysis points to the need for a coherent policy framework that is conducive to business development of eco-innovations.

Before considering the role of public policy, policy makers will always need to question whether the emergence of new business models and the related innovation can simply be left to the market or whether policies are needed to support it. It is important to carefully consider the rationale for policy intervention, analyse the relevant market or systemic failures that may provide a rationale for policy intervention (OECD, 2011b), and consider whether policy can efficiently lead to better outcomes.

Indeed, not all potential failures in innovation systems make government intervention necessary or desirable. There is often no guarantee that government policy will be able to address a market or systemic failure in a way that effectively improves the outcome, e.g. in welfare terms. Even where governments may improve welfare in principle, they may lack the means or information to do so in practice. Governments' space of action may be limited: in fact, policy or government failures are often the result of the same (e.g. informational) constraints as those faced by private actors. Awareness of the possibility of government failure and rigorous ex ante evaluation of policies can help to limit the risk of costly but ineffective intervention.

A final step, and often the most difficult, is to assess which policy mix is the most efficient to achieve public policy objectives in the area of green growth. Policy makers have a wide range of policy tools at their disposal but some are more efficient at achieving public objectives than others, and they have important interactions that may need to be considered.

Based on these considerations, the case studies and previous OECD analysis on green growth and green innovation (OECD, 2011a; 2011b), a number of implications can be drawn. These implications typically confirm previous analysis, although in some areas the perspective emerging from case studies is not well aligned with a public policy perspective. For example, firms may favour the use of consumer subsidies for their products, but such policies are typically very costly and inefficient in achieving public objectives.

\subsection{Market creation and demand}

In fostering eco-innovation, government policies should focus not only on the creation and supply of new technologies, but also on the diffusion and uptake of such innovations in the market place. Hence, policies to drive diffusion, strengthen markets for eco-innovations, and change user behaviour should be considered as part of the overall policy mix. ${ }^{9}$

The analysis of green business models illustrates the important role of market demand for the development and deployment of eco-innovations. Policy may intervene where the demand for innovations 
is insufficient or has not yet emerged but where a technology or product has a high potential social benefit; or where the articulation of demand may be insufficient, as human or social needs are not automatically translated into clear market demands. In particular, several case studies confirm that some barriers to ecoinnovations are not easily addressed by supply-side policies:

- Lack of demand for a product or technology may lead to a situation where "green" discoveries and prototypes reside in a "valley of death" between the invention of a product and its commercialisation.

- Demand-side policies can send a signal to economic agents that public policy is serious about green growth and committed to invest in the green transformation.

Market-based instruments, such as carbon taxes are an important component of the policy mix for "getting prices right", and help send the appropriate signals to firms, households and individuals to internalise environmental externalities. Such instruments are particularly important for business models focused on enhancing energy efficiency, such as energy saving companies.

Regulation of harmful substances and activities, performance standards, green labels and certificates, as well as technology-based standardisation, also appear to be important in developing new eco-innovative products, materials and processes. Public procurement also has a promising potential for ensuring the economic viability and diffusion of eco-innovative product and services. Consumer subsidies were also mentioned in several case studies, but are often an inefficient and costly tool to achieve public policy objectives.

The stability and certainty of the regulatory framework also plays a substantial role in long-term economic viability of many eco-innovations (OECD, 2011a). The economic opportunity for eco-innovative solutions and practices can only be unleashed with a sufficient level of regulatory certainty. To make longterm investments and commitments, firms require a stable regulatory environment and clear market signals, including a level playing field without competitive distortions (Meenakshisundaram and Shankar, 2010; OECD, 2011a).

Yet, one important finding emerging from the case studies is that companies value different types of policy interventions that are tailored to the specific barriers to be addressed, typically targeting one particular aspect of the innovation process. Policy makers have generally recognised that supply-push and demand-pull policies do not work well in isolation, and a mix of the two types of instruments is often to be preferred, thus allowing policy to address failures and barriers throughout the entire innovation chain.

\section{2 $\quad$ Financing}

The case studies confirm that finance is an important constraint for new business models, even if much of the financing comes from inside the firm, and some is provided by parent firms that may be at the origin of some new business models. However, financing is an important challenge for many young and innovative firms, and also for larger and riskier business models that engage in more systemic or radical innovations.

Policies to enhance access to finance for green business models are therefore important, particularly given the failures and constraints that are specific to markets for eco-innovation. In particular, there is a role for governments to help firms overcome the "valley of death" between the early R\&D, demonstration and verification stages and commercialisation of their eco-innovations. Thus, public policy should take steps to ease access to finance for new and innovative firms, both with respect to debt (which the case studies confirm to be a prevalent source of external funding among enterprises) and equity finance. This could involve risk-sharing schemes with the private sector. 
The case studies show that young, innovative firms adopting green business models often seek equity financing in the form of private equity, including venture capital and angel financing. However, few of them succeed, as the combination of high technology and market risk, high capital investment requirements and long payback periods tend to put off potential investors. Thus, governments can take steps to foster seed capital and start-up financing, for example by promoting venture capital as well as business angel funds and networks.

In addition to acting as facilitators and providing networking and matchmaking services, governments can also deploy public funds. But when they do so, policy makers should ensure that funds are channelled through existing market-based systems and private funds, and shaped with a clear market approach. Public policy should focus on using financial engineering approaches to develop the market for early-stage equity finance, rather than directly providing finance to private firms (OECD, 2011b).

Moreover, it is important to understand what is at the origin of the lack of finance. In some cases, the main bottleneck is a lack of high-quality projects and experienced entrepreneurs with the necessary business skills, rather than the funding as such. In this case, public policy may need to focus on the mentoring of entrepreneurs as well, e.g. in the context of so-called accelerator programmes.

Because of the relative dearth of venture capital investment in the early stages of development of innovative low-carbon business models, direct government funding can also be mobilised, while leaving a greater role for private finance in later-stage technology deployment and commercialisation. The rationale for government funding lies particularly in the potentially large gap between the social and private returns of eco-innovation, where private actors may not see a sufficiently large return on their investment if the social and environmental benefits could be large.

\subsection{Entrepreneurship policies and barriers to entry, exit and firm growth}

Unsurprisingly, entrepreneurship emerges as a key driver of green business models and related ecoinnovations, in particular for young and innovative firms. Entrepreneurs fuel innovation by developing new or improving existing products, services and processes. In several case studies, the generation of the idea leading to the business development of an eco-innovation and its subsequent commercialisation came from an "initiator" with a bold vision. Often, the same person also acts as the "champion", contributing the most to the success of the innovation.

The process of entry and exit of firms is an important driver of productivity growth and innovation. Market selection leads to the exit of less productive firms and the success of the more productive. Young, innovative firms are particularly crucial in this respect: they are more likely to exit, but those that survive grow more rapidly than mature firms. The contribution of new firms to productivity and employment growth is much stronger and positive in higher-technology industries, and there is evidence that entrepreneurs are particularly crucial in industries with technological opportunities. These include industries that address global challenges such as climate change (e.g. clean technologies, renewable energies (OECD, 2010c)).

The crucial role of young firms in introducing eco-innovations is confirmed by the analysis of case studies of green business models. The majority of firms in the sample are small or micro firms, and many of them are start-ups who have come up with a new, bold vision and are looking to exploit technological or commercial opportunities that more established firms have neglected or not yet explored. Indeed, challenging the existing way of doing things is at the core of innovative business models. This is especially evident in areas that require a systemic shift, as in mobility systems or green cities, but the disruptive effects of newcomers permeate all other types of business models. 
Some of the firms that introduced innovative business models as start-ups later grew to becoming medium or even large firms. For example, LanzaTech was founded in 2005 with a vision to be a dominant technology provider in the industrial bio-commodities area, aiming at developing and commercialising technologies for the production of low-carbon fuels that do not compromise food or land resources. At the time the case study was collected, the company had already grown to 60 employees. Better Place provides an even more telling example: the company was founded in 2007 as a venture-backed American-Israeli company based in the Silicon Valley, and by early 2011 it had become a large global company, with 450 employees.

At the same time, the case studies show that eco-innovative firms face high barriers to entry. Perverse subsidies to incumbents or policy measures that delay the exit of failing firms may stifle competition and slow the process of reallocation of resources towards the firms that are more innovative, productive, and bring about sustainable business models. Governments should remove barriers to the entry and growth of newcomers, thus unleashing their innovation potential. For example, it appears from the case studies of innovative financing schemes that decreasing or removing energy subsidies can have a positive impact on demand for energy efficiency and ESCOs. This is because subsidy removal makes the true cost of energy more apparent to end users and increases the incentives for efficiency (Vine, 2005). While not directly emerging from the case studies, barriers to exit such as bankruptcy regulations are important too; successful business models often require experimentation where talented entrepreneurs should be able to try again (Bravo-Biosca, Criscuolo and Menon, 2012).

It emerges from the case studies that in several OECD countries companies engaged in eco-innovation activities perceive burdensome regulations and complex administrative requirements as significant barriers to their business growth. Simplifying and reducing start-up regulations and administrative burdens can go a long way in lowering barriers to entry of newcomers, and later to their growth.

The case studies also confirm that new firms and business models may well face additional barriers to growth compared to existing firms. For example, new firms may find that their business model is not compatible with existing regulations and as such rules may not be sufficiently up-to-date. Governments can help such firms by providing tailored assistance, e.g. through a specialised portal, which can help enhance compatibility between government and entrepreneurs and also place new developments and opportunities for eco-innovation on the policy agenda.

Finally, in an effort to build the skills needed for operating in an international environment and help innovative small firms reach their growth potential, entrepreneurship policies in OECD countries have broadened their scope to include the establishment of one-stop shops, training programmes, networking activities, counselling services and support for internationalisation. Policy makers should ensure that these measures reach the right target audience or provide an adequate quality level of services, as companies interviewed for the case studies (especially SMEs) often seem to be dissatisfied with public support to entrepreneurship. Enhancing the efficiency of such measures is particularly important in the context of growing budget pressures in many countries.

\subsection{Intellectual property rights}

The weight attached to IPR by companies in the case studies of green business models underscores the crucial role of well-functioning systems of intellectual property protection and enforcement. The need to strike a balance between protecting IPR on the one hand and facilitating the access to and transfer of knowledge on the other hand is well understood by companies engaged in eco-innovation activities. Thus, governments should design IPR systems that are properly tailored to provide incentives for investment in innovation, while fostering the diffusion of knowledge and technologies. 
In addition, the case studies show that patents and other categories of IPRs are particularly important for young and innovative firms, especially start-ups that, unlike large and established firms, have few other means of protecting their innovations. IPRs facilitate young firms' entry into new markets and enable their competition and collaboration with other firms. They can also enhance firm's ability to access finance. Recent OECD work shows that, in the cleantech sector, entrepreneurial companies that are patenting are more likely to receive financing by private investors. The costs of IPR, including the possible costs of legal protection, are an important barrier for many business models, and in particular for SMEs. Governments should help ensure that young, innovative firms can easily and efficiently access the IPR system, and use it to create value from their intellectual assets.

IPR is also important to facilitate co-operation and partnerships with other companies. Many case studies stress the need for a balance between protecting their own IPR and sharing knowledge with other innovators and partners. Moreover, the case studies confirm that effective IPR protection is a means to facilitate technology transfer abroad where technology providers face the threat of imitation by local competitors.

\subsection{Skills}

The case studies of green business models confirm the high value of education and training to fostering eco-innovation. According to OECD (2012c), compulsory schooling should provide all students with strong skills in core fields, including mathematics and science, while tertiary education should train quality graduates, who can contribute directly or indirectly to innovation in their workplace, and also foster research excellence and links to industry. As illustrated by several case studies, eco-innovations are the product of multidisciplinary approaches, drawing on a wide range of technical expertise and scientific (as well as non-scientific) skills.

There appear to be relatively few unique "green skills", and vocational skills that are required in "green jobs" typically overlap with those used in similar non-green occupations. Nonetheless, some green occupations do appear to require new educational or training pathways, e.g. research and engineering positions in the renewable energies sector or system analysts who develop ICT support for smart grids (OECD, 2012c).

The case studies point to the existence of skills shortages in some countries and in specific occupations and business models, such as efficiency optimisation by ICT and innovative financing schemes (ESCO). Policy makers should ensure that the education and training system is well equipped to provide those skills, or support upgrading the skills of existing workers. As suggested in OECD (2012d), a labour market information system that tracks emerging skill needs and shares that information with labour market actors could play a useful role in this respect. Forecasting of skill needs or skill mismatches would be useful if it can be made to be sufficiently reliable.

The case studies also show that companies are increasingly collaborating with each other, but also partnering with universities and governments, to obtain the knowledge and skills they need for enhancing their capabilities to innovate. Policy makers should facilitate these partnerships by promoting collaborative mechanisms, knowledge networks and research consortia.

Finally, some case studies of green business models reveal a trade-off between the skills required for the management of day-to-day established business processes and the creativity and ability to think out of the box that are required for further innovations. As suggested by the OECD Innovation Strategy, although many decisions about how human resources are used and developed are the subject of firms' individual human resource management policies, governments may be able to shape national institutions to support higher levels of employee learning and training in the workplace. 


\subsection{R\&D and innovation policies}

The case studies confirm that government support to R\&D is pivotal to overcome some of the market failures and systemic barriers that may result in a slow transition to a low-carbon and energy-efficiency systems. They also illustrate the main sources of market failures that have traditionally provided the rationale for public funding of R\&D: i) R\&D activities often incur high fixed costs and economies of scale, while learning by doing gives rise to dynamic economies of scale; ii) investment in R\&D is inherently risky and information asymmetries abound in markets for knowledge and technologies; iii) knowledge has properties of public goods as performers of $R \& D$ can only imperfectly appropriate the results of their efforts, and the use of knowledge does not preclude its simultaneous use by others.

While many companies interviewed for the case studies have benefitted from general support to R\&D, some of them lament the lack of R\&D policies targeted at specific clean technologies and other forms of eco-innovation. Direct support for R\&D and innovation could have the advantage that it can be focused on activities and actors of greatest interest for meeting public policy goals. They may also help governments in meeting their targets to improve environmental outcomes. For example, as the search to develop, diffuse and apply low-emission technologies is taking place within defined time-horizons, direct and targeted support can help to meet such timeframes, in ways that more generic instruments might not.

In addition, policy makers should consider simplifying administrative procedures for obtaining funding and ensure that programmes meet business needs. Several firms, in particular SMEs, find existing procedures too cumbersome, to the point that in some cases they were discouraged from applying due to the red tape and bureaucracy related to R\&D support programmes. Moreover, in some instances there seems to be a mismatch between government support (which focuses narrowly on the domestic market) and the needs of the companies whose business model is oriented towards exporting innovative goods, services and processes to the global market.

Finally, policies to support the testing, demonstration and verification are considered critical by many firms, as these are important stages ahead of the commercialisation of technologies, in particular in areas such as alternative energy-based business models and sustainable mobility systems.

\subsection{Overall governance and broad framework conditions}

The role of the government was considered particularly important in supporting new partnerships and creating favourable conditions for new business models. Government support was especially significant in larger scale projects (e.g. green cities, industrial symbiosis, mobility).

Considering the impact of policies on business models to promote eco-innovation, the design of public policies supporting eco-innovation should explicitly consider the dimensions of business models. This reflection should take into account the possible wider impacts of business model changes on shifts in value creation, value chains and value systems. The impact of policies on new business models should be considered taking into account a mix of various policies, rather then singled out policy measures.

Several studies show that national policies that focus on energy and resource efficiency could encourage firms to adjust their strategies for gaining competitiveness. For example, the Eco-Town Programme promoting urban and industrial symbiosis in Japan gained its boost when the government put in place a comprehensive legal framework for a "recycling-based society" in 2001. There are many other examples of large-scale eco-innovative projects which would not have taken place without strong political support from the national government, clear, long-term and stable targets and high levels of regulatory stringency (Johnson and Suskewicz, 2009; Reiche, 2010; Chertow, et al, 2004; Carillo Hermosilla, et al, 2009). 
The need for policy support at the national level is often differentiated from policy support at the local level. The analysis of green business models points out the challenge of ensuring effective governance of support policies, as eco-innovation often has a strong local dimension. Aligning policies between local, regional and national levels is important to ensure that they are consistent, complementary and efficient.

Implementation of many eco-innovative projects requires active support and involvement of regional or local government and municipalities. Since the start of the building of a biogas-based transport system in Linköping, for example, local politicians have continued to drive the development of biogas and supported research. The success of this system comes primarily from "political consensus and the municipalities firm belief in the project" (Martin, 2009). Creating preferable market conditions for ecoinnovative firms by the local authorities also helps to sustain specific projects, as seen in the case of French advertising agency JC Decaux, which was given a monopoly over the large section of billboard advertising in Paris in return for operating the Vélib' bicycle sharing system (OECD, 2010a). 


\section{NOTES}

Commonly known examples of which include communal washing machines.

In this model the provider agrees with the client on the delivery of a result. The provider is completely free to choose how that result is then delivered. Typical examples of this form of PSS are companies that promise farmers a maximum harvest loss rather than selling pesticides (Tukker, 2004).

Johnson and Suskewicz (2009) focus on the role of enabling technologies in creating systemic shifts. The era of railways was catalysed by the invention of the steam engine and the creation of the microprocessor launched the information age. However, the real impact was felt only after broader systems, in these cases railways and the communication infrastructure, had evolved around them.

For a detailed discussion on the role of market demand in stimulating eco-innovation, see OECD (2012b), Driving Eco-Innovation: The Role of Demand-side Policies, forthcoming.

Total intermediate goods and services account for a larger share of total output than household consumption in the 33 OECD and non-OECD economies for which the most recent data are available, with only Chinese Taipei, Greece, Japan, Mexico and the United States being exceptions. Even in the latter economies, only services for final household consumption have a greater share of total output than intermediate services, while the percentage of intermediate goods in total output is higher than the corresponding figure for household consumption goods.

F-gases are, for example: chlorofluorocarbons (CFCs); hydrochlorofluorocarbons (HCFCs); and hydrofluorocarbons (HFCs). They contribute to GHG emissions and ozone depletion.

However, the use of patent counts as indicators of inventive activity also has some limitations, for example: not all innovations are patented; not all patented innovations have the same economic value; and the propensity to patent varies across countries and technological fields. Therefore, the number of patents is not necessarily an indicator of policy relevance, nor of market success or environmental benefit (OECD, 2011c).

The debate, however, is far from being settled. For example, recent evidence for the United States manufacturing industry show that the economic costs of environmental regulations are substantial (Greenstone, List and Syverson, 2012). Using detailed production data from nearly 1.2 million plant observations drawn from the 1972-1993 Annual Survey of Manufacturers, the authors estimate the effects of air quality regulations on manufacturing plants' total factor productivity (TFP) levels. They find that among surviving polluting plants, stricter air quality regulations are associated with a $1.6 \%$ decline in TFP. In particular, regulations on ozone, particulates and sulphur dioxide emitters have particularly large effects on productivity, while carbon monoxide regulations appear to increase measured productivity.

These policies are being developed in the context of a report OECD (2012b), Driving Eco-Innovation: The Role of Demand-side Policies, forthcoming. 


\section{REFERENCES}

Behrendt, S., C. Jasch, J. Kortman, G. Hrauda, R. Pfitzne and D. Velte (2003), Eco-Service Development Reinventing Supply and Demand in the European Union, Sheffield: Greenleaf Publishing

Bernauer, T., S. Engels, D. Kammerer and J. Seijas (2006), "Explaining Green Innovation - Ten Years after Porter's Win-Win Proposition: How to Study the Effects of Regulationon Corporate Environmental Innovation?", CIS Working Paper No. 17, Center for Comparative and International Studies (ETH Zurich and University of Zurich).

Bowden, S., K. Kearins, E. Collins and H. Tregidga (2010), "Good Water and Good Plastic?", Case Research Journal, 30(4), pp. 1-11.

Bravo-Biosca, A., C. Criscuolo and C. Menon (2012), "What Drives the Dynamics of Business Growth?", forthcoming STI Working Paper, OECD Publishing.

Broad Group, (n.d), www.broad.com, accessed September 2012.

Carrillo-Hermosilla, J., P. del Río González and T. Könnöla (2009), Eco-innovation: When sustainability and competitiveness shake hands, Palgrave Macmillan.

Chertow, M., W. Ashton and R. Kuppalli (2004), The Industrial Symbiosis Research Symposium at Yale: Advancing the Study of Industry and Environment, Yale F\&ES Publication Series, Report \#3: http://environment.yale.edu/publication-series/industrial_ecology/.

Chesbrough, H. and K. Schwartz (2007), "Innovating Business Models with Co-development Partnerships", Research Technology Management; 50, 1, pp. 50-55.

Christensen, J. (2004), Presentation at The Industrial Symbiosis Research Symposium at Yale: Advancing the Study of Industry and Environment, http://environment.yale.edu/topics/946.

Confino, J. (2011), Companies must push harder for sustainable growth, posted for the Guardian Professional Network, sustainable business blog, http://www.guardian.co.uk/sustainablebusiness/blog/businesses-social-environmental-impact-sustainable-growth accessed September 2011.

Criscuolo, C. and C. Menon (2012). "The role of government policies, local knowledge stocks and firms patenting activity for high-growth financing in clean technologies", forthcoming OECD Science, Technology and Industry Working Paper.

del Río González, P. (2009), "The empirical analysis of the determinants for environmental technological change: A research agenda", Ecological Economics 68, pp. 861-878.

EC (2011), "Innovation for a sustainable Future - The Eco-innovation Action Plan (Eco-AP)", Communication from the Commission COM(2011) 899. 
EC and COWI (2008), Innovative Business Models with Environmental Benefits, DG Environment, European Commission.

EPA (2009), "Green Servicizing" for a More Sustainable Economy: Key concepts, tools and analyses to inform policy engagement, EPA.

FORA (2010), "Green Business Models in the Nordic Region: A Key to Promote Sustainable Growth", FORA Green Paper.

Greenstone, M., J. A. List and C. Syverson (2012), "The Effects of Environmental Regulation on the Competitiveness of U.S. Manufacturing", NBER Working Paper No. 18392, Cambridge, MA: NBER.

Griliches, Z. and J. Schmookler (1963), "Inventing and Maximising", The American Economic Review, Vol. 53, No. 4 , pp. 725-729.

Hallegatte, S., G. Heal, M. Fay, and D. Treguer (2011), "From Growth to Green Growth: A Framework", NBER Working Paper 17841, Cambridge, MA: NBER.

Halme M., M. Anttonen, M. Kuisma, N. Kontoniemi and E. Heino (2007), "Business models for material efficiency services: Conceptualization and application", Ecological Economics, 63(1), pp. 126-137.

Haltiwanger, J., Jarmin, and R. Miranda, J (2009) Business Dynamics Statistics Briefing: Jobs Created from Business Start-ups in the United States, Ewing Marion Kauffman Foundation, Kansas City.

Huberty, M., H. Gao, J. Mandell, J. Zysman (2011), Shaping the Green Growth Economy: A review of the public debate and the prospects for green growth, The Berkeley Roundtable on the International Economy.

IGES (2011), "Green Economy for Sustainable Development: Japan should lead the policy shift towards global poverty alleviation", Policy brief, Vol.12, June 2011.

IIED (2009), Business models for sustainable development, www.iied.org/pubs/display.php?o=17056IIED, accessed December 2011.

India Governance Knowledge Centre (n.d.), Waste Concern - Bangladesh, http://indiagovernance.gov.in/bestpractices.php?id=161, accessed July 2012.

International Energy Agency (2011a), World Energy Outlook 2011, OECD Publishing.

International Energy Agency (2011b), "Energy-efficient buildings: Heating and Cooling Equipment", IEA Technology Roadmaps, OECD Publishing.

International Energy Agency (2012), Energy Technology Perspectives 2012: Pathways to a Clean Energy System, OECD Publishing.

Jaffe, A. B., R. G. Newell and R. N. Stavins (2000), "Technological Change and the Environment", NBER Working Paper Series No. 7970, Cambridge, MA: National Bureau of Economic Research .

Johnson, M. and J. Suskewicz (2009), "How to Jump-Start the Clean-Tech Economy", Harvard Business Review, http://hbr.org/2009/11/how-to-jump-start-the-clean-tech-economy/ar/pr. 
Louche, C., S. Idowu and W. Leal Filho (2010), Innovation in corporate social responsibility: how innovative is it? An exploratory study of 129 global innovative CSR solutions in "Innovative CSR: From Risk Management to Value Creation”, Sheffield: Greenleaf Publishing.

Mair, J. (2006), "Waste Concern: Turning a Problem into a Resource", Waste Concern \& IESE Business School Case Study, European Academy of Business in Society.

Martin, M. (2009), The "Biogasification” of Linköping: - A Large Technical Systems Perspective. Environmental Technology and Management, Linköping Universitet.

Meenakshisundaram, R. and B. Shankar (2010), "Business Model Innovation by Better Place: A Green Ecosystem for the Mass Adoption of Electric Cars", Oikos sustainability case collection, ICMR Center for Management Research, http://www.oikos-international.org/projects/cwc.

Mirata, M. and T. Emtairah (2005), "Industrial symbiosis networks and the contribution to environmental innovation: The case of the Landskrona industrial symbiosis programme", Journal of Cleaner Production 13, pp. 993-1002.

Nordic Innovation (2012), Green Business Model Innovation - Policy Report, Nordic Innovation, Oslo.

"Open Innovation in Global Networks", in OECD, Open Innovation in Global Networks, OECD Publishing. doi: $\underline{10.1787 / 9789264047693-4-e n}$

OECD (2008b), Biofuel Support Policies: An Economic Assessment, OECD Publishing. doi: $\underline{10.1787 / 9789264050112-\mathrm{en}}$

OECD (2009), Sustainable Manufacturing and Eco-innovation: Framework, Measurement and Industry and Policy Practices, Synthesis Report, www.oecd.org/sti/innovation/sustainablemanufacturing.

OECD (2010a), Eco-Innovation in Industry: Enabling Green Growth, OECD Publishing. doi: $\underline{10.1787 / 9789264077225 \text {-en }}$

OECD (2010b), The Impacts of Nanotechnology on Companies: Policy Insights from Case Studies, OECD Publishing. doi: $10.1787 / 9789264094635$-en

OECD (2010c), The OECD Innovation Strategy: Getting a Head Start on Tomorrow, OECD Publishing. doi: $\underline{10.1787 / 9789264083479-e n}$

OECD (2011a), Towards Green Growth, OECD Green Growth Studies, OECD Publishing. doi: $\underline{10.1787 / 9789264111318 \text {-en }}$

OECD (2011b), Fostering Innovation for Green Growth, OECD Green Growth Studies, OECD Publishing. doi: $\underline{10.1787 / 9789264119925-e n}$

OECD (2011c), Science, Technology and Industry Scoreboard 2011, OECD Publishing. doi: $10.1787 /$ sti scoreboard-2011-en

OECD (2011d), Better Policies to Support Eco-innovation, OECD Studies on Environmental Innovation, OECD Publishing. doi: 10.1787/9789264096684-en

OECD (2012b), Driving Eco-Innovation: the Role of Demand Side Policies, (OECD publishing) forthcoming 
OECD (2012c), "Green Growth and the Future of Aviation", Paper prepared for the 27th Round Table on Sustainable Development, 23-24 January 2012, http://www.oecd.org/dataoecd/13/38/49482790.pdf.

OECD (2012d), "The Jobs Potential of a Shift Towards a Low-Carbon Economy", OECD Green Growth Papers, No. 2012/01, OECD Publishing. doi: 10.1787/5k9h3630320v-en

OECD/Eurostat (2005), OECD/Statistical Office of the European Communities, Luxembourg (2005), Oslo Manual: Guidelines for Collecting and Interpreting Innovation Data, 3rd Edition, The Measurement of Scientific and Technological Activities, OECD Publishing. doi: $\underline{10.1787 / 9789264013100-e n}$

Osterwalder, A., Y. Pigneur and A. Smith (2010), Business Model Generation, www.businessmodelgeneration.com

Porter, M (1991), "America's Green Strategy", Scientific American 264, no. 4.

Porter, M. E. and C. van der Linde (1995), "Green and Competitive: Ending the Stalemate", Harvard Business Review September-October, pp. 119-134.

Reiche, D. (2010), "Renewable Energy Policies in the Gulf countries: A case study of the carbon-neutral 'Masdar City' in Abu Dhabi", Energy Policy, 38(1), pp. 378-382.

Rennings, K (1998), "Towards a Theory and Policy of Eco-Innovation - Neoclassical and (Co-) Evolutionary Perspectives", ZEW Discussion Paper 98-24.

Schmookler, J. (1966), Invention and Economic Growth, Cambridge, Mass.: Harvard University Press.

Scrase I., A. Stirling, F.W. Geels, A. Smith and P. Van Zwanenberg (2009), Transformative Innovation: A report to the Department for Environment, Food and Rural Affairs, SPRU - Science and Technology Policy Research, University of Sussex.

Smith, K. (2008), "The challenge of environmental technology: promoting radical innovation in conditions of lock-in", Final report to the Garnaut Climate Change Review.

Solar Sister. (n.d.), www.solarsister.org, accessed September 2012.

Steward, F. (2008), "Breaking the boundaries. Transformative innovation for the global good", NESTA Provocation 07: April 2008, NESTA.

Tukker, A. (2004), "Eight types of Product-Service Systems: Eight Ways to Sustainability, Innovating for Sustainability", Business Strategy and the Environment, 13, pp. 246-260.

Tukker, A. and U. Tischner (2006), "New Business for Old Europe: product-service development as means to enhance competitiveness and eco-efficiency",. Greenleaf publishing

UN Global Compact (2012), "Policy Measures to Support Inclusive and Green Business Models", Federal Ministry for Economic Cooperation and Development, Bonn/Berlin.

Van Beers, D. (2008), "Capturing Regional Synergies in the Kwinana Industrial Area. 2008 Status Report", Project 3B1: Capturing Regional Synergies in the Kwinana Industrial Area, Centre for Sustainable Resource Processing, www.csrp.com.au/publications/2008/pubs2008.html. 
Van Berkel, R., T. Fujita, S. Hashimoto, Y. Geng (2009), "Industrial and urban symbiosis in Japan: Analysis of the Eco-Town program 1997-2006", Journal of Environmental Management, 90, pp. $1544-1556$.

Vine, E. (2005), "An international survey of the energy service company (ESCO) industry" Energy Policy 33, pp. 691-704.

Waste Concern (2012), About Waste Concern, www.wasteconcern.org, accessed July 2012.

World Bank (n.d.a), "Urban Solid Waste Management", http://go.worldbank.org/A5TFX56L50, accessed September 2012.

World Bank. (n.d.b), "Energy - The Facts", http://go.worldbank.org/6ITD8WA1A0, accessed September 2012.

Yang, S. and N. Feng (2008), "A case study of industrial symbiosis: Nanning Sugar Co., Ltd. in China", Resources, Conservation and Recycling, 52(5), pp. 813-820.

Zott, C., R. Amit and L. Massa (2010), "The Business model: Theoretical roots, recent developments, and future research", Working paper WP-862, IESE Business School, University of Navarra. 


\title{
ANNEX 1: ECO-INNOVATION BUSINESS MODELS CASE STUDIES
}

\author{
Greener Products and Processes based Models
}

\section{Zero-waste powder coating, CSIRO}

The CSIRO powder coating does not involve toxic solvents and uses a vacuum shed that catches any powder coating that has been over-sprayed. This results in zero-waste during the application. The process is both more efficient and less environmentally harmful than traditional solvent-based coating technologies. The business model supporting this technology offers a number of benefits both for buyers and for the company selling the technology. Significant annual sales and cost savings are expected to result from its application. The innovative powder coating is estimated to be some $20-30 \%$ cheaper than the traditional wet paint technology which will result in savings in the Australian automotive industry alone of some USD 100 million per annum. This technology can be applied in the automotive, aerospace, furniture, plastic and wood product industries. This has ensured a relatively large market outreach, which is a significant addition to the business values/benefits captured by the company. Also, there is currently no competition and, as a result, further interest and demand is expected. The process has the same durability and performance as traditional powder coating technologies that are used mainly on inherently conductive or metallic products, which naturally facilitates electrostatic coating. www.csiro.au/

\section{Caroma dual-flush toilet, Caroma}

The dual flush toilet is an invention of the Caroma company. This is a water efficient toilet system that disposes of human waste into the drain line system, using less water than traditional single-flush toilet systems. The two-button dual-flush cistern allows the user to make the selection between half-flush or fullflush mode. The technology resulted in the development of new flush valve systems for the cistern tank, and a new generation of highly efficient toilet bowl designs. The system was introduced in the 1980s and since then, has been diffused all over the world. Considering the scale of diffusion, this invention has produced enormous savings in water, thus generating a high environmental impact. The business model supporting the dual-flush toilet system is centered on a product/technology that offers customers water savings in the use phase, which are then translated into financial savings. In comparison to the business as usual case, based on the single-flush toilet system, the business model for the dual-flush toilet offers considerable value both for the company and its customers. Customers are attracted largely by the fact that throughout the life-time of the system it will achieve water resources and financial savings. In addition, its technological simplicity, affordability and compatibility with the existing infrastructure add to its advantages and extend the value offered to the customer. The company or producer has captured value by reaching a wider market. Time has shown that the dual-flush system has become very successful, both in the original Australian and then in the global market. It has been widely welcomed by all types of customers including individuals, companies and public institutions. Many customers have chosen this system not only for economic but, increasingly, for ecological reasons, which points to the development of more specific customer groups with a high environmental awareness. The dual-flush toilet has also become a part of the eco-standards applied in sustainable houses and offices, which, in turn, has increased the market for this system. www.caroma.com.au

\section{Vanadium redox battery, UNSW}

The vanadium redox battery, developed by the University of New South Wales, is a type of rechargeable flow battery with improved performance. It can offer almost unlimited capacity by using larger and larger storage tanks. It can also be left completely discharged for long periods of time with no ill effects. The solutions used in the battery have an indefinite life and this provides low maintenance costs for 
the battery and ensures a long life-cycle. This innovation has not been introduced to the market and is currently being trialled in Australia, Japan, Canada, the United States, Europe and China. Overall, it is seen to have a great business potential, particularly in light of the increasing demand for large power storage applications, such as helping to average out the production of variable sources of power such as wind or solar energy. In addition, energy storage has been identified as an essential component of smart grids. The unique characteristics of vanadium redox batteries make them useful in applications in smart grids where the batteries must be stored for long periods of time with little maintenance. This has led to their adoption in large-scale, grid-connected applications such as load-levelling, back-up power for factories and energy storage for large wind farms. In the context of the business model, the company can expect to work for, or be contracted by, developers of renewable energy sources, municipalities, private and public organisations that will be promoting smart grid-based systems of energy supply. www.vrb.unsw.edu.au

\section{Eco-surfactant, Ecover}

Ecover has developed the world's first "Eco-Surfactant" using an energy-efficient and entirely biochemical production process powered by yeast. Surfactants, the active ingredient in the majority of household cleaners, are produced largely from petrochemical substances using high temperature and pressure processes. These petrochemicals do not biodegrade completely and therefore leave behind stable metabolites in watercourses and may be absorbed into soil, in both cases increasing environmental risk and hindering the use of sewage sludge for agricultural re-use as a fertiliser. Ecover has invented an innovative new process using a special 'bioreactor', a machine which provides the perfect breeding ground for yeast cells. In turn, this enables them to harness yeast's unique ability to combine water-soluble sugars and non water-soluble oils to produce what Ecover has termed an 'Eco-Surfactant'. This is the first time that a surfactant has been produced using an entirely biochemical, low energy process on such a scale. Eco surfactants have a number of unique and beneficial characteristics: due to the nature of the production process they are produced rapidly using low levels of energy and other resources; they reduce ingredient transportation miles as the required ingredients can be grown throughout Europe; they are completely renewable; they are as effective as petrochemical equivalents at a neutral $\mathrm{pH}$ level which is kind to the skin. Ecover intends to broaden the product folio and continue research to develop not only eco-surfactants for hard surface areas, but also for other areas (textiles, etc.) and licence the product. Ecover looks at the product as a whole: not only is the content completely biodegradable, all of Ecover's plastic bottles are made from green polyethylene from sugarcane, which is $100 \%$ renewable and recyclable with all existing petrol based polyethylene. www.ecover-ecosurfactants.com

\section{Earth tray, Roltex}

More and more businesses are looking to prevent waste through intelligent design of their products. Attention is paid to the reusability and biogradability of their products. Roltex, in response to demand from a major fast food chain, has developed the Earth Tray, the first $100 \%$ ecological tray for professional use. The Earth Tray is $\mathrm{CO}_{2}$ neutral and consists exclusively of regenerative and sustainable raw materials. The tray also has a sustainable surface design. The raw materials for normal trays - cardboard and phenol resin - were replaced by hard cardboard originating from FSC certified forests and organic resin obtained from bio waste. Thanks to the method of watercolour printing and the use of natural colours, the tray has the same look as traditional trays. Ultimately Roltex wants to join forces with fast food chains to set up a system in which end of life serving trays are returned to the factory for ecological processing. www.roltex.be/

\section{Green cleaning products (INTEMAN)}

INTEMAN, an SME, was founded in 1980 and its activity has been traditionally centred in the chemical sector. The activity of the company has moved recently towards the development and manufacture of 
biological products that are more respectful of the environment and safer for the people who handle them. INTEMAN has developed a new strategy to open new markets whereby it is reengineering all its products, by changing the chemical bases to biological, non-contaminating, safer and more effective bases that are less harmful for the environment. This new strategy "Eco-design" produces "green" cleaning products to be used by the institutional, industrial and commercial cleaning industry. INTEMAN is particularly targeting the food industry which is regulated increasingly by Hazard Analysis Critical Control Point (HACCP) that is a systematic preventative approach to food safety that addresses physical, chemical, and biological hazards as a means of prevention rather than finished product inspection. The environmental improvements are due to the application of natural substances (surfactants, enzymes etc) to increase the biodegradability and eliminate the ecotoxicity, together with packing waste reduction. The sales of the products have increased in the last two years. Twenty three eco-designed products have been incorporated into the firm's catalogue and in June 2010 they represented $5.8 \%$ of its turnover. Sales networks have expanded all over Spain and INTEMAN is looking to expand in Europe.

\section{BIONADE , BIONADE}

BIONADE is a completely new kind of soft drink produced by fermentation that offers consumers an alternative to conventional carbonated soft drinks. The invention has opened up a new line of business in the market for beverages. The original idea was to produce a healthier type of soft fizzy drink for children as an alternative to conventional high-sugar soft drinks. BIONADE is a fermented and carbonated beverage, which is manufactured in an organic way, similar to the brewing methods used to produce beer. The brewing process converts the malt sugar into gluconic acid instead of alcohol. This is a natural ingredient of bee honey. Because gluconic acid is a weak acid, BIONADE needs only a fraction of the sugar found in a normal soft drink. No other chemical additives are used. The natural juices and extracts used to flavour BIONADE stem from organically farmed fruits and herbs. The product promotes a sustainable way of doing business and drives organic farming. It is available to consumers in restaurants, at supermarkets, etc. in Germany and is being expanded internationally. The company keeps its business activities and the generated added value within the region as much as possible by working closely with the Rhön Biosphere Reserve, a nature reserve, in which its production site is located. Employees, raw material suppliers, and other firms in the supply chain benefit from this approach. www.bionade.de/

\section{Reuse system house, Sekisui Chemical Co. Ltd.}

The Sekisui Chemical Co. Ltd. uses a construction method in which the units of a house are constructed in the factory and the units are transported to and assembled at the site. In 2002, the company started to offer the "reuse system house" where the house units are reused when rebuilding a house, to provide the same quality and function as the original model, and the residential structure can be exchanged freely from the old unit to fit the demand. There are different demands for house structure such as space and layout as the lifestyle of residents and family members change over time. The reuse system house is innovative in that it fulfils those demands, deploys the latest technologies to realise energy and resource saving in rebuilding, and addresses the issue of the lack of landfill sites in Japan. Techniques to recover the ruggedness of the house and techniques to take back used-houses (to disassemble and transport usedhouses) were developed. Since the units are reused, resources and energy for house construction are saved. According to a Life Cycle Analysis (LCA) calculation made by the company, a reuse system house has the effect of saving substantial $\mathrm{CO}_{2}$ emissions, approximately $7 \%$ less, and costs approximately $20 \%$ less than a new house. During the period 2009 to 2012, purchasers of reuse system houses received a subsidy from the government. The number of the sales had been about 10 per year, but during that period it rose to 20 per year. The Japanese Eco Products Award accorded to the company increased its visibility in Japan. Rather than being the mainstay of the company, this business is conceived to be part of corporate social responsibility. To explore market opportunities, the company has collaborated with some universities and discussed future business opportunities. www.sekisuichemical.com/ 


\section{Cork-based absorbents, Corticeira Amorim}

The CorkSorb range developed by the Amorim Group is designed to be an effective, environmentally friendly and sustainable solution in the combat of a variety of oil and hydrocarbons spill situations. It uses heat treated cork as an absorbent to increase its absorbency and hydrophobic characteristics (does not absorb water). By selectively absorbing oil and hydrocarbons and not water, CorkSorb avoids unnecessary waste absorption and minimises waste which then has to be treated. This allows a significant reduction in costs for the customer. The CorkSorb products are a natural and technically efficient alternative to the polypropylene based products that dominate the market. CorkSorb absorbent material (100\% natural cork) is produced by taking advantage of the manufacture process of other products in the Amorim Group and thus does not require input of energy, does not generate waste and does not emit into the air, water or soil. Cork can be used in many applications connected with pollution control and the experience obtained with the CorkSorb range is very useful for developing future products in this area. The Corksorb product range came to market in early 2010 and is steadily building up a good brand reputation in the international market with about $87 \%$ of its sales exported. Corksorb is currently sold in 21 countries, including Spain, Germany, France, Morocco, Canada, Australia and South America. www.corksorb.com/ www.amorim.com/en/

\section{LIFE, LIFE Consortium}

The Life Consortium project LIFE (Lighter, Integrated, eco-Friendly and Efficient aircraft cabin) developed a visionary concept for an innovative executive aircraft cabin focusing on the use of natural and sustainable materials such as leather and cork. The LIFE project, with an investment of EUR 1.85 million, is funded by the Portuguese National Strategic Framework Programme. The concept allows for a better conciliation of executive and private uses within the same aircraft as the cabin is divided accordingly and different elements are multi-functional to serve both ends. Floating on a suspended carbon fibre structure, the seats enhance passenger comfort by reducing vibration, and are designed to integrate biometric sensors to monitor the passenger's body temperature and heart rate. LEDs and motion sensors embedded in composite and cork sandwich side and ceiling panels provide each passenger with "personalised light intensities and colour". Efficiency and cost reduction are also part of the design and development drivers that are reflected in the use of natural and lighter materials with stronger environmental performance than the traditional alternatives. Energy use in standard systems is also reduced, e.g. the lighting system that uses LEDs and optical fibres to replace traditional lighting systems is lighter and more energy-efficient, resulting in reduced fuel consumption. The different solutions that were developed with LIFE are now being further developed for commercial purposes. Some of the solutions generated spin-off projects, and some are starting to be applied in the aeronautical industry. This project has also allowed participating companies to consolidate and develop new capabilities to approach the highly competitive aeronautical interiors market, positioning themselves in the early stages of development of new cabins and related systems. life.inegi.up.pt/

\section{Eco-featured tiles, Revigrés}

Revigrés produces a diverse range of eco-featured ceramic wall and floor tiles with technical, aesthetic and functional advantages. These include Light, Solar, Self-Cleaning, Sense, Health Care Tiles and Ecotech. Revigrés opted for eco-design, the rational management of natural resources and energy, prevention of emission (solid liquid or gaseous) in production and transport processes and the reuse of recycled waste. Some tiles are a result of in-house innovation, others of collaboration. For example the solar tile was developed by a Consortium made up of parties with different backgrounds: industry, research and government. The Solar Tiles Consortium, of which Revigrés is the promoter, is supported by the Portuguese National Strategic Reference Framework (NSRF). The solar tiles are equipped with photovoltaic cells and have a triple functionality: they protect the roof and walls of a building from heat, 
cold and rain, they convert sunlight into electricity and they promote greater architectural integration. The aim is to develop and manufacture wall and roof tiles that look like traditional tiles. All products are produced to take into account environmental protection, energy efficiency, preservation of health and well being and greater architectural integration. The development of multi-ceramic products with higher value added will contribute to increased competitiveness in the ceramic industry by offering new products and solutions. The future development of products will be of an inclusive nature, with, for example, tactile and environmentally responsible flooring, safe for people with special mobility needs. www.revigres.com

\section{NetOLift, Orona}

"Net0lift", Orona is a research project that aims to develop new concepts to produce zero energy lift systems, which are safer, smart, more accessible and friendly. The project sets environmental, social and financial sustainability objectives. "Net0lift" is a consortium of 12 companies led by ORONA. The cooperation between partners is driven by the complement of technologies: manufacturers of full elevator systems and products or services suppliers. The project has recently been finalised after four years, with a budget close to EUR $27.5 \mathrm{~m}$, and the resulting innovations have been included in the new models of lifts which are being marketed. The new lifts will include improvements such as capacitor systems adapted to elevators to accumulate the saved energy, software for smart energy management, and new lighter materials to reduce energy demands. Environmental sustainability will be ensured by promoting the regeneration of new energy neutral building concepts, by generating more rational urban models and "sustainable cities" through the application of the 4 Rs (Reduce, Reuse, Recycle and Recover) in lift systems to minimise their environmental impact. Social sustainability objectives will be met by defining new lift solutions for people with mobility limitations, which are more intelligent, and enable greater autonomy. Financial sustainability is expected through economical lift solutions which are more compact requiring less space and smaller power installations. These lifts are expected to result in $45 \%$ energy saving and $50 \%$ power reduction to operate. Another project output is the possibility to expand the concept of smart energy management from the lift to other systems (e.g. moving walk ways). Orona IDeO- innovation city will be a demonstration of this last idea, and it could be considered a continuation of "Net0lift" project in a new scenario. New services and employment will be developed from this future project. www.oronagroup.com

\section{Pollution Prevention Pays (3P), 3M}

3M through its benchmark programme Pollution Prevention Pays (3P) benefits from corporate culture where from the top down and broad-based employee engagement the company is committed to innovation and whereby the strategy is integrated across the company's business functions. The 3P programme helps prevent pollution at the source, in products and manufacturing processes, rather than removing it after it has been created. $3 \mathrm{M}$ is a diversified technology company with 45 technology platforms: its products range from health care and highway safety to office products and abrasives and adhesives. The 3P programme encourages and recognises ideas and innovative thinking by $3 \mathrm{M}$ employees that result in greater efficiency and more sustainable environmental improvement. Projects qualify for 3P if they prevent pollution by reducing or eliminating pollutant of concern or energy consumption and if they also provide a monetary benefit to $3 \mathrm{M}$. Upon introduction of the $3 \mathrm{P}$ programme employees were encouraged to eliminate or replace the solvents that they had used for decades. Early 3P programme efforts included 3M Scotch Magic tape being reformulated to a water-based formulation resulting in thousands of tons of VOCs being eliminated, about USD 1 million cost savings, and avoidance of pollution control (which represent additional cost savings); and 3M Box Sealing tape being reformulated and changed to a new hot melt coating process with similar results. 3M has continued to develop new water-based and hot melt tape products, as well as explore other solvent-less coating processes. The company increasingly relies on pollution prevention and design changes in products and processes, and internal recycling. Significant repeat savings occur through lower operating costs from pollution treatment, decreased raw material needs, reduced energy 
consumption, and increased sales of existing or new products. The projects that have been implemented have enabled the company to reach the 3-billion-pound pollution prevention milestone and produce over USD 1.4 billion in cost savings. 3M has become more competitive because of its 3P projects, since they reduce costs, save resources, and provide customer value. One unanticipated offshoot of 3M's environmental programme has been its development of new products that were only possible because of the company's new solvent-less processes. In 2010, 3M developed its first set of sustainability goals that go beyond the environment and now include social responsibility and economic objectives. By 2015 the company wants to reduce volatile air emissions (15\%), waste (10\%) and greenhouse gas emissions (5\%). $3 \mathrm{P}$ will be a key contributor to progress towards these goals. $3 \mathrm{M}$ will continue to seek partnerships with environmental organisations, such as the United States. Environmental Protection Agency and Department of Energy's ENERGY STAR Program, to address climate change. www. $3 \mathrm{~m} . c 0 \mathrm{~m}$

\section{Natural refrigerants, Refrigerants, naturally!}

Refrigerants, Naturally! (RN) is a global initiative of companies committed to combat climate change and ozone layer depletion by substituting harmful fluorinated gases ('F-gases', such as CFCs, HCFCs and HFCs) with natural refrigerants with a focus on their point-of-sale cooling applications. Point-of-sale cooling may include the entire retail infrastructure, e.g. HVAC, but excludes manufacturing and distribution. Refrigerants, Naturally! is supported by Greenpeace and the United Nation Environment Programme and recognised as a "Partnership for Sustainable Development" by the UN Commission on Sustainable Development. The Refrigerants, Naturally! initiative was launched in 2004 by The Coca-Cola Company, Unilever and McDonald's. These companies committed to an HFC-free future during the "Refrigerants, Naturally! Conference 2004", where innovative technologies were showcased. In 2005, the Refrigerants, Naturally! initiative was the recipient of the United States. Environmental Protection Agency's Climate Protection Award. Current membership also includes PepsiCo and Red Bull. Over the last years these companies have, together with their suppliers, developed and tested new technologies and placed natural refrigerant using equipment on the market. Together these companies are reducing their impact on climate change by replacing refrigerants with HFC-free cooling agents, by using HFC-free insulation material, and by reducing the energy consumption of new refrigerating equipment. To date they have collectively phased out more than 1 million tonnes of $\mathrm{CO}_{2}$ emissions equivalent based on the avoided HFC refrigerant emissions and they have collectively placed more than 2.5 million HFC-free refrigeration units in almost all countries around the world. $\mathrm{RN}$ is encouraging other major companies interested in HFC-free technologies to join their partnership initiative. New partners will be expected to contribute resources in terms of internal research and development/investment in alternative refrigeration technologies.www.naturalrefrigerants.com/

\section{Sustainable cuisine programme, Xanterra parks \& resorts}

Xanterra's sustainable cuisine program is a means to provide higher quality and healthier menu offerings for its guests and employees. It is the practice of using food products that are grown, harvested, processed, packaged, and distributed with the least amount of environmental impact. Typically these products are locally sourced, sustainably or organically grown, or third-party verified as having a reduced environmental impact. Xanterra's Environmentally Preferable Procurement (EPP) Program is substantial and includes: i) an EPP policy with quantifiable goals and targets; ii) a formal assessment protocol to determine if a product or service is environmentally preferable; and iii) a sustainable cuisine program to purchase more organic, local, and/or sustainable food products. Xanterra is able to implement its sustainable options in remote locations and track its sustainable cuisine purchased and sold through its computerised Ecometrix tracking system. The programme improves guest satisfaction, and reduces the company's impact on food systems, and the resulting pollution and fossil fuel consumption associated with less sustainable food options. Xanterra constructed greenhouses on site at two locations and began growing its own vegetables and serving them to guests. In the greenhouses, no fossil fuels are used in harvesting, 
processing, packaging, or transporting the harvest to market; no trees are used in packaging; and everything is organic and fresh. Where possible, Xanterra composts food scraps to provide plant nutrients for their on-site gardens, uses rain barrels to reduce water consumption, and also practices natural pest control methods instead of using pesticides. Xanterra's sustainable cuisine purchases have increased from USD 1.4 million in 2004 to USD 5.7 million in 2009, a 307\% increase in five years and these represent nearly $20 \%$ of all its food purchases. The goal is to increase purchases of sustainable cuisine items to $50 \%$ of all company-wide food expenditures by 2015. A Sustainable Cuisine Task Force determines what meets Xanterra's definition of sustainable, shares vital product information, and assists all Xanterra properties in achieving their sustainable cuisine goals. www.xanterra.com

\section{Waste regeneration systems}

\section{Enhancing the value of bauxite residue, Alcoa}

A bauxite residue commonly known as "red sand" is a by-product of alumina production. Alcoa currently produces around 3-4 million tonnes per annum of this red sand residue. Up until now, Alcoa Western Australia had stockpiled the red sand at their plant. The proposed eco-innovation will recycle 'red sand', and use it in a wide variety of applications. In comparison to the former situation whereby this by-product was deposited as waste, the new method provides a number of benefits for Alcoa, including the provision of a new product that can replace virgin sand materials in a wide variety of applications such as cement formulations, road bases, landfill and top soil dressing. By introducing this innovation, Alcoa has managed to reconfigure the value chain by turning waste into a product, assigning an economic value to it and capturing this value by selling it to other industries, as well as by reducing the company's resource inflows and the associate costs. In addition, the recycling allows Alcoa to significantly reduce their stockpiling-related costs and assists it in the long-term management of its production waste. New revenue streams and cost savings are the central economic value capture of the business model adopted by Alcoa. Along with the environmental benefits associated with this model, it offers branding value - the image of being an environmentally responsible company. www.alcoa.com

\section{BioBooster, Grundfos}

BioBooster is a wastewater treatment plant that cleans wastewater for reuse. The biological wastewater treatment solution has a small footprint compared to existing technologies treating the same volume of wastewater. The removal of pollutants from waste water (bacteria and other such as phosphor and nitrate) ensures a healthy aquatic environment. The treated water is of high quality and can also be reused for irrigation of crops, parks and other recreational areas; thereby reducing fresh water consumption. The decentralised treatment plant is an onsite installation which eliminates the need for investments in infrastructure by which waste water is led in pipes via a pumping station to a centralised waste water plant. By eliminating the infrastructure of pipes and pumping stations, $\mathrm{CO}_{2}$ emissions are reduced. Electricity consumption is no higher than that of existing systems. The combination of compactness, treatment capacity and electricity consumption makes it an innovation within the field of biological waste water treatment. The technology has been installed in 14 sites (permanently in three sites) and target users are: small communities with Person Equivalent (PE) 500-5000, food and beverage manufacturers with PE of 2000-5000, and resorts and hospitals etc. The product will be made available in three European countries and in the United States. Sales, marketing and distribution are currently centralised in Denmark. The innovation led to the creation of 45 jobs within the Grundfos organisation. www.grundfos-biobooster.com/ 


\section{Sustainable olive oil production, Humolea}

Humolea uses the residues of olive processing to produce high-quality soil conditioner. All the treatment processes for olives produce some liquid and solid wastes, which are toxic. This invention includes a novel method of turning olive residues into a high-quality soil conditioner. The soil conditioner is produced exclusively from plants, and it has proven to be ideal for the cultivation of many products such as citrus fruits, vines, aromatic herbs and asparagus. Traditional olive waste treatment methods such as aerobic/anaerobic biological treatment, incineration or gasification, do not generate any recycled products and have not been technically efficient or cost effective. Humolea's business model associated with the innovation reconfigures the value of the waste by processing it and upgrading it to a valuable product. It proposes a new value chain associated with the new product and the business model enables the value from it to be captured. It also offers a number of other attractive values. Notably, it allows farmers to switch easily to biological cultivation and enter the bio-products market, which offers a promising economical profit perspective, as the price of biological olive oil is 1.5 times higher than the price of the olive oil deriving from "chemical" cultivation. www.humoolea.com

\section{ECOVIA, Brisa}

LIFE ECOVIA is a project led by Brisa, Auto-Estradas de Portugal, S.A., the largest motorway operator in Portugal with a global budget of EUR 1235 454, co-funded by the European Union within the scope of the LIFE environment programme. The project aims to create new material from the recycling of Cardboard Packages for Liquid Food (CPLF), granulated rubber from used tires, and mixed plastics residues, to be used on motorways. A range of options were considered with three products selected and produced: fencing posts to replace the current wood posts used to boarder the motorway, pathways for telematic sites to aid technicians to access these sites and stone kerb protectors that are positioned on the kerb stones beneath toll machines. The benefits expected include: an increase in rubber, mixed plastics and CPLF recycling rates, production at competitive prices of new products with the same technical specifications of currently used products, and an increase in road safety. The advantage with the ECOVIA products is that there is no need for a specific plant to manufacture these products, several plastic recycling units worldwide would be able, with some adaptation and given the correct specifications, to manufacture these products. Therefore, it should be quite easy to replicate the manufacturing at other locations. New products such as sound-proofing barriers and anti-glare protection will be tested in the near future. The potential for the market is large as the road network is extensive. www.ecovia.brisa.pt/uk

\section{Reuse of leather (CARRE), Tecmacal}

TECMACAL is a market leader in sales of machines to the footwear industry. It also has a large number of machines installed across other industrial sectors. In response to demand TECMACAL has produced a new machine that reuses leather that has been recuperated from wastes from the footwear, leather goods and textile industries. This machine combines the various pieces of leather, which have been previously prepared/cut, and produces leather blankets that can be used as raw material for the manufacture of new products such as bags, wallets, accessories, etc. This project "CARRE" is a result of co-operation between TECMACAL, a client, the Technological Center of Footwear (CTC) and Instituto de Engenharia Mecânica e Gestão Industrial (INEGI). The machine can be used for all types of products that can be manufactured in leather or similar materials (shoes, wallets, textiles, etc). The amount of the investment depends on customers' specifications and on the size of machine. www.tecmacal.pt

\section{Ecoera Biochar, Ecoera}

The process, which is the foundation of Ecoera's business, starts with by-products from agriculture that do not have traditional areas of use. These residues are usually land filled and are therefore a potential 
source of methane emissions. Using these residues as raw material, and blending them according to specific proprietary formulas, Ecoera manufactures "Bio-agropellets" which are combusted in a lowoxygen environment in a process called pyrolysis. This produces agricultural biochar or Bioagrochar" which, when assimilated in soils, removes carbon, and during pyrolysis produces syn-gas, which can be used for heat or bio-fuel production. The business model that evolved around this innovation offers a new type of climate compensation service, so called "Biochar Carbon Sequestration"

The system enables a bridge to be made between agricultural soil carbon and the Carbon Accounting Systems of companies. On the farm, the biochar creates a provisioning for the soil ecosystem service. Also, it lowers the methane emissions from crop residues by turning them into biochar carbon. It has been shown that the biochar from Ecoera has increased the soil's nitrogen-holding capacity. Currently this voluntary climate compensation is sold to emitters at a higher rate. The rate will go down as the system is scaled up. In the end and with the right policies, farmers should be able to be paid to store carbon in their soil. This would be a "fair carbon tax". Ecoera has its own equipment to produce biochar and is also using subcontractors to manufacture biochar-producing equipment. www.ecoera.se

\section{Alternative energy-based systems}

\section{Bio-carbon, Preseco Oy}

Preseco Oy is a Finnish environmental technology company that solves challenges related to biowaste. Preseco delivers facilities and equipment for water and waste water treatment as well as bio-waste refining. It aims to deliver integrated solutions with its partners and has initiated the development of bio-carbon technology. Preseco's carboniser plants are designed to produce high-quality bio-carbon from a variety of organic materials by means of pyrolysis burning technology. Bio-carbon ${ }^{\mathrm{TM}}$ is a bio-fuel with a superior energy value and very low emissions that can be used in applications where coal is used at present. This is an advantage for the Bio-carbon ${ }^{\mathrm{TM}}$ producers and sellers, as well as for the users. Preseco has developed and tested the technology and is commercialising the technology by means of licensing. Other companies can then use the pyrolysis technology to transfer organic waste into a coal-like product with high energy content and use it as a resource or bio-fuel, instead of land-filling, burning or digesting the waste.

\section{PanePowerTM solar windows, Brite Hellas}

Brite Hellas is a start-up from Greece that was established in 2009 and currently has 10 employees. It intends to introduce solar windows onto the market. These windows have an energy demand reduction effect, as they reduce the use of air conditioning and, at the same time, produce electricity by means of a solid electrolyte $\mathrm{TiO} 2$ nano-coating. Thus, they could become an important feature in zero-energy buildings. Brite Hellas has developed a cheap process for their mass production. The business model is based on selling a product that reduces energy consumption and produces electricity, which makes it economically viable to buy. Traditionally, buildings have coloured panes and air-conditioners for climate control and may have separate solar panels for electricity production. When using solar windows, the energy needs for AC are reduced and electricity is produced by means of integrated photovoltaic (PV) cells. This could be both better and cheaper than other options. www.britesolar.com

\section{Super critical water reactor, Solray Energy Limited}

Solray Energy applies super critical water technology to the production of commodity chemicals using different types of bio-mass, but mainly bio-waste, as feedstock. Conversion occurs through a combination of heat, pressure, catalysts and timing and it uses super critical water that is heated to a temperature in excess of $300^{\circ} \mathrm{C}$, with pressure above $20 \mathrm{Mpa}$. Subsequent to the reactor stage, a solvent is 
used to extract the commodity chemical, which is bio-crude oil, from the sludge residue. At present, the development is at a pre-commercial testing point. The potential target users are wide, and include organisations that are harvesting algae via wastewater treatment or as a method of cleaning up eutrophic lakes. Target users also include facilities that have an abundance of sawdust or lignin, such as paper mills, saw mills, forestry industries and energy crops producers. Solray wants to use its IPR to enter into concurrent co-development arrangements to get to the market. In this way, the technology will be spread and organic waste can be transferred into a crude oil type of product by means of a super critical water reactor, instead of being land-filled, burnt or digested. www.solaray.com.au/

\section{Cigar ${ }^{\circledR}$ Biogas Reactor, Waste Solutions}

Waste Solutions started as a New Zealand government research institute, but is now a division of CPG New Zealand. For over 35 years, Waste Solutions has researched, developed and implemented a number of biotechnology solutions to harness and optimise the energy potential from industrial, agricultural and food processing wastes. The Cigar ${ }^{\circledR}$ Biogas Reactor is a treatment and energy recovery solution or process for agricultural, food processing, industrial or municipal sources of wastewater. The Cigar ${ }^{\circledR}$ Biogas Reactor system is a low capital cost option in countries or regions where land area is not at a premium and it is also exhibiting low operating costs. In general, Waste Solutions builds the water treatment installation that is then owned and operated by the client. This client will retrieve the investment costs by using/selling the energy produced and, when applicable, by reducing the costs of water treatment. www.wastesolutions.co.nz

\section{Microbial gas fermentation process, LanzaTech}

LanzaTech has developed a microbial gas fermentation process to produce ethanol fuels and chemical intermediates that can be used in a range of markets, including plastics and polymers. The gas resources for the fermentation process contain carbon and hydrogen and can come from a broad range of sources, from industrial waste gases through to biomass-based syngas. So far the focus has been on developing the technology for waste gases (or off-gases) from the steel industry due to the great volume of gases available and their relatively high carbon content. The off-gases go through a cooling process before they go into a bioreactor where LanzaTech's proprietary fermentation microbe uses carbon and hydrogen (if available) to produce ethanol fuel. Low-cost media are required to assist the growth of proprietary fermentation bacteria. The company is also exploring the use of gas-fired biomass as a feedstock and also aims to develop the technology to ferment and sequester carbon dioxide using hydrogen as the energy source to capture the carbon and fix it in the chemical product. Generating fuels and chemicals not reliant on traditional petrochemicals and food feed-stocks reduces the dependence on global fossil fuel supply and the associated environmental impacts of fossil fuel use, particularly green house gas emissions. It also decreases the demand to convert food production and natural areas to biofuel crops which reduces food production and biodiversity respectively. LanzaTech started testing the fermentation technology at scale in 2008. In 2010, the company entered a joint venture agreement with BaoSteel Group Corporation to build a demonstration plant in China for the production of fuel ethanol from steel mill off-gases. The intention is that the model will be rapidly scaled up, and the first fully commercial plant will be operational and profitable by 2013, and may potentially be replicated throughout China. The potential to scale up the LanzaTech fermentation technology is vast, as it can be applied to a diverse spectrum of gases, including carbon dioxide and syngas. www.lanzatech.com

\section{Commercial scale concentrated solar power (CSP), Torresol Energy Investments}

Torresol Energy Investments S.A. is the owner of GEMASOLAR, a full-scale Concentrated Solar Power (CSP) plant in Spain, in which four new technologies have been introduced: 1) software (SENSOL) for managing and operating solar plants; 2) a new collector design; 3) a new energy storage system based 
on molten salts; and 4) a new heliostat system. Based on demonstration at this full-scale plant, Torresol will promote technological development and construct, operate and provide maintenance for large CSP plants all over the world. The business model is not fully fixed, as it will depend on the actual local circumstances such as selling an energy production plant, selling the service of energy production, or selling energy. This is in line with general business model developments in supplying public utility services. By reconfiguring the value chain according to the BOO principle (build, own, operate) Torresol has been able to create a full scale CSP for further commercialisation and in this way has been able to make further developments in CSP. www.torresolenergy.com

\section{Net-Zero Plant, Frito Lay}

One of PepsiCo's key brands is its convenient foods business unit, Frito-Lay. In 2007, PepsiCo and Frito-Lay decided to conduct a sustainability experiment at one of Frito-Lay's facilities in Casa Grande, Arizona. The Casa Grande plant's goal is to run almost entirely on renewable energy and recycled water while producing nearly zero waste to the local landfills. Frito-Lay wants its Casa Grande plant to become a net zero facility. Break-through technologies reuse the water used in the process of making potato chips by filtering the water until it meets the EPA's primary and secondary drinking water standards and thereby recycle at least $75 \%$ of all process water generated by the facility. Photovoltaics collect solar power to produce electricity to run the plant. Biomass sources (e.g. tree trimmings, sawdust,) are used as boiler fuel. Reuse or recycle of most of the facility's residuals is ensured, e.g. potato peelings and corn husks, are sent to livestock operations for use as animal feed. Casa Grande has reduced its overall waste being sent to local landfills to less than $1 \%$ and during the last four months of 2011 had completely eliminated landfill waste being generated from the site. The facility retrofits and investments in near net zero technology have reduced water consumption by $75 \%$ and increased the use of renewable energy to approximately $70 \%$ of the total energy needed to operate the facility. The company has developed 5 year near net zero plans for all 36 of their manufacturing plants. It is expected that the company's value chain will be enhanced through the execution of the project. Frito Lay plans to market this innovation to both up-stream and downstream supply chain partners and also to its end consumers of its products. www. fritolay.com

\section{Efficiency optimisation by ICT}

\section{Smart Energy Box and the Smart Grids, Fifthplay}

Fifthplay is a Belgian high-tech company that develops and produces innovative technologies for energy management in buildings and health monitoring of patients. It provides consumers with tools for energy monitoring and savings, and for a more intelligent management of electricity, heating, water and gas. The company has produced the Smart Energy Box and, through its Fifthplay labs, is undertaking the Smart Grids project. The Smart Energy Box was developed through co-operation between three companies: Fifthplay (software and gateway), Niko (hardware) and Electrabel (the Smartphone application). With this box, consumers can manage the consumption of their electrical devices, using their computer, tablet or smartphone; they can also switch devices on and off remotely and be alerted when something unusual occurs. It is the first relatively inexpensive energy management control system on the market in Belgium, There is a cost of acquisition, and a monthly fee to have access to a real-time platform. Consumers can use the platform to provide feedback, and share their experiences with the product. The product is expected to be expanded internationally. Fifthplay labs is a series of progressive and innovative projects relating to smart cities and smart grids. The Smart Grids project consists of research on the interaction between smart devices in homes and buildings and smart meters and electrical grids for the purpose of creating $\mathrm{CO}_{2}$-neutral buildings. An important partner in the development of the project is the Local Intelligent Networks and Energy Active Regions (LINEAR) project, a partnership between industry and research institutes, that seeks to demonstrate smart grids in a Belgian residential area. In smart grids, energy and information flows are bi-directional. As an example a washing machine is started without 
taking the amount of energy available at that moment into account. With smart grids, the consumer gives in some of this control, and the washing machine will start depending on the solar or wind energy available at that time. Today, demand for energy steers the offer; in the future the offer of energy will steer demand. www.fifthplay.com

\section{Social energy network, Intelen}

Intelen provides real-time energy metering, analysis of consumption results and integration with social networks. It also provides real-time social demand response services to raise the awareness of the end-user/consumer about efficiency. The innovation is a complete service for the customer, incorporating specific Web 1.0 process and back-end intelligence. The means used are Web 1.0 technology and mobile and social nets directed to the end-user or customer. The innovation allows the company to bring a rather unique ICT technology to the mass market. In comparison with the traditional energy metering that uses a once a month or once a year measuring of the energy consumption, this new tool is user-friendly and a smart way of monitoring energy consumption on a day-to-day basis. Intelen has introduced a new business model at two levels: combining energy efficiency with social incentives through social networks and alternative revenue streams, for example, by establishing green deals like www.groupon.gr for the end-user or customers of large clients such as supermarkets. www.intelen.com

\section{Smart wireless network communication, Carta Sense}

Carta Sense is a wireless sensing system to track the temperature and relative humidity of products and their environments. The system comprises wireless sensors, a gateway and a communication server. The business model has a very specific market orientation. It focuses on cold chain management solutions. The system spans the supply chain by monitoring the product conditions, from the raw materials through their processing and to their transportation to their final destinations. Carta Sense based this business model on the fact that the market had failed to offer an effective solution to food quality monitoring in large retail chains. Normally, such quality checks are based on a primitive visual monitoring of food quality, which is ineffective and can result in the loss of products. By introducing the new system, Carta Sense captured the value from the unexploited market by introducing its affordable and simple online monitoring system. www.cartasense.com

\section{Water infrastructure monitoring, TaKaDu}

Water utility companies experience large losses of water resources due to inefficiencies in various parts of the water supply network. TaKaDu pioneered the use of algorithmic data analysis for the online monitoring of water networks. In other words, in its business model TaKaDu offers a service to the utility company and becomes its "eyes and ears" in its water network. It does this by analysing raw network data such as flow, pressure and quality readings from various metering points within the network, and then transforms that data into useful information for its clients. The core of the company's business model is a simple online system for the daily monitoring of water consumption at various points of the water supply network, using convenient and intelligent software tools, and timely interventions. The traditional method of monitoring carried out by water companies tended to be inefficient and non-transparent and it did not ensure a timely reaction to accidents or water leakages in the network. TaKaDu has managed to offer a very efficient solution and to capture value from an otherwise unexploited market. www.takadu.com

\section{Remote monitoring of mining and construction equipment and its remanufacturing, Komatsu Ltd}

Komatsu Ltd. is the largest manufacturer of construction and mining machines in Japan. The company has installed the KOMTRAX system or KOMTRAXPlus system as standard equipment on its machines to remotely monitor the positional information and operation status of the construction machines via satellite 
or wireless communication. The KOMTRAXPlus system is installed on mining machines where in addition the detailed status of machines parts are monitored and transmitted. The KOMTRAX and KOMTRAXPlus systems monitor the fuel efficiency of the machines as fuel consumption is affected greatly by the way the machines are operated. The information can be shared between KOMATSU, the agents, and customers. Customers can take measures to improve fuel consumption or in the case of mining machines, can re-design the mine roads. Particularly, KOMTRAXPlus is used to enhance remanufacturing (renovation of the product that has completed its lifecycle) and to increase the lifespan of the machines. Komatsu restores the engines and transmissions of the mining machines to almost new condition thus resulting in resource and energy saving compared to producing a new product. For the customer, KOMTRAX and KOMTRAXPlus systems have the benefit of decreasing the overall running cost of the machines. In some cases in mining machines, conventionally the product was overhauled and the parts were remanufactured after about 12000 hours of use, but now overhaul and remanufacturing are done after about 20000 hours of use. The extended time of overhaul and remanufacturing contributes to the increased lifespan of the machines. The KOMTRAXPlus system will be developed further including a system to grasp in real time where the produced or remanufactured parts such as engines are located or are in operation; this may further increase the remanufacturing efficiency. www.komatsu.com

\section{Inductive Power Transfer (IPT) wireless charging, HaloIPT, Qualcomm}

HaloIPT is an innovative wireless charging system for electric vehicles based on Inductive Power Transfer technology. It is currently at the business development stage. This innovation is integrated into both electric vehicles and the road infrastructure. Its function is to facilitate electric-powered mobility. HaloIPT works by fitting cars with a receiver pad that enables automatic charging when the car is parked over a transmitter pad embedded in the road. This can be done when the car is stationary or when moving. This way, the system takes the bulk energy storage away from the electric vehicles and out into the electric grid, addressing the key challenges of electric car uptake: re-charge convenience and battery size and cost. The technology can be used in a range of climatic conditions. The current product is designed for electric cars, but the technology can also be applied to light commercial vehicles and heavier vehicles such as buses. If the dynamic charging finds market application the technology could be rolled out across cities and eventually on major transit routes. Wireless charging significantly reduces the amount of car batteries needed; enables owners of electric cars to travel greater distances; and reduces the need for plugging a car into a power socket each day. Batteries are the most expensive component of electric cars and a life cycle assessment of an electric vehicle indicates that about $15 \%$ of its total environmental burden comes from the life cycle impacts of the (lithium-ion) battery. Depending on the source of the power supply, a substantive shift to electric vehicles could significantly reduce transport carbon emissions within cities. Electric cars do not emit air pollutants; there are, however, public health concerns over the effects of electromagnetic fields, and HaloIPT has responded to these concerns by designing strictly within the given standards. Rolling out wireless charging entails public-funded infrastructure investment, and addressing public concerns and gaining public acceptance will therefore be critical. HaloIPT was at the time of the interview in 2011 a small independent company. It has since been integrated into the Qualcomm group under its Wireless Electric Vehicle Charging (WEVC) programme. www.qualcomm.com

\section{InovGrid, EDP Distribução}

EDP Distribuição developed the InovGrid Project which is a smart grid solution in Évora, Portugal for up to 30000 consumers. Industrial activities account for $57 \%$ of electricity use, while services account for $34 \%$ and agriculture and other activities for the remaining 9\%. InovGrid, the smart grid project, and InovCity, the city where the smart grid project is in place are real examples of the importance and crucial impact that customers have in the development of Smart Grid projects. Placing the customer at the centrer of its strategy, EDP Distribuição designed an approach for the implementation of the InovGrid project in Évora, having in mind that, on the one hand clear value creation for customers must be achieved, and, on 
the other hand, that customers must perceive this value: not only technology educated customers, but mainly ordinary electricity customers, whose focus is mostly on the reduction of their electricity bills. The InovGrid Project is equipping the electricity grid with information systems and intelligent equipment capable of automating network management, improving service quality, reducing operating costs and fostering energy efficiency and environmental sustainability. The result will be a more efficient use of energy resulting in benefits for the whole value chain, in particular consumers. The consumer/producer will benefit from the increase in the ability to produce energy through micro-production, while reducing their energy consumption. They will also have access to new services, new types of pricing and innovative price plans by managing their consumption in near real time. Retailers will be able to diversify their supply of services and offer new types of pricing to their customers, reduce the operational costs of metering as well as cut-off and reconnecting. The regulator will see the creation of better conditions for market development, with positive implications on the reduction of electricity consumption. Likewise it will have access to a set of value-added information for controlling how the market operates along with operating conditions. The distribution grid operator will increase operating efficiency, the reliability of their grids and can also increase the quality of service in the electricity supply by optimising investments while reducing their operational costs and energy losses. A structure for monitoring and measuring the economic impact of the project was put in place. Consolidated results of customers' energy savings are already showing significant gains between $12 \%$ and $20 \%$ for some of them. Recent studies in Évora show that the implementation of Smart Grids infrastructure led to an average increase in energy efficiency of $3.9 \%$. The project is now in a demonstration phase. The EDPD is evaluating the technical and commercial benefits of the project on a larger scale and participates in several European FP7 projects. www.edpdistribuicao.pt

\section{eCoupled wireless power, Fulton Innovation}

Fulton Innovation eCoupled wireless power is a technology solution for integration of wireless power into virtually any product that uses traditional cord and plug power; it removes the age-old constraints of inductive coupling (magnetically induced flow of current). It assesses and determines not only power needs but also factors in battery or device age and charging. The use of a wireless charging system for a range of portable consumer electronic products has the potential to develop a common charging platform for a wide range of consumer electronic products; and reduce i) the number of conventional chargers used in the future; ii) energy consumption and resources required to manufacture, package, and transport conventional chargers; iii) energy wasted due to use of inefficient external power supplies and chargers; iv) the amount of toxic and non-biodegradable electronic waste arising from conventional chargers due to the lack of a common charging platform; and $v$ ) the amount of time, resources, facilities, and energy in handling the electronic waste arising from conventional chargers. The company estimates that from just one product manufactured by a sister organisation that incorporates this technology there are cost savings in excess of USD30 million per year in reduced warranty claims, improved product reliability, and reduced costs of manufacturing, etc. There have been many jobs created internally to support this innovation as well as many jobs with external vendors who support the company. Over the past 12 years, 1.5 million eSpring water purification units have been sold in 40 countries and territories. The eSpring units use eCoupled technology to wirelessly power the 38 watt UV lamp which disinfects water that passes through the filter. In addition to over 150 Fulton partners, there are over 100 members of the Wireless Power Consortium who are integrating wireless power into their product lines. Fulton's goal is to apply this technology to other industries, including industrial and transportation applications, medical, and printed electronics. www.fultoninnovation.com 


\section{Functional sales and management services models}

\section{LED lighting rental service, Cowell}

Cowell engages in the sales, rental, and leasing of LED (Light-emitting diodes) lighting products of the Beautiful Light Technology Corporation (BLTC) of Chinese Taipei. Initially Cowell started as a distributer and seller of LED lighting but early concern over price and performance led to strong demand for rental services. Currently, customer demand is highest for rentals which involve a short period (such as one month), and for which the agreement can be terminated at any time. The company subcontracts the rental to external rental companies (the LED products are owned by the rental companies). The main customers are stores, and the company's business is to replace the halogen light bulbs used as spotlights for store displays with LED lights. Because LED lighting was at a very early stage of diffusion, the warranty system played an important role in gaining customers trust and developing the business; Cowell has now developed a five-year warranty. LED lighting consumes less power than conventional lighting, and its power consumption is about one-eighth compared to incandescent light, and about half compared to fluorescent light. Therefore it is expected to contribute to the reduction of $\mathrm{CO}_{2}$. The lifespan of the LED product is about 40000 hours, which is a dozen times longer than incandescent light and about four times longer than fluorescent light. The initial investment can be recovered within one year. Through technological advances of LED lighting, performance has increased and the price dropped to one-third between 2009 and April 2012, although it remains higher than traditional lighting equipment. Demand for LED lighting has increased significantly in Japan owing to increased awareness for energy conservation during the power shortage due to the nuclear power plant problems. Cowell plans to expand the business of LED lighting rentals further and develop rentals of other eco-products such as water-saving equipment, energy-saving air conditioners, etc.

\section{Qlean cleaning with Ultra-pure water, Qlean Scandinavia}

The Qlean cleaning process is based on the use of ultra-pure water. The founders of Qlean discovered that the cleaning of surfaces can be done with cold water, low pressure and without detergents, when ultrapure water is used. This reduces the environmental pressures from detergents; noise and energy use and makes it possible to clean more difficult surfaces like plaster and wood. It is also cheaper because no detergents and less energy are used and the execution time, including the drying process, is shorter. The water dissolves algae, mould and dirt and works equally well on grease and oil. Three groups of services are provided: surface cleaning of buildings and boats (Qlean surface); cleaning of utility constructions such as transformers and surveillance cameras (Qlean construction); and cleaning in industrial processes (Qlean industry). In the business cases Qlean surface and Qlean construction, Qlean provides the cleaning service, not just the ultra-pure water. The ultra-pure water cannot be stored for longer than a day, as otherwise its oxygen and nitrogen gases re-dissolve into the water. In the business case Qlean industry, Qlean provides the cleaning equipment. Further insights into the novelty of the functional sales business model can be acquired by comparing the Qlean case to its business as usual counterpart. Usually, the cleaning of surfaces and equipment is done by using chemicals and hot water at high pressure and this produces environmental pressures and leaves residues of chemicals on the cleaned items and their surroundings. With the Qlean method, value is re-configured at two locations in the value chain as the cost of certain inputs are reduced, namely chemicals and high-pressure equipment, whereas the client gains value by eliminating residues. With the functional sales business model, Qlean has managed to capture this value and share it with their customers, making the innovation beneficial for both. www.qleanscandinavia.com 


\section{Innovative financing schemes}

\section{ESCO solutions, Danfoss, Scanenergi}

An ESCO solution is a commercial service in which the provider analyses the clients' production processes and routines. This is with the aim of reducing the clients' use of energy and the next steps are to design and implement an energy efficient solution. The client is guaranteed energy savings by the ESCO provider. There is no financial risk for the client and the risk remains completely with the ESCO provider. The provider is paid according to performance, and the payment is proportional to the resulting energy savings. If the guaranteed savings are not achieved, the provider compensates the client accordingly. The ESCO concept was developed in the United States in the aftermath of the energy crises of the 1970s, and it is predominantly used for reducing energy use in buildings. Danfoss Solutions, an energy saving service provider, primarily targets industrial sectors such as the food and beverage markets. With an innovative approach, that not only focuses on technological solutions but also includes people engagement, Danfoss Solutions is normally able to reduce utility costs by $10-20 \%$ and obtain significant $\mathrm{CO}_{2}$ emission reductions and reductions in water consumption. It has since been integrated into Scanenergi. $\underline{\text { www.scanenergi.dk/ }}$

\section{Power-Saving consultancy services, Kankyo-keiei}

Kankyo-keiei Senryaku Soken (Kankyo-keiei) provides power-saving consultancy services. The main clients of the service are retail chain stores and entertainment halls. Kankyo-keiei's service requires a relatively small initial investment by clients to install remote power monitoring systems at their sites. The systems measure the power consumption at a site and send the monitored information to the server at Kankyo-keiei who then provides the clients with consulting services, and alerts them when the power consumption at the site is in danger of increasing the base electricity charge. The clients pay an initial charge and monthly charges for the service. Because of the low initial investment, although most clients are small power consuming companies they can normally recoup their investment within a year. The company is regarded as a "megawatt broker" in Japan. It has also been undertaking solar panel sales and intermediation of solar power securitisation (collecting financial resources from investors, investing them to equip solar power systems, and sharing the profits with the investors and the stakeholders). The company had 4300 client sites as of May 2012 (a client can have several sites; e.g. several chain stores). Kankyo-keiei contributed to reducing power consumption by approximately 60 tons of $\mathrm{CO}_{2}$ annually per site, and in total reducing power consumption by 510 million $\mathrm{kWh}$ per year which is equivalent to the reduction of about 200000 tons of $\mathrm{CO}_{2}$. The company's annual sales are about JPY 1.2 billion (USD 15 million). It contributed to reducing its clients' electricity costs by JPY 7.7 billion (USD 100 million) in total per year. Costs are expected to increase in 2012 due to the suspension of nuclear power plants in Japan and this will contribute to the innovation.

\section{Sustainable mobility systems}

\section{Zero vehicle, National Technical University of Athens}

The National Technical University of Athens (NTUA) has developed a prototype ultra light vehicle for cities (Near Zero Fatality (NEZEF) vehicle). NTUA has taken an innovative approach to circulation in urban areas by taking into account not only the safety aspects of the car but also the safety of potential victims of road accidents including pedestrians and cyclists. The lightweight vehicle has an additional energy absorbing external layer added to the body to provide protection much the same as an external airbag (constantly employed) for the safety of pedestrians, or other vehicles. The approach was focused on the requirement to move lighter at friendlier speeds and save energy; thus being less dangerous to all parties involved in an accident. The vehicle should be viewed as a new market between a car and a 
motorcycle, offering a safer and greener option. It has low energy consumption, low cost of construction and recycling of materials, optimised safety for passengers and pedestrians, low noise level and minimal parking space requirements. The proposed vehicle is ultra light $(300-350 \mathrm{~kg})$ and at the same time offers high safety standards due to the materials used for its construction (energy absorbing foam materials), making it at least $40 \%$ more energy efficient than any current small city vehicle (approximately $800 \mathrm{~kg}$ ), providing safety for its occupants and pedestrians or other light vehicles, thus reducing the cost of traffic accidents. Also its low weight makes it easier to make it fully electric (although alternative means of propulsion could also be used) with a good range of autonomy, and reduced time for charging. The carbon footprint of materials used is also reduced and a smaller amount of materials, batteries etc., is to be recycled. The vehicle has already been used for transport/testing and exhibition in the NTUA university campus. http://polymers.mechan.ntua.gr/nezefhomepage.html

\section{Better Place}

Better Place delivers a network and services that promote the use of electric vehicles. The drivers of each electric car have access to a network of charging spots, battery switching stations and systems that optimise the driving experience and minimise the environmental impact and cost. What distinguishes the business model of Better Place is that it separates the ownership of the car from the ownership of the battery, which remains the property of the network service provider. Better Place also offers a user-friendly in-car IT information system which provides the driver with information on the car's energy performance and on the nearest charging and switching stations. Israel, Denmark and Australia are the first three markets for the Better Place model; the company also has projects in North America (Hawaii and California) and the Netherlands (Schiphol airport). In 2011, China Southern Power Grid (CSG) and Better Place announced the opening of their Switchable Electric Car Experience Center in Guangzhou's Pearl River New Town.www.betterplace.com/

\section{Car rental at gas stations, Rentas}

Rentas Corporation provides a car rental service called "NicoNico rent-a-car" and uses "used-cars". Rentas chose to operate their business out of national gas-station franchises to reduce overhead costs, thereby allowing them to offer cars at much more affordable prices, for about half the price charged by major car rental companies. Previously car rental services had been mainly targeted at the leisure industry, whereas the company targets customers in urban areas and for daily use. Clients are mostly repeat customers. The number of people who do not possess their own cars, especially the younger generation, has increased, and the demand has moved from product to product services. The service is provided by gas stations that, faced with decreased revenues and profits, have sought new business opportunities that require no substantial initial investment. Recently, auto-supply shops and car maintenance shops have also started to provide the service. Each franchised station has about 5 to 7 cars in average for rental. The cost for the business is low, compared with companies that specialise in car rental services, because gas stations already have facilities for car storage and maintenance, staff, etc. Because it uses used-cars (but none over $150000 \mathrm{~km}$ ), the business is eco in terms of material circulation (product reuse). The company started the business in April 2009 with 70 franchised gas stations. The service grew rapidly, and as of March 2012 it had 800 franchises with about 5000 used cars. The annual sales of the service were about JPY 3 billion (USD 38 million; it was USD 7.8 million in 2010).

\section{YikeBike, YikeBike}

The YikeBike is the smallest, lightest, electric folding bike in the world; it is highly portable and weighs $10.8 \mathrm{~kg}$. It can be used for getting around the city, and for commuting into cities, as commuters can travel part of the commute by car or public transport and part by the bike, thus extending its $10 \mathrm{~km}$ range. It does not require new electric charging infrastructure; it can be charged at any normal power point and 
runs on a lithium phosphate battery with a forty minute recharge. The operating costs are low. It is the first bike to be equipped with electronic antiskid brakes, which enables it to be safely ridden in snow and ice and reduces skidding in an emergency braking scenario. The built in lights and indicators increase the visibility of the rider and bike. The bike's speed is limited to $23 \mathrm{~km}$ per hour to reduce potential crash impacts. YikeBike is still essentially in the development stage. In the short term target customers are early adopters of new and cool technology who help fund development of a wider market and build social acceptance of the new bike design. The longer term goal is to develop a relatively less expensive YikeBike. The primary environmental benefit is the reduction in fossil fuel-powered vehicle use. The current design and manufacturing of YikeBike has not focused on reducing the product's direct and indirect environmental footprint (e.g., through material selection, manufacturing processes, etc.) however the company intends to address that aspect as the bike is developed into a mass-produced model. While the initial cost of the current model, however, is set at a premium price, a mass-produced version may start to see transport savings to the customer. In terms of the wider economy, some economic benefits would occur once a mass-produced option is developed through job creation and economic stimulus. It is anticipated that any subsequent mass production would move offshore to be physically located near key suppliers and markets (Asia and Europe). Therefore, while design would likely remain in New Zealand, manufacturing jobs and supply contracts arising from mass manufacturing would be created offshore.www.yikebike.com

\section{Industrial symbiosis}

\section{Kwinana regional synergies project}

The Kwinana Industrial Area (KIA) is one of the most well studied cases of industrial symbiosis. The project is one of the largest industrial symbiosis projects in the world and has assisted in the development of over 47 synergies, which were 32 by-product synergies and 15 utility synergies. KIA provides ecoefficient solutions for the management of ongoing waste, energy and water needs with both environmental and financial benefits. The introduction of industrial symbiosis stimulated a change from an unco-ordinated industrial district where by-products were treated as waste to a connected system in which by-products and excess energy are exchanged and reused. www.kic.org.au/

\section{Ulsan eco-industrial park, Korea}

Korea has launched an eco-industrial park (EIP) initiative with the aim of encouraging all Korean industrial parks to become EIPs. Ulsan promotes the development of "designed" symbiosis networks in the Ulsan Mipo-Onsan industrial complexes. One of the key stakeholders in the Ulsan EIP project is the Korea Industrial Complex Corporation (KICOX), affiliated with the Korean Ministry of Knowledge Economy, that is the agency to which all the identified symbiosis projects are submitted for their evaluation and possible financial assistance to carry out feasibility assessments. The adoption of industrial symbiosis in Ulsan helps accelerate the innovation process through enhanced resource/energy efficiency, and the reduction of carbon and other pollutant emissions, which are considered to be important drivers for ecoinnovation at the industrial park level. The main added value is the economic value created and captured by the members of the network as well as significant benefits for the community that include job creation and better quality of life for those working in the complexes, attracting more businesses to the region. Ulsan EIP centre has so far facilitated forty symbioses and sixteen networks in operation that have resulted in an estimated economic benefit of USD 68.52 million per year with a research and development support of USD 1.9 million and an investment of USD 63.93 million. The industrial complexes have achieved greater resource efficiency through the reduced use of water and energy and significant air quality improvements with the reduction of $\mathrm{CO}_{2}, \mathrm{SOx}$, and other air pollutant emissions. The model of industrial symbiosis is a clear example of a business model that can be adapted in different countries, regions or cities. There is an enormous potential benefit in savings from creating synergies. Work is underway to 
disseminate the industrial symbiosis knowhow to the Chittagong export processing zone (CEPZ) in Bangladesh to transform it to a low carbon green EPZ.

\section{Green neighbourhoods and cities}

\section{Active housing, Active House Alliance}

An Active House is energy efficient and all energy needed is supplied by renewable energy sources integrated in the building or from the nearby collective energy system and electricity grid. It creates healthier and more comfortable indoor conditions for the occupants and the building ensures a generous supply of daylight and fresh air. Materials used have a positive impact on comfort and the indoor climate. An Active House interacts positively with the environment by its relationship with the local context, focused use of resources, and its overall environmental impact throughout its life cycle. Since 2010 the Active House Alliance, which includes architects, engineers, developers, scientists, building component manufacturers, and non-governmental organisations have shared and developed the Active House vision. It is based on a notion of "open source" and has three focus areas: knowledge sharing; specification and demonstration; and communication. One of the first concrete results of the Active House Alliance is the Active House Specification that is intended to be a guideline for construction and design industries at an international level. It seeks innovative approaches at technical levels whilst introducing goals of architectural quality and environmental design responsiveness and still securing energy efficiency. These specifications have been developed using an open-source model. The development has involved online debates and contributions as well as offline meetings and workshops with broad participation across the building industry globally. The Active House specification is free for all to use and build after. The Alliance is open to interested parties and currently consists of 34 companies and organisations. www.vkr-holding.com/sitecore/content/ActiveHouse/Home/01\%20Principperne\%20bag.aspx

\section{Housing in Torrelles de Llobregat, BB Architects}

Spanish firm, BBArchitects has developed an environmentally friendly housing project, called Torrelles Public Housing in Torrelles de Llobregat near Barcelona. The approach to the housing project has been to incorporate traditional knowledge, nature and state of the art techniques. The innovation lay in how traditional knowledge was re-used. The Torrelles project utilised local resources (materials as well as systems) to better integrate the building and its surroundings. It is made up of 12 separate, low-rise apartment buildings that gently rise from the landscape. They require minimum construction and disruption to the local environment and are cooled both by wooden screens that shade them and natural valley air. Each building has one inner courtyard, which not only provides sitting areas, but also important natural cross-ventilation throughout the buildings. Each apartment faces the valley, allowing optimal natural light as well as scenic views. Each dwelling is also fitted with a brise-soleil, or sun screen, which provides shade for terraces. The buildings curtail heat loss in the winter and heat gain in the summer. Rain water is recuperated for plant watering and solar panels provide hot water. The Torrelles housing project also satisfies an economical need for inhabiting the area. The houses were occupied immediately after they were completed in 2010 and feedback from residents after one year has been very positive. The result of the intervention can be appreciated in the reduction of the environmental impact of the building on its surroundings; a commitment to the contextualisation and integration of the new building in its setting, and to energy efficiency. These strategies interact directly with the landscape and with people's well-being. www.bbarquitectes.com

\section{DigiEcoCity, Finland}

DigiEcoCity (DEC) is a unique Nordic city that combines ecological principles with innovations, which use ICT. The objective of the city model is to combine living, working, public and private spaces as well as culture and leisure within walking distance - a "human alternative" to concentrated, crowded 
metropolises. DEC combines three concepts: i) digitally-integrated, high-interaction information systems which provide access to various city systems. These systems include: virtual services; telecommunication; online shopping; online building maintenance and management services; e-learning; interaction between home and school; e-health; and e-care; ii) ecologically sustainable solutions that provide energy efficiency and material efficiency both in the buildings and at community level. The holistic building concept also covers the efficient use of space and adaptability; and iii) localised urban solutions that offer efficient logistics, new combinations of working and living, and functional diversity, making the urban structure more resistant to changing social and macro-economic conditions. www.digiecocity.com

\section{Eco system for apartments, Raidis Architecture}

The Eco System service provided by Raidis Architecture provides efficient green sustainability solutions and energy savings in an urban context. In order to make each system workable and sustainable, several factors are taken into account including the locality, weather conditions and local materials. The solutions result in a substantial increase in green areas, and reuse of abandoned or unused built spaces. The process goes beyond a simple green roof design process; it includes integration of other environmental systems (green energy production through photovoltaic systems, energy saving, water saving, high insulation, use of recycling materials, local vegetation, and greywater and composting systems) in order to form a complete sustainable solution that can be used in blocks of flats or urban areas. The service tends to promote local agricultural activities in green urban areas. It seeks to provide high quality open and closed spaces and reinforce social interactions between the tenants. The savings for tenants have been estimated at approximately $20 \%$ of the annual costs. This is due to less energy consumption for heating and cooling and the additional passive energy and renewable energy systems that are used in the installation. This specific innovation was applied to the PASOK (political party) office building. This approach could create additional jobs in various specialised sectors including construction of energy saving systems, green roofs, software development and agricultural development in an urban context. Raidis Architecture's goal is to promote the approach in several countries and to form an advisory body to support similar initiatives. www.dimitrisraidis.com

\section{LEED certified renovation historic building, Barton}

Barton is a manufacturer and distributor of garnet abrasives for a wide variety of technical applications. In 2006, Barton purchased an historic three-story brick building in Glen Falls, New York that would become the new location of Barton's corporate headquarters. The goals of the renovation were to preserve the historical integrity of the building's design and structure and to dramatically reduce its energy consumption and other environmental impacts. The resulting state-of-the-art improvements earned the building a LEED (Leadership in Energy and Environmental Design by the United States. Green Building Council (USGBC) certification at the Platinum level (LEED's highest level) to recognise its whole building approach to sustainability and its transformation into an environmentally-sound and resource efficient structure and its performance in five key areas of human and environmental health. These were: i) sustainable site development; ii) water savings; iii) energy efficiency; iv) materials selection; and v) indoor environmental quality. The improvements included $97 \%$ of the original building structure and shells were retained; and over $50 \%$ of the construction debris was recycled. The building includes a rain water collection system on the roof, energy-efficient thermal windows, a vegetated green roof acting as insulation and reducing heat retention from absorbed sunlight, and the first "green" elevator in the state. Local, post-consumer recycled and environmentally-responsible building materials were used wherever possible and office furniture and carpeting made from recycled materials. Indoor environmental quality created a pleasant and healthy indoor air environment to encourage productive employees, reduce absenteeism, and improve employee retention. Low emission materials were used in paints, glues, and carpeting. Energy use was reduced by $49 \%$ over New York State building code requirements. Potable water consumption was reduced by $68 \%$ due to design and installation of rainwater and storm water 
collection systems and water efficient plumbing fixtures. The renovations were also expected to reduce building operation and maintenance costs. www.barton.com

\section{Smart town in Fujisawa, Panasonic}

Panasonic works with eleven other companies (including construction, car-sharing and banking companies) on the project "Fujisawa Sustainable Smart Town (Fujisawa SST)" which will house approximately 1000 households. Fujisawa City is about $50 \mathrm{~km}$ west of Tokyo. The aim of the project is to realise a new type of town development and services through the company's comprehensive solutions focused on day to day life, including its energy management systems. Specifically, the company plans to install solar modules and storage batteries in houses, apartments, facilities and public areas In the approximately 19 hectare town, solar power generation systems will be installed in residential areas and in public facilities and land, maximising the utilisation of renewable energy in the town, and making the whole town itself the largest individual distribution system in the world, with a total of approximately $3 \mathrm{MW}$ of solar modules and $3 \mathrm{MW}$ of storage batteries. Panasonic aims to lower the town's $\mathrm{CO}_{2}$ emissions by $70 \%$ compared to 1990 , reduce water consumption by $30 \%$ compared with water usage in the home in 2008 , make the renewable energy utilisation rate over $30 \%$, and achieve a safety and security target. The total project expenses are JPY 60 billion. It is forecast to open in Spring 2014. http://panasonic.net/fujisawasst.

\section{Smartcity Málaga, Endesa}

SmartCity Malaga is a demonstration project. It aims to provide a holistic response to the environmental challenges facing consumers: improving energy efficiency, reducing $\mathrm{CO}_{2}$ emissions and shifting consumption to renewable energies, involving final users. A consortium of 11 companies and 14 research centres led by Endesa has created a "Living Lab" where new technologies are tested in a small area of Malaga. State-of-the-art technologies in smart metering, communications and systems, network automation, generation and storage, and smart recharging infrastructure for e-vehicles are being rolled out. The aim is to improve the management of energy in the grid, and involve all agents in the electricity system, from generation to consumption. The "Living Lab" allows testing in real conditions. Individual companies support knowledge development and installations providing different areas of expertise and facilitating convergence of different technologies. Citizens (end users) are active participants with new technologies installed at home (new smart meters, advanced telecommunications and remote control systems, etc) at no cost to encourage more sustainable electricity consumption. The motivation factor has been the environmental impact reduction and economic savings. Project partners are involved not only for technology but also to benefit from new business models and opportunities in their area of competence. The project is being carried out over four years with a budget of EUR 31 million. The environmental project targets are a $20 \%$ saving on energy consumption; reduction in annual $\mathrm{CO}_{2}$ emissions and all related emissions for energy generation in the last year. Target reductions are for: $i$ ) smart energy management (efficient management of energy end-use) (8-15\%); ii) smart buildings (30-50\%); and iii) smart and informed customers (5-15\%). The community benefits are associated with improving quality of life by improving the urban air quality, reducing the energy costs to end users and reducing the global environmental impacts by energy savings. Endesa is benchmarking and transferring the experience to other countries such as Brazil, and is also promoting another smart city in Spain. The nature of the project was to explore the potential of new technologies and there are no exploitation agreements signed between the companies, it is purely a collaboration agreement in the framework of the SmartCity project. www.smartcitymalaga.es 


\section{Hammarby Sjöstad, Sweden}

Hammarby Sjöstad is Stockholm's biggest green urban development project. The area's location, as a natural continuation of Stockholm's inner city, has helped shape the infrastructure, planning and design of the buildings. The eco-cycle solution in Hammarby Sjöstad is called the "Hammarby Model". This model is the thread that binds together the entire environmental programme and demonstrates how the various technical supply systems are integrated into a symbiotic system. The approach aims to reduce energy consumption and waste generation, whilst maximising resource efficiency, the re-use of materials and recycling. For example, waste heat from the treated wastewater is used for heating up the water in the district heating system, which, in turn, heats the apartments and offices in the district. www.hammarbysjostad.se 
www.oecd.org/greengrowth 